GRAZIELA NEVES HAGIHARA

RESPOSTA À ANGIOTENSINA II EM ARTÉRIAS MESENTÉRICAS DE RESISTÊNCIA NA OBESIDADE: PARTICIPAÇÃO DAS MAPKS

Dissertação apresentada ao Programa de PósGraduação em Farmacologia do Instituto de Ciências Biomédicas da Universidade de São Paulo, para obtenção do Título de Mestre em Ciências. 
GRAZIELA NEVES HAGIHARA

RESPOSTA À ANGIOTENSINA II EM ARTÉRIAS MESENTÉRICAS DE RESISTÊNCIA NA OBESIDADE: PARTICIPAÇÃO DAS MAPKS

Dissertação apresentada ao Programa de PósGraduação em Farmacologia do Instituto de Ciências Biomédicas da Universidade de São Paulo, para obtenção do Título de Mestre em Ciências.

Área de concentração: Farmacologia

Orientadora: Profa. Dra. Zuleica Bruno Fortes

Coorientadora: Núbia de Souza Lobato

Versão original

São Paulo 
DADOS DE CATALOGAÇÃO NA PUBLICAÇÃO (CIP)

Serviço de Biblioteca e Informação Biomédica do

Instituto de Ciências Biomédicas da Universidade de São Paulo

reprodução não autorizada pelo autor

Hagihara, Graziela Neves.

Resposta à angiotensina II em artérias mesentéricas de resistência na obesidade: participação das MAPKs / Graziela Neves Hagihara. -São Paulo, 2012.

Orientador: Profa. Dra. Zuleica Bruno Fortes.

Dissertação (Mestrado) - Universidade de São Paulo. Instituto de Ciências Biomédicas. Departamento de Farmacologia. Área de concentração: Farmacologia. Linha de pesquisa: Hipertesão, diabetes e obesidade

Versão do título para o inglês: Differential participation of MAPKs in angiotensin II-induced contraction in obesity.

1. Obesidade 2. Angiotensina II 3. MAPKs 4. Resistência à insulina 5.Receptor AT2 participação das MAPKs 6. eNOS I. Fortes, Profa.

Dra. Zuleica Bruno II. Universidade de São Paulo. Instituto de Ciências

Biomédicas. Programa de Pós-Graduação em Farmacologia III. Título. 
Candidato(a):

Título da Dissertação:

Orientador(a):
Graziela Neves Hagihara.

Resposta à angiotensina II em artérias mesentéricas de resistência na obesidade: participação das MAPKs.

A Comissão Julgadora dos trabalhos de Defesa da Dissertação de Mestrado, em sessão pública realizada a

Profa. Dra. Zuleica Bruno Fortes.
( ) Aprovado(a)
( ) Reprovado(a)

Examinador(a): Assinatura:

Nome:

Instituição:

Examinador(a): Assinatura:

Nome:

Instituição:

Presidente: Assinatura:

Nome:

Instituição: 


\section{Certificado}

Certificamos que o protocolo registrado sob $n^{\circ} \mathbf{7 5}$ nas fls. 89 do livro 02 para uso de animais em experimentação, sob a responsabilidade do Prof(a) $\operatorname{Dr}(\mathrm{a})$ Zuleica Bruno Fortes, Coordenador(a) da Linha de pesquisa Obesidade, suas complicações e a resposta vascular: efeito de fármacos do qual participam o(s) alunos Núbia de Souza Lobato, Graziela Neves Hagihara, Eveline Aparecida Isquierdo Fonseca, Simone Marcieli Sartoretto, Beatriz Ponzio Felice e os pesquisadores Maria Helena Catelli de Carvalho, Maria do Carmo Pinho Franco, Eliana Hiromi Akamine, está de acordo com os Princípios Éticos de Experimentação Animal adotado pela Sociedade Brasileira de Ciência de Animais de Laboratório (SBCAL) e foi aprovado pela COMISSÃO DE ÉTICA NO USO DE ANIMAIS (CEUA) em 27.07.2010, com validade de 3 anos.

São Paulo, 27 de julho de 2010.
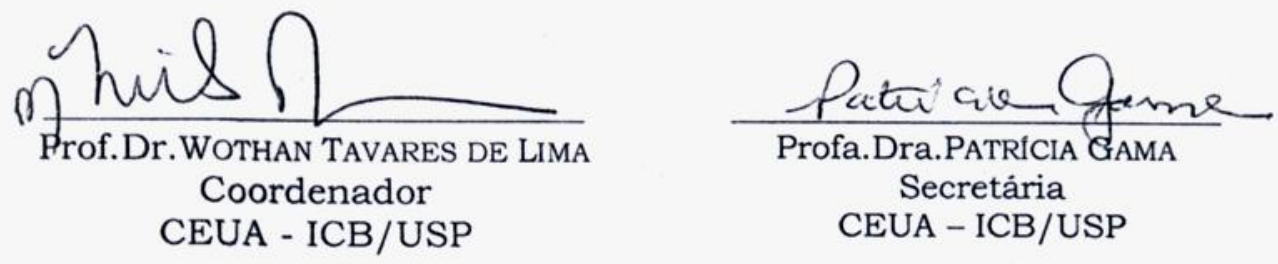
Dedico este trabalho aos meus pais, Paulo e Edna, que sempre me apoiaram e incentivaram meu desenvolvimento acadêmico e pessoal. 
Agradecimento especial...

À Dra Zuleica Bruno Fortes pela orientação, dedicação, estímulo e críticas construtivas. Pelo excelente exemplo de professora, pesquisadora e de vida. Deixo registrado aqui a minha profunda gratidão e admiração. 


\section{AGRADECIMENTOS}

Agradeço à Deus por ter me presenteado com o dom da vida.

Agradeço:

À minha família pelo amor, compreensão e palavras sábias nos momentos em que mais precisei.

Ao Renato, meu noivo, por diversos motivos e principalmente pela simples frase - "Vai dar tudo certo!".

À minha coorientadora Núbia Lobato pelo encorajamento, aconselhamentos, e por dividir suas ideias.

Aos docentes Maria Helena Carvalho e Eliana Akamine por me ensinarem que excelentes pesquisadores também podem ter corações generosos.

Aos meus amigos do laboratório do grupo de Hipertensão, diabetes e reatividade vascular da Universidade de São Paulo pelo apoio e incentivo, estes são: Eveline Isquierdo, Maria Aparecida, Simone Sartoretto, Tiago Costa, Fernando Filgueira, Antônio Garcia, Gisele Facholi, Cynthia Echem, Priscila Xavier, Luciana Giaquinto, Sônia Leite, Marta Rodrigues, Manoel Rocha, Ana Rita, Rosângela Eichler, Beatriz Ponzio, Vanessa Oliveira, Selma Rigonati, Julieta Santos, Maria Alice, Graziela Ceravolo, Mônica e Camila.

À Fundação de Amparo a Pesquisa do Estado de São Paulo (FAPESP), ao Conselho Nacional de Desenvolvimento Científico e Tecnológico (CNPq) e à Coordenação de Aperfeiçoamento de Pessoal de Nível Superior (CAPES) pelo apoio financeiro.

Enfim, às pessoas que contribuíram direta ou indiretamente na realização desse trabalho e que porventura tenham sido omitidas, meus sinceros agradecimentos. 


\section{RESUMO}

HAGIHARA GN. Resposta à angiotensina II em artérias mesentéricas de resistência na obesidade: participação das MAPKs. [Dissertação (Mestrado em Farmacologia)] São Paulo: Instituto de Ciências Biomédicas da Universidade de São Paulo, 2012.

$\mathrm{Na}$ obesidade há alteração da função vascular. Um dos mecanismos envolvidos nessa alteração é o aumento da ativação do sistema renina-angiotensina, comprometendo a resposta à angiotensina II (Ang II), que pode ativar as vias de sinalização intracelular das proteínas quinases ativadas por mitógenos (MAPKs). Para investigar o papel da obesidade e das MAPKs na resposta à Ang II, utilizamos ratos Wistar que receberam injeção de glutamato monossódico $(4,0 \mathrm{~g} / \mathrm{Kg}$, s.c.) a partir do $2^{\circ}$ ao $6^{\circ}$ dia e vida e que foram analisados com 16 semanas. Esse tratamento foi eficaz em induzir a obesidade caracterizada por aumento do Índice de Lee, das gorduras periepididimal e retroperitoneal, sem alteração da massa magra (sóleo e EDL), além de induzir a hipertrigliceridemia, aumento das frações VLDL e LDL, sem alteração no colesterol total, HDL-colesterol e na pressão arterial sistólica. A resposta à Ang II foi estudada em artérias mesentéricas de resistência isoladas utilizando o miógrafo de arame. Os ratos obesos apresentaram menor resposta à Ang II quando comparados aos controles. Essa alteração foi dependente do endotélio e envolveu o receptor AT2 (ATR2), pois o seu antagonismo corrigiu a menor resposta nos obesos. A expressão proteica de AT1R não diferiu dos controles, enquanto os obesos apresentaram aumento da expressão de AT2R. A inibição da óxido nítrico sintase pelo L-NAME, corrigiu a menor resposta à Ang II em obesos, indicando que o NO participa da menor contração, o que foi confirmado pelo aumento da expressão basal da eNOS. A inibição da NADPH oxidase pela apocinina reduziu a contração à Ang II nos dois grupos estudados, mostrando que a alteração encontrada nos ratos obesos não envolve a participação das espécies reativas de oxigênio. A menor resposta à Ang II nos obesos envolve a via da ERK 1/2 que favorece a vasodilatação, pois a sua inibição corrigiu essa resposta. Demonstramos também que os ratos obesos já apresentam aumento da expressão de ERK1/2 no estado basal e que o estímulo de Ang II aumentou ainda mais a fosforilação dessa MAPK. Já as vias da JNK e p38 MAPKs estão envolvidas na manutenção da 
resposta contrátil à Ang II, pois a inibição de cada uma dessas vias diminuiu ainda mais a contração nos obesos. A alteração parece ser específica, pois não foi observada diferença na resposta contrátil induzida por noradrenalina e cloreto de potássio. As MAPKs parecem não constituir o principal mecanismo pelo qual a Ang II e a noradrenalina promovem vasoconstrição nos controles, uma vez que a inibição de cada uma dessas três MAPKs não alterou a resposta contrátil a esses agentes. Portanto, concluímos que na obesidade, a resposta contrátil à Ang Il é menor, como possível mecanismo adaptativo frente ao aumento da ativação do sistema renina angiotensina. Esse mecanismo envolve a participação do endotélio com maior liberação de NO, aumento do número de AT2R, e da fosforilação da eNOS e da ERK1/2. Essas vias favoreceriam a vasodilatação em ratos obesos, que se traduz em menor resposta contrátil à Ang II.

Palavras-chave: Obesidade. Angiotensina II. MAPKs. 


\section{ABSTRACT}

HAGIHARA GN. Differential participation of MAPKs in angiotensin II-induced contraction in obesity. [Master thesis (Pharmacology)] São Paulo: Instituto de Ciências Biomédicas da Universidade de São Paulo, 2012.

Obesity is associated to vascular dysfunction. One of the mechanisms involved in this alteration is increased activation of the renin-angiotensin system, compromising the response to angiotensin II (Ang II), a vasoactive peptide that can activate the mitogen-activated protein kinases (MAPKs) pathways. To investigate the role of obesity and MAPKs in vascular reactivity to Ang II, Wistar rats received monosodium glutamate injections $\left(4.0 \mathrm{~g} / \mathrm{kg}\right.$, s.c.) from $2^{\text {nd }}$ to $6^{\text {th }}$ day after birth and were used at the age of 16 weeks. This treatment was effective in inducing obesity characterized by increased Lee's index, retroperitoneal and periepididymal fat with no change in lean body mass (soleus and EDL), and induced hypertriglyceridemia, increased VLDL and LDL fractions, with no change in total cholesterol, HDL-cholesterol and systolic blood pressure. The response to Ang II was analyzed in isolated mesenteric resistance arteries using a wire myography. The obese rats had lower response to Ang II when compared to controls. This alteration was endothelium-dependent and involved the AT2 receptor (AT2R) because the AT2R antagonism corrected the lower response. The AT1R protein expression did not differ from controls, while AT2R expression was increased in obese rats. Inhibition of nitric oxide synthase by L-NAME corrected the response to Ang II, indicating the participation of NO in the lower response, which was confirmed by the increased basal expression of eNOS. Inhhibition of NADPH oxidase by apocynin reduced the contraction to Ang II in both groups, indicating that the alteration observed in obese rats did not involve the participation of reactive oxygen species. Because the inhibition of ERK1/2 corrected the Ang II response, we concluded that the lower response to Ang II involves ERK1/2 pathway that promotes vasodilatation. We have also demonstrated that obese rats have increased ERK1/2 expression in basal and Ang II stimulus. Since the inhibition of JNK and p38 MAPKs pathways decreased even more the Ang II response, we concluded that they are involved in maintenance of the contractile response to this agonist. The alterations were specific because there was no difference in the contractile response to norepinephrine and potassium chloride. The MAPKs appear not to be the main 
mechanism by which Ang II and noradrenline promote vasoconstriction in controls, since inhibition of each of three major MAPKs pathways did not alter the contractile response to thes agents. Therefore, we concluded that in obesity, the lower contractile response to Ang II might be an adaptive mechanism against the increased activation of the renin-angiotensin system. This mechanism involves the participation of the endothelium through a greater release of NO, increased AT2R, eNOS and ERK $1 / 2$ expressions. These pathways would contribute to vasodilatation in obesity, which was expressed as a lower contractile response to Ang II.

Key words: Obesity. Angiotensin II. MAPKs. 


\section{LISTA DE ILUSTRAÇÕES}

Figura 1 - Esquema ilustrativo da reatividade vascular em miógrafo de arame

Figura 2 - llustração do procedimento de normalização

Figura 3 - Caracterização da obesidade

Figura 4 - Teste de viabilidade do endotélio

Figura 5 - Resposta contrátil à Ang II

Figura 6 - Losartan na concentração de $10 \mu \mathrm{M}$ aboliu a contração à Ang II

Figura 7 - Participação do AT1R na contração à Ang II

Figura 8 - Conteúdo Proteico do AT1R em artérias mesentéricas de resistência

Figura 9 - Participação do AT2R na contração à Ang II

Figura 10 - Conteúdo Proteico do AT2R em artérias mesentéricas de resistência

Figura 11 - Participação do NO na resposta à Ang II

Figura 12 - Participação das EROs na resposta à Ang II

Figura 13 - Participação da ERK1/2 na resposta à Ang II

Figura 14 - Expressão proteica da ERK1/2 em artérias mesentéricas de resistência

Figura 15 - Participação da JNK na resposta à Ang II

Figura 16 - Participação da p38 MAPK na resposta à Ang II

Figura 17 - Expressão proteica da ERK1/2 com antagonistas de AT1R e AT2R

Figura 18 - Resposta à Ang II com bloqueio de AT2R e inibição da ERK1/2

Figura 19 - Expressão proteica da eNOS após inibição da ERK1/2

Figura 20 - Resposta contrátil à NA

Figura 21 - Participação da ERK1/2 na contração à NA

Figura 22 - Participação da JNK na contração à NA

Figura 23 - Participação da p38 MAPK na contração à NA 


\section{LISTA DE TABELAS}

Tabela 1 - Perfil lipídico e pressão arterial

Tabela 2 - Características dos vasos utilizados na reatividade vascular

Tabela 3 - Resposta máxima ( $R$ máx.) e sensibilidade $\left(\mathrm{pD}_{2}\right)$ à $N A$ das artérias mesentéricas com $(E+)$ e sem endotélio $(E-)$

Tabela 4 - Resposta máxima ( $R$ máx.) e sensibilidade $\left(\mathrm{pD}_{2}\right)$ a NA das artérias mesentéricas com endotélio, sem inibidor e com inibidor da via ERK 1/2 $(\mathrm{C}+\mathrm{PD}$ ou $\mathrm{Ob}+\mathrm{PD})$

Tabela 5 - Resposta máxima ( $R$ max.) e sensibilidade $\left(\mathrm{pD}_{2}\right)$ a NA das artérias mesentéricas com endotélio, sem inibidor e com inibidor da via JNK (C + $\mathrm{SP}$ ou $\mathrm{Ob}+\mathrm{SP})$

Tabela 6 - Resposta máxima (R max.) e sensibilidade (pD2) a NA das artérias mesentéricas, com endotélio, sem inibidor e com inibidor da via p38 ( $\mathrm{C}+$ $\mathrm{Sb}$ ou $\mathrm{Ob}+\mathrm{Sb})$ 


\section{LISTA DE ABREVIATURAS E SIGLAS}

ACh - Acetilcolina

Ang II - Angiotensina II

ANOVA - Análise de variância

AT1R - Receptor de angiotensina do tipo 1

AT2R - Receptor de angiotensina do tipo 2

${ }^{\circ} \mathbf{C}$ - Unidade de temperatura Celsius

$\mathrm{Ca}^{2+}-$ Cálcio

$\mathrm{CaCl}_{2} \cdot \mathbf{2} \mathrm{H}_{2} \mathrm{O}$ - Cloreto de cálcio diidratado

CEUA - Comissão de Ética no Uso de Animais

cGKI - Proteína cinase I dependente de cGMP

cGMP- 3',5'-monofosfato cíclico de guanosina

cm - Centímetro

$\mathrm{CO}_{2}$ - Dióxido de carbono

D-glicose - Glicose

EDL - músculo extensor digital longo

EDTA - Ácido etilenodiaminotetracético

eNOS - enzima sintase de óxido nítrico endotelial

epm - erro padrão da média

ERK - proteínas quinases reguladas por sinalização extracelular

ET-1 - endotelina-1

EUA - Estados Unidos da América

g - Unidade de medida Grama 
GTP - Trifosfato de guanosina

HDL - Lipoproteína de alta densidade

iNOS - enzima sintase de óxido nítrico induzível

JNK - proteínas quinases do terminal c-jun

$\mathbf{K C I}$ - Cloreto de potássio

kg - Unidade de medida quilograma

$\mathrm{KH}_{2} \mathrm{PO}_{4}-$ Fosfato monobásico de potássio

$\mathbf{L}$ - Unidade de medida Litro

LDL - Lipoproteína de baixa densidade

L-NAME - N $\omega$-nitro-L-arginina metil éster

M - Unidade de concentração molar

MAPK - Proteína quinase ativada por mitógenos

mg - Unidade de medida miligrama

$\mathrm{MgSO}_{4} \cdot 7 . \mathrm{H}_{2} \mathrm{O}$ - Sulfato de magnésio heptahidratado

min - Unidade de medida minuto

$\mathbf{m L}$ - Unidade de medida mililitro

mM - Unidade de concentração milimolar

mm - Unidade de medida milímetro

mmHg - milímetro de mercúrio

mN - Unidade de medida MiliNewton

ms - Unidade de medida Milisegundo

$\mathbf{n}$ - Número de animais utilizados no experimento

NA - Noradrenalina 
$\mathrm{NaCl}$ - Cloreto de sódio

$\mathrm{NaHCO}_{3}-$ Bicarbonato de sódio

ng - Unidade de medida nanograma

nNOS - Enzima sintase de óxido nítrico neuronal

NO - Óxido nítrico

NOS - Enzima sintase de óxido nítrico

$\mathrm{O}_{2}-$ Gás oxigênio

p38 MAPK - proteínas quinases p38

PBS - Tampão fosfato

PD 123,319 - antagonista de receptor de angiotensina do tipo 2

PD 98059 - inibidor da ERK1/2 MAPK

$\mathrm{pD}_{2}$ - Concentração de um fármaco para atingir $50 \%$ da resposta máxima

$\mathbf{p} \mathbf{D}_{2}$ - Logaritmo negativo da $\mathrm{EC}_{50}$

pH - Potencial hidrogeniônico

q.s.p. - Quantidade suficiente para

$\mathbf{R}_{\text {máx }}-$ Efeito máximo produzido pelo agonista

s.c. - subcutâneo

SB 203580 - inibidor da p38 MAPK

SBCAL - Sociedade Brasileira de Ciência de Animais de Laboratório

SDS-PAGE - Gel de eletroforese de poliacrilamida em dodecil sulfato de sódio sGC - Guanilato ciclase solúvel

SP 600125 - inibidor da JNK MAPK

TBS - Tampão de salina Tris 
TBS-T - Tampão de salina Tris com Tween 20

V - Unidade de medida Volts

VLDL - Lipoproteína de muito baixa densidade

$\mu \mathrm{L}$ - Unidade de medida microlitro

$\boldsymbol{\mu M}$ - Unidade de concentração micromolar

$\mu \mathrm{m}$ - Unidade de medida micrômetro 


\section{SUMÁRIO}

1 INTRODUÇÃO

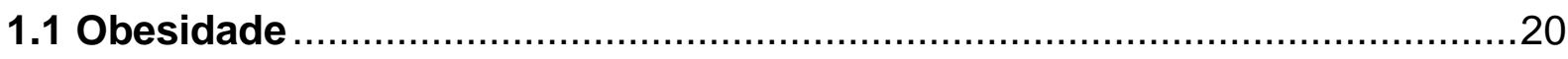

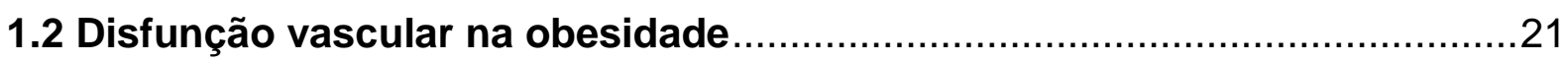

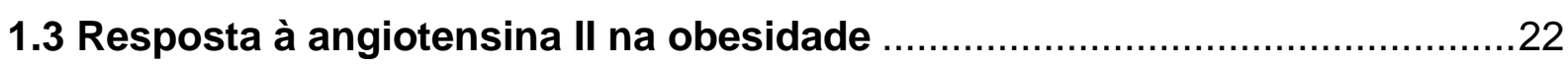

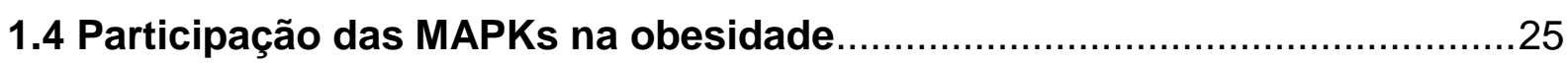

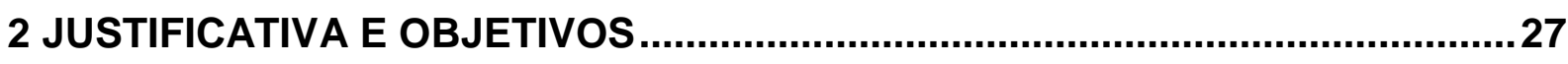

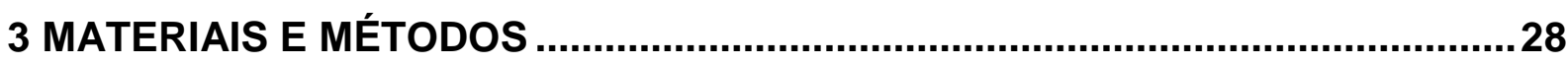

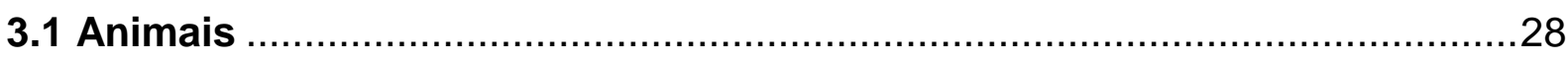

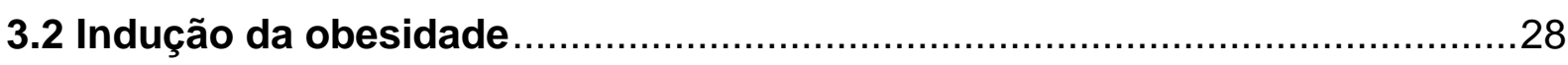

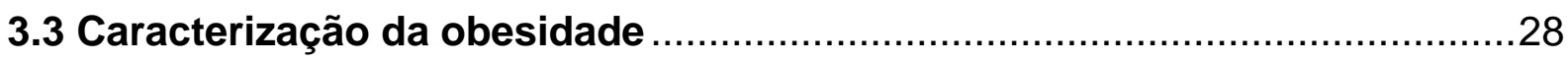

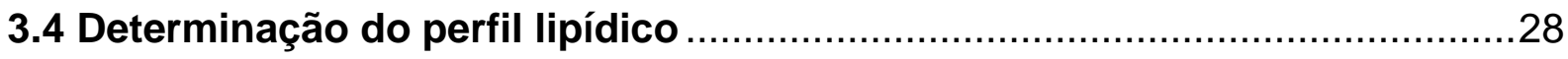

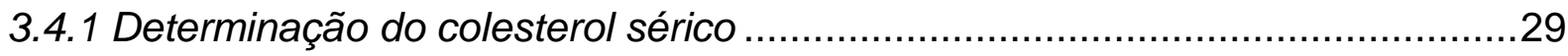

3.4.2 Determinação de triglicerídeos séricos.........................................................29

3.4.3 Determinação sérica de HDL colesterol ...................................................29

3.4.4 Cálculo da concentração sérica de VLDL colesterol ........................................30

3.4.5 Cálculo da concentração sérica de LDL colesterol..........................................30

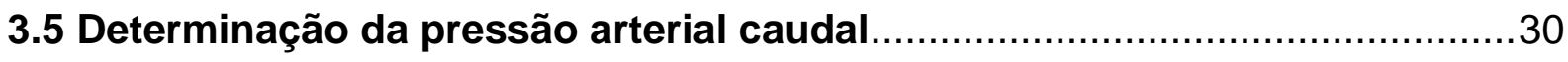

3.6 Estudo da reatividade vascular em artérias mesentéricas de resistência ...31

3.6.1 Normalização das artérias de resistência.....................................................32

3.6.2 Padronização das curvas concentração-resposta à Ang II em artérias

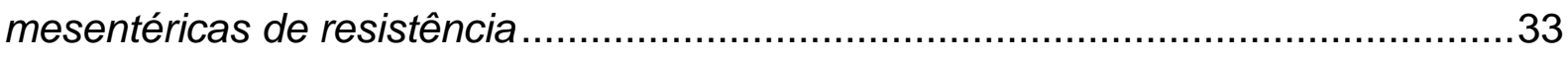

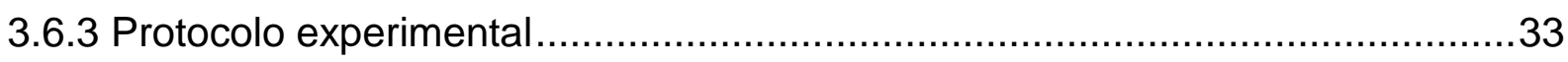

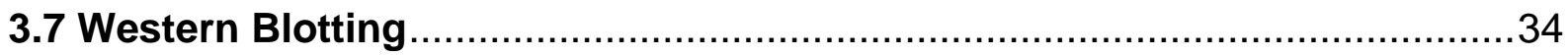

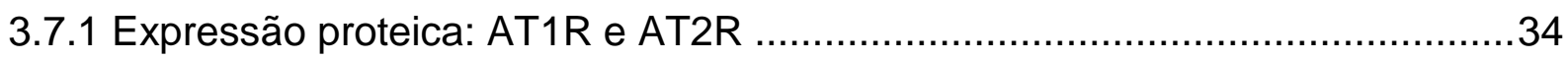

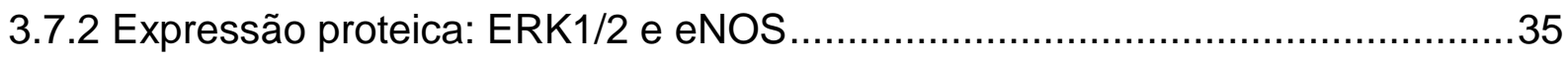

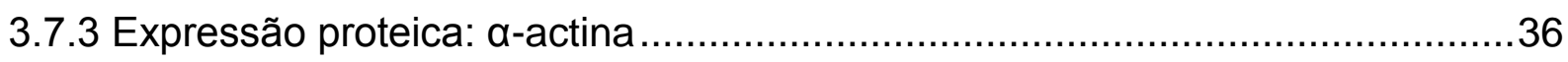




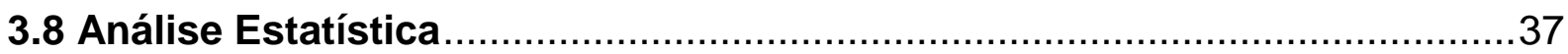

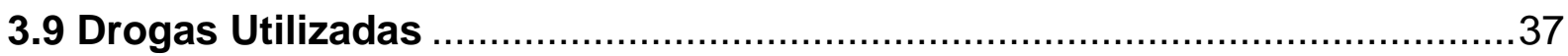

4 RESULTADOS

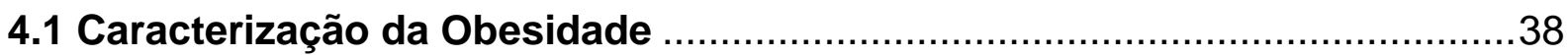

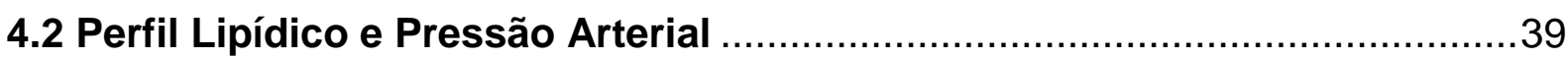

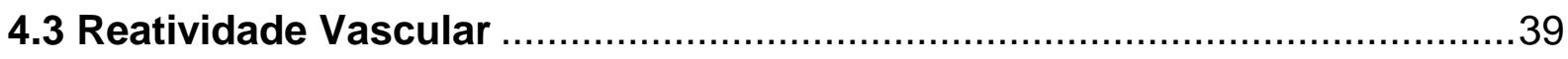

4.3.1 Avaliação da Resposta Vasoconstritora à Ang II...........................................41

4.3.2 Avaliação da participação dos receptores AT1 na resposta vasoconstritora à

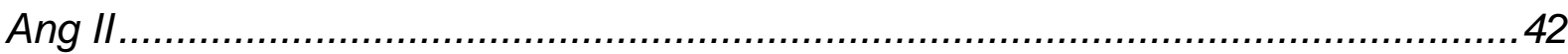

4.3.3 Avaliação da participação dos receptores AT2 na resposta vasoconstritora à Ang II.

4.3.4 Avaliação da participação do óxido nítrico na modulação da resposta vasoconstritora à Ang II......

4.3.5 Avaliação da participação das espécies reativas de oxigênio na modulação da

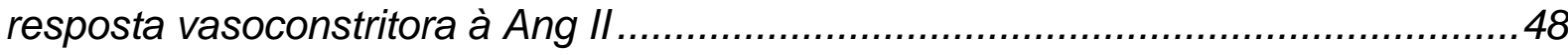

4.3.6 Avaliação da Participação das Vias das MAPKs na Resposta Vasoconstritora à

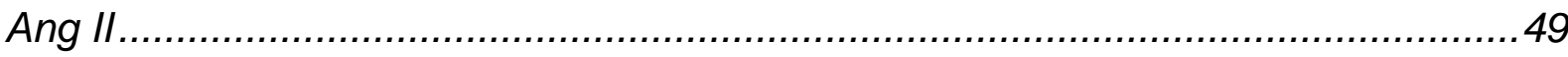

4.3.7 Avaliação da resposta vasoconstritora à NA …..........................................56

4.3.8.... Avaliação da participação das vias das MAPKs na resposta vasoconstritora à

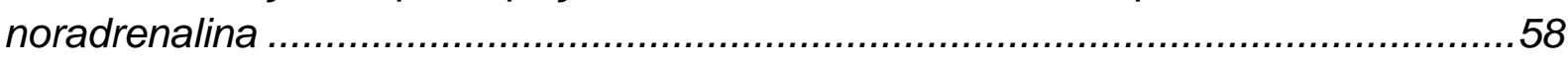

5 DISCUSSÃO

6 CONCLUSÃO

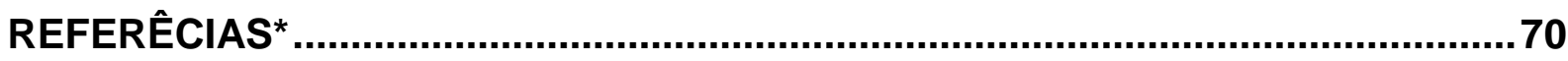

ANEXO A: Lobato NS, Filgueira FP, Hagihara GN, Akamine EH, Pariz JR, Tostes RC, Carvalho MHC, Fortes ZB. Improvement of metabolic parameters and vascular function by metformin in obese non-diabetic rats. Life Sci.

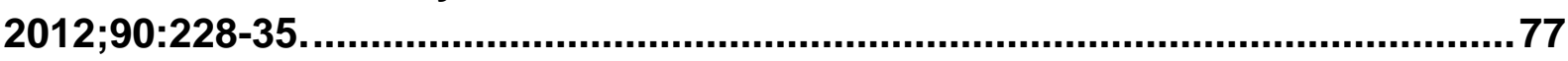

ANEXO B: Publicações em anais de congressos nacional e internacional.......86

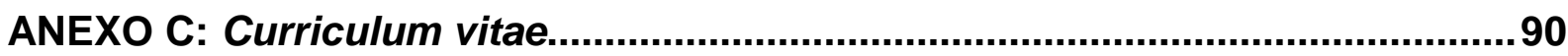




\section{INTRODUÇÃO}

\subsection{Obesidade}

A obesidade e as doenças que surgem como consequência dela, tais como o diabetes tipo 2, a hipertensão e as doenças cardiovasculares, estão aumentando de modo significativo a mortalidade em todo o mundo (Wild et al., 2004). Estudos epidemiológicos demonstram que a prevalência de obesidade, principalmente entre indivíduos jovens, em países em desenvolvimento, como é o caso do Brasil, aumentou significantemente em relação a países industrializados (Zimet et al., 2001). Adicionalmente, dados da Sociedade Brasileira de Endocrinologia e Metabolismo mostram que 18 milhões de brasileiros são obesos e cerca de 70 milhões apresentam sobrepeso. Segundo dados da Organização Mundial da Saúde (2005), nas últimas duas décadas, o número de indivíduos diabéticos aumentou dramaticamente de 30 para 177 milhões em todo o mundo.

Os mecanismos fisiopatológicos que levam ao desenvolvimento da obesidade estão apenas parcialmente elucidados. Sabe-se que ela surge como consequência do modo pelo qual o corpo regula a ingestão, o gasto e o estoque energético. Além disso, fatores biológicos, comportamentais e ambientais podem interagir e afetar o equilíbrio energético, contribuindo para o desenvolvimento da obesidade (Hill, 2006).

$\mathrm{Na}$ obesidade frequentemente detecta-se resistência à insulina e hiperinsulinemia compensatória (Quatanani, Lazar, 2007; Wilcox; 2005). A resistência à insulina pode ser definida como efeito diminuído da insulina sobre a captação, o metabolismo e o armazenamento de glicose, em virtude da redução da sensibilidade de tecidos periféricos à ação deste hormônio (Avogaro et al., 2005; Saltiel, Kahn, 2001). Nesta condição, a captação de glicose estimulada pela insulina encontra-se diminuída no músculo esquelético e no tecido adiposo, além de haver prejuízo na supressão da produção de glicose hepática (Greenfield, Campbell, 2004).

Estudos clínicos e experimentais sugerem a existência de uma relação causaefeito entre obesidade e resistência à insulina, tendo em vista que ganho/perda de peso está intimamente correlacionado com diminuição/aumento da sensibilidade à 
insulina, respectivamente (Freidenberg et al., 1988). A resistência às ações da insulina na obesidade contribui para uma série de alterações metabólicas e cardiovasculares, que favorecem o desenvolvimento de condições como o diabetes tipo 2 e a hipertensão arterial (Caballero, 2003).

\subsection{Disfunção vascular na obesidade}

A função vascular também sofre alterações decorrentes da obesidade (Fruhbeck, 2004). Estudos sugerem que o acúmulo de tecido adiposo branco nesta condição, com aumento da liberação de citocinas, de substratos e de hormônios na circulação, pode ter participação importante no processo de disfunção vascular (Fernández-Sánchez, 2011). O papel da resistência à insulina nas alterações da resposta vascular também foi demonstrado em estudos clínicos onde se verificou que indivíduos obesos com resistência à insulina apresentam redução de 40 a 50\% da vasodilatação dependente de endotélio quando comparados ao grupo controle (Larson et al, 1984). Adicionalmente, a capacidade da insulina de aumentar a vasodilatação dependente de endotélio por modulação da produção ou liberação de óxido nítrico (NO) encontrava-se notadamente prejudicada nestes indivíduos, indicando que a obesidade e a resistência à insulina, independentemente de outros fatores de risco, podem contribuir para alterar a função endotelial (Steinberg et al., 1996; Chen et al., 2003).

As células endoteliais vasculares representam papel importante na manutenção da homeostase vascular. Além de proporcionar uma barreira física entre o lúmen e a parede do vaso, o endotélio regula ativamente o tônus vascular basal e a reatividade vascular em condições fisiológicas, respondendo a forças mecânicas e a mediadores neuro-humorais, além de liberar uma variedade de fatores contráteis e relaxantes. Frente a estímulos específicos, as células endoteliais podem liberar fatores relaxantes derivados do endotélio (EDRFs), como também fatores contráteis derivados do endotélio (EDCFs). Os EDRFs incluem o NO, a prostaciclina (PGI2) e o fator hiperpolarizante derivado do endotélio (EDHF). Os EDCFs compreendem a angiotensina II (Ang II), a endotelina-1 (ET-1), espécies reativas de oxigênio (EROs) e os prostanóides vasoconstritores (Furchgott, Vanhoutte, 1989). Em condições fisiológicas, o tônus vascular é garantido pelo equilíbrio exercido por estes fatores. O desequilíbrio na produção e/ou liberação 
desses fatores, com aumento de EDCFs e/ou diminuição dos EDRFs, é uma das características da disfunção endotelial (Mather et al., 2002).

Alguns mecanismos têm sido propostos para explicar a disfunção endotelial presente na obesidade, como alterações na geração e/ou liberação dos mediadores envolvidos no relaxamento (Steinberg et al.,1996; Sánchez et al., 2010), especialmente o NO, e na contração vascular, como os produtos do ácido araquidônico (Mather et al., 2002). Estudos demonstram também o papel importante do estresse oxidativo, sendo este considerado o principal mecanismo pelo qual a resistência à insulina causa disfunção endotelial na obesidade. No estresse oxidativo há aumento da geração de EROs como o radical ânion superóxido $\left(\mathrm{O}_{2}^{-}\right)$ou peróxido de hidrogênio $\left(\mathrm{H}_{2} \mathrm{O}_{2}\right)$ (Fernández-Sánchez et al., 2011). Em um estudo clínico a diminuição da resposta vasodilatadora dependente do endotélio em indivíduos obesos foi atribuída, ao menos em parte, ao estresse oxidativo, pois a infusão de vitamina $\mathrm{C}$, um antioxidante, melhorou a resposta à acetilcolina ( $\mathrm{CCh}$ ), um agente vasodilatador dependente de endotélio (Perticone et al., 2001). Estudos experimentais também demonstram que a obesidade é acompanhada de diminuição da vasodilatação dependente de NO, que pode ocorrer devido ao aumento da produção de (EROs), como o $\left(\mathrm{O}_{2}^{-}\right)$, que inativa o $\mathrm{NO}$ (Schiffrin et al., 2008).

Estudo recente realizado em nosso laboratório demonstrou que a obesidade promove aumento da resposta contrátil induzida por agonista adrenérgico e redução da resposta vasodilatadora dependente de endotélio no leito arteriolar mesentérico. Essas alterações estão relacionadas com redução da produção de NO, aumento da geração de EROs e redução da razão $\mathrm{PGI}_{2} / \mathrm{TXA}_{2}$ no leito arteriolar mesentérico (Lobato, et al., 2011).

\subsection{Resposta à angiotensina II na obesidade}

Um fator que pode levar à resistência à insulina e hipertensão na obesidade é o aumento da ativação do sistema renina-angiotensina (SRA). O SRA é um dos principais sistemas regulatórios da pressão arterial, da perfusão tecidual e do volume sanguíneo. Simplificadamente, o angiotensinogênio é clivado pela protease renina em angiotensina I, que por sua vez é convertida pela enzima conversora de angiotensina (ECA) em Ang II (Metha, Griendling, 2006). A Ang II é um dos principais peptídeos efetores desse sistema e possui a maioria de suas ações conhecidas desencadeada pela ligação ao receptor AT1, um receptor acoplado à 
proteína G que, uma vez ativado, pode estimular múltiplas vias intracelulares de transdução do sinal, levando a diversas ações biológicas. A ativação do receptor AT1 estimula a fosfolipase $C$, induzindo a formação de trifosfato de inositol e diacilglicerol, o que promove aumento dos níveis citoplasmáticos de $\mathrm{Ca}^{2+}$, levando à ativação da proteína quinase C (PKC) e da adenilil-ciclase (Lee et al., 1993). A ligação da Ang II ao receptor AT1 pode também ativar uma via de sinalização mediada por tirosina-quinases (Fleming et al., 2006). Uma série de tirosina-quinases pode ser ativada a partir da ligação da Ang II ao receptor AT1. Essas tirosinaquinases regulam vias efetoras intracelulares, incluindo a PLC-gama e ativadores de transcrição (STATs) (Carvalho-Filho et al., 2007).

Além do receptor AT1, a Ang II pode ativar o receptor AT2, e sua ativação está relacionada a diversos mecanismos de sinalização intracelular, tais como a ativação de proteínas fosfatases, ativação do sistema NO/cGMP, estimulação da fosfolipase A2 e na regulação negativa de diversas respostas iniciadas pela ativação do receptor AT1 (Fleming et al., 2006; Steckelings et al., 2005).

A Ang II influencia a pressão sanguínea atuando em múltiplas vias. Sua ação em diversos territórios vasculares e em diferentes tecidos pode levar ao aumento do volume extracellular e dos níveis pressóricos. A Ang II promove vasoconstrição de arteríolas renais e sistêmicas, contribuindo para o aumento da resistência periférica e da pressão arterial. A ativação de receptores de Ang II no sistema nervoso central também contribui para o aumento da pressão arterial, por aumentar a descarga simpática para o coração e para o sistema vascular, aumentando o débito cardíaco e a resistência periférica total (Touys, Schiffrin, 2000).

Além de atuar sobre o sistema vascular, a ativação do receptor AT1 pela Ang Il estimula a produção de aldosterona pela zona glomerulosa no córtex da glândula adrenal. A aldosterona é um hormônio esteroide que promove aumento da reabsorção de sódio e água nos túbulos distais e nos ductos coletores do rim, contribuindo para a elevação da pressão arterial (Siddiqui, Hussain, 2007).

A importância do SRA na obesidade foi sugerida em estudos demonstrando que este sistema está ativado em indivíduos obesos apesar do estado de expansão de volume e retenção de sódio. Demonstrou-se que indivíduos com índice de massa corporal (IMC) maior do que $31 \mathrm{Kg} / \mathrm{m}^{2}$ apresentam níveis de ECA elevados em tecidos, como os vasos e os rins (Barton et al., 2003). O próprio acúmulo de gordura visceral na obesidade pode contribuir para este quadro em virtude da compressão 
mecânica renal associada à expansão de tecido adiposo, fator determinante para a maior reabsorção de sódio nos segmentos proximais do néfron promovendo ativação da mácula densa, no sentido de preservar o fluxo plasmático renal e a taxa de filtração glomerular. Esse mecanismo leva à retenção hidrossalina e à elevação dos níveis pressóricos (Rahmouni et al., 2005).

O metabolismo também pode sofrer influências da Ang II. Estudos recentes demonstraram a presença de diversos constituintes do SRA no tecido adiposo e em adipócitos isolados. Além disso, estudos demonstram que a Ang II potencializa os efeitos inibitórios de ácidos graxos não esterificados sobre a captação de glicose mediada pela insulina e que o bloqueio sistêmico do SRA melhora a sensibilidade à insulina em indivíduos obesos que apresentam hipertensão arterial (Kurtz et al., 2004).

Elevados níveis plasmáticos e aumento da expressão de angiotensinogênio no tecido adiposo têm sido verificados na obesidade (Formiguera, Cantón, 2004). Esses fatores contribuem para o aumento da produção local de Ang II nesses pacientes. Estudos experimentais demonstraram que o angiotensinogênio produzido pelo tecido adiposo pode atuar localmente, estimulando a diferenciação de adipócitos locais, além de ser liberado na corrente sanguínea. Isso reforça a hipótese de que os altos níveis de angiotensinogênio em pacientes obesos podem ocorrer como consequência do aumento da massa de tecido adiposo. Adicionalmente, a ativação sistêmica e tecidual do SRA na obesidade pode potencializar o aumento da reabsorção renal de sódio e o desvio da pressão de natriurese contribuindo para a elevação da pressão arterial (Carvalho-Filho et al., 2007).

Alterações na resposta mediada pela Ang II no sistema vascular têm sido descritas por diversos autores em modelos animais de obesidade, assim como em humanos (Siddiqui, Hussain, 2007). Porém, estudos de reatividade vascular em modelos experimentais de obesidade são conflitantes no que se refere aos efeitos da Ang II. Estudos avaliando a resposta à Ang II em aorta de ratos com obesidade induzida por dieta hiperlipídica (Ghatta, Ramarao, 2004) e em ratos Zucker (Nishimatsu et al., 2005), um modelo genético de obesidade e resistência à insulina, relataram aumento da resposta vasoconstritora à Ang II quando comparados aos controles. Por outro lado, estudos anteriores não demonstraram aumento da resposta à Ang II em anéis de aorta de ratos Zucker (Harker et al., 1993). Essas 
informações indicam que não há um consenso quanto à alteração da resposta vasoconstritora à Ang II na obesidade e que mais estudos são necessários para esclarecer os mecanismos envolvidos nessa patologia.

\subsection{Participação das MAPKs na obesidade}

A ligação da Ang II ao aos seus receptores ativa diversas vias sinalizações intracelulares que regulam seus efeitos fisiológicos. Dentre elas destacamos as vias de sinalização constituídas por proteínas quinases ativadas por mitógenos (MAPKs) (Metha, Griendling, 2006).

Dados de estudos recentes indicam que na obesidade há ativação de MAPKs em tecidos que regulam a homeostase energética, como o fígado, o músculo esquelético e o tecido adiposo. Os mecanismos envolvidos no desenvolvimento dessa alteração incluem aumento da produção de ácidos graxos livres e de citocinas pró-inflamatórias pelo tecido adiposo branco (Hirosumi et al., 2002).

O sistema de sinalização intracelular que envolve a cascata das MAPKs é representado principalmente por três grupos: quinases reguladas por sinalização extracelular (ERKs), quinases do terminal c-jun (JNKs), e p38 MAPKs. Essas proteínas incluem quinases de serina/treonina, que são reguladas por cascatas de fosforilação organizadas em grupos específicos. Diversos ativadores situados nos passos iniciais da cascata respondem a estímulo extracelular. Este, por sua vez, deflagra a cascata por meio da ativação de proteínas quinases, que promovem a fosforilação de proteínas específicas. Essas proteínas, uma vez ativadas, fosforilam as MAPKs. As MAPKs atuam, então, em vários alvos situados em passos mais avançados da cascata, que afetam, por sua vez, processos relacionados a eventos adaptativos, tais como expressão gênica, diferenciação, metabolismo e apoptose (Seger, Krebs, 1995; Sprague, Khalil, 2009).

As ações das MAPKs são estreitamente integradas em condições fisiológicas. A ativação da p38 MAPK está relacionada com cardioproteção (Muslin et al., 2008). A via da MAPK é também importante para as ações proliferativas da insulina. $\mathrm{Na}$ vasculatura, essa via medeia não somente o crescimento celular, mas também a capacidade migratória das células endoteliais, do músculo liso vascular e dos monócitos. Além disso, ela parece mediar a expressão de um fator pró-trombótico, pró-fibrótico, o inibidor do ativador do plasminogênio 1 (PAl-1), em resposta a diversos estímulos. Estudos demonstraram que a JNK regula negativamente a 
sinalização da insulina contribuindo para o desenvolvimento de resistência aos efeitos desse hormônio (Hirosumi et al., 2002), ao passo que a p38 MAPK está implicada na regulação positiva do gasto energético (Puigserver et al., 2001).

As MAPKs representam também papel importante na regulação da contração do músculo liso vascular. Demonstrou-se que a noradrenalina (NA) e a ET-1 ativam a p38 MAPK em artérias mesentéricas de resistência de ratos. Porém, apenas a contração induzida pela NA depende da ativação da p38 MAPK, demonstrando que os mecanismos de ativação da p38 MAPK diferem entre estes dois agonistas (Ohanian et al., 2001). O papel da p38 MAPK na contração induzida pela Ang II em aorta de ratos também já foi demonstrado, assim como a participação das EROs e a sensibilização do aparato contrátil também medeiam esse efeito (Zhou et al. 2010). Além da p38 MAPK, a ativação da ERK possui também papel importante na contração vascular mediada pela Ang II (Touyz et al., 1999).

A participação das MAPKs na disfunção vascular presente em condições como a hipertensão tem sido proposta. Assim, demonstrou-se que a ativação da p38 MAPK possui papel importante no aumento da vasoconstrição induzida pela ET-1 em ratos espontaneamente hipertensos. Essa alteração é independente da fosforilação de proteínas da cadeia leve de miosina (Kwon et al., 2004). Em outro estudo demonstrou-se que o aumento da reatividade vascular à felinefrina, um agonista a1-adrenérgico, em aorta de ratos hipertensos DOCA-sal é mediado pela ativação da ERK1/2 (Giachini et al., 2010).

Embora alguns estudos tenham sido realizados no sentido de avaliar os efeitos da obesidade sobre a resposta contrátil à Ang II, não há um consenso quanto à participação e ao papel desempenhado pelas MAPKs nestas alterações. 


\section{JUSTIFICATIVA E OBJETIVOS}

Na obesidade há alteração da função vascular. Um possível mecanismo pelo qual a disfunção vascular pode ocorrer na obesidade é o aumento da ativação do SRA. Indivíduos obesos ou animais em que se induz obesidade apresentam aumento da atividade da ECA, da expressão de receptores AT1, ou ainda, aumento ou diminuição da reatividade vascular à Ang II.

Considerando que a Ang II ativa a via das MAPKs e que na obesidade há ativação dessa via em tecidos que regulam a homeostase energética, o objetivo do presente projeto foi investigar o papel da via de sinalização das MAPKs na resposta à Ang II na obesidade. Para isso, avaliamos as respostas de artérias mesentéricas de resistência ao agente contrátil Ang II, bem como a participação dos componentes da cascata de sinalização das MAPKs. A especificidade das alterações da reatividade vascular à Ang II foi avaliada pela comparação com as respostas mediadas pela $\mathrm{NA}$ e pelo $\mathrm{KCl}$. 


\section{MATERIAIS E MÉTODOS}

\subsection{Animais}

O protocolo para uso de animais em experimentação está de acordo com os Princípios Éticos de Experimentação Animal adotado pela Sociedade Brasileira de Ciência de Animais de Laboratório (SBCAL) aprovado pela Comissão de Ética no Uso de Animais (CEUA) do Instituto de Ciências Biomédicas (ICB) em 27/07/2010, com validade de 3 anos, protocolo registrado sob número 75 na folha 89 do livro 2.

Foram utilizados ratos Wistar neonatos, provenientes do biotério do ICB da Universidade de São Paulo. Os ratos foram mantidos durante todo o período experimental em caixas de polipropileno, acondicionadas em ambiente com temperatura controlada de $22 \pm 2{ }^{\circ} \mathrm{C}$ e ciclo claro-escuro de 12horas, com livre acesso à água e alimento. Os ratos foram divididos em dois grupos experimentais:

I) Controle; II) Obeso.

\subsection{Indução da obesidade}

Os ratos receberam injeções subcutâneas (sc.) de MSG (4 mg/g de peso corporal) do $2^{\circ}$ ao 6으 dia de vida (Rodriguez-Sierra et al., 1980). Ratos do grupo controle receberam igual volume de solução fisiológica $0,9 \%$. Os ratos com 16 semanas de idade foram utilizados para os protocolos descritos a seguir.

\subsection{Caracterização da obesidade}

Para a caracterização e confirmação da eficácia do tratamento com MSG, a obesidade foi avaliada pela determinação do Índice de Lee \{[peso corporal ${ }^{1 / 3}$ (g)/comprimento naso-anal (cm)] x 100\}, do peso relativo ( $\mathrm{g} / 100 \mathrm{~g}$ peso corporal) das gorduras periepididimal e retroperitoneal e dos músculos sóleo e extensor digital longo (EDL) bem como do perfil lipídico.

\subsection{Determinação do perfil lipídico}

Os ratos foram submetidos à privação alimentar de 04 horas (período das 07:00 - 11:00 horas) e anestesiados com tiopental sódico (50 mg/kg), via intraperitoneal, e em seguida submetidos à laparotomia e exposição da artéria aorta 
descendente. Amostras de 5,0 mL de sangue foram coletadas. O soro, separado por centrifugação a 1610 x g, por 10 minutos, foi estocado a $-80^{\circ} \mathrm{C}$, em alíquotas para as determinações do perfil lipídico.

\subsubsection{Determinação do colesterol sérico}

O colesterol total foi determinado pelo método enzimático Colesterol Liquiform - Labtest (Referência: 76), utilizando-se alíquotas de $10 \mu \mathrm{L}$ de soro, que foram misturadas ao reagente fornecido pelo kit e incubadas em banho-maria a $37{ }^{\circ} \mathrm{C}$ por 10 minutos. Neste método, a colesterol-oxidase catalisa a oxidação do colesterol produzindo peróxido de hidrogênio. Este, através de uma reação oxidativa catalisada pela peroxidase, reage com a 4-aminoantipirina e fenol produzindo a antipirilquinonimina vermelha, cuja intensidade de cor é proporcional à concentração de colesterol na amostra, que foi determinada por fotômetro (CELM SB190) capaz de medir com precisão absorbâncias entre 490 e 510 nm. Os resultados foram expressos em $\mathrm{mg} / \mathrm{dL}$.

\subsubsection{Determinação de triglicerídeos séricos}

Os triglicerídeos foram determinados pelo método enzimático Triglicérides Liquiform - Labtest (Referência: 87), utilizando-se alíquotas de $10 \mu \mathrm{L}$ de soro coletado, que foram misturadas ao reagente fornecido pelo kit e incubadas em banho-maria a $37^{\circ} \mathrm{C}$ por 10 minutos. Neste método, os triglicerídeos sofrem ação de lipases resultando na molécula de glicerol, e este é posteriormente convertido a glicerol-3-fosfato. A glicerol-3-fosfato-oxidase catalisa a oxidação do glicerol-3fosfato produzindo peróxido de hidrogênio. Este, através de uma reação oxidativa catalisada pela peroxidase, reage com a 4-aminoantipirina e clorofenol produzindo a quinoneimina vermelha, cuja intensidade de cor é proporcional à concentração de triglicerídeos na amostra, que foi determinada por fotômetro (CELM SB190) capaz de medir com precisão absorbâncias entre 490 e 510nm. Os resultados foram expressos em $\mathrm{mg} / \mathrm{dL}$.

\subsubsection{Determinação sérica de HDL colesterol}

As lipoproteínas de baixa e muito baixa intensidade (LDLs e VLDLs, repectivamente) foram precipitadas seletivamente pelo ácido fosfotúngstico e cloreto 
de magnésio, presente em reagente do método Colesterol HDL - Labtest (Refência: 13). No sobrenadante, separado por centrifugação, restaram as HDLs e realizou-se a determinação do colesterol ligado às mesmas pelo método enzimático descrito no item 3.4.1. Os resultados foram expressos em $\mathrm{mg} / \mathrm{dL}$.

\subsubsection{Cálculo da concentração sérica de VLDL colesterol}

A partir da concentração sérica de triglicerídeos, determinada pelo método descrito anteriormente no item $\underline{3.4 .2}$, foram calculadas as concentrações de VLDL colesterol, utilizando o seguinte cálculo:

$$
\text { VLDL Colesterol }(\mathrm{mg} / \mathrm{dL})=\text { Triglicérides }(\mathrm{mg} / \mathrm{dL}) / 5
$$

\subsubsection{Cálculo da concentração sérica de LDL colesterol}

A partir das concentrações séricas de HDL e VLDL colesterol, conforme descritos anteriormente nos itens $\underline{3.4 .3}$ e $\underline{3.4 .4}$, respectivamente, foram calculadas as concentrações de LDL colesterol, utilizando o seguinte cálculo:

LDL Colesterol $(\mathrm{mg} / \mathrm{dL})=$ Colesterol Total $-($ HDL Colesterol + VLDL Colesterol).

\subsection{Determinação da pressão arterial caudal}

A pressão arterial caudal de ratos não anestesiados foi determinada por método indireto, através da pletismografia de cauda. Os ratos foram submetidos a um período de adaptação que envolvia o aquecimento dos animais em estufa especial por 10 minutos a $37^{\circ} \mathrm{C}$ e posterior contenção em cilindro de acrílico com abertura para o focinho e cauda em temperatura ambiente por cinco minutos. Este procedimento foi realizado uma vez ao dia durante dois dias.

Após o procedimento de adaptação foram determinados os níveis pressóricos dos ratos. Para isso os ratos foram aquecidos por 10 minutos a $37{ }^{\circ} \mathrm{C}$ e posteriormente colocados no cilindro de contenção. Um oclusor e um sensor foram ajustados à porção proximal da cauda do rato, acoplados ao esfigmomanômetro elétrico PE-399 conectado a um sistema de transdução de sinal (PowerLab 4/S, AD Instrument Pty Ltda) e este, estava ligado a um computador contendo um programa de análise desse sinal (LabChart 6, AD Instrument Pty Ltda). O valor final da pressão 
arterial caudal de cada animal representa a média aritmética de três medidas sequenciais.

\subsection{Estudo da reatividade vascular em artérias mesentéricas de resistência}

Foi utilizado o método descrito por Mulvany e Halpern (1977). Os animais foram anestesiados com injeção intraperitoneal de tiopental sódico (5 mg / $100 \mathrm{~g}$ peso corporal, sc.). O leito mesentérico foi removido e colocado em uma placa de Petri contendo solução de Krebs-Henseleit a $4{ }^{\circ} \mathrm{C}$ (composição em mM: $\mathrm{NaCl} 130$; KCl 4,7; NaHCO3 14,9; CaCl2.2H2O 1,6; KH2PO4 1,18; MgSO4.7H2O 1,17; EDTA 0,026 e glicose 5,5). O segundo ramo da artéria mesentérica superior foi dissecado e cortado em segmentos de $2,0 \mathrm{~mm}$ de comprimento com o auxílio de um microscópio de dissecação. Dois fios de tungstênio (40 $\mu \mathrm{m}$ de diâmetro) foram então inseridos no lúmen das artérias e fixados em um miógrafo para vasos de resistência (Figura 1) para o estudo da tensão isométrica. Esse miógrafo, por sua vez, foi conectado a um sistema para aquisição de dados (PowerLab / 8SP, ADinstruments, Austrália) e este a um computador.

Figura 1 - Esquema ilustrativo da reatividade vascular em miógrafo de arame.

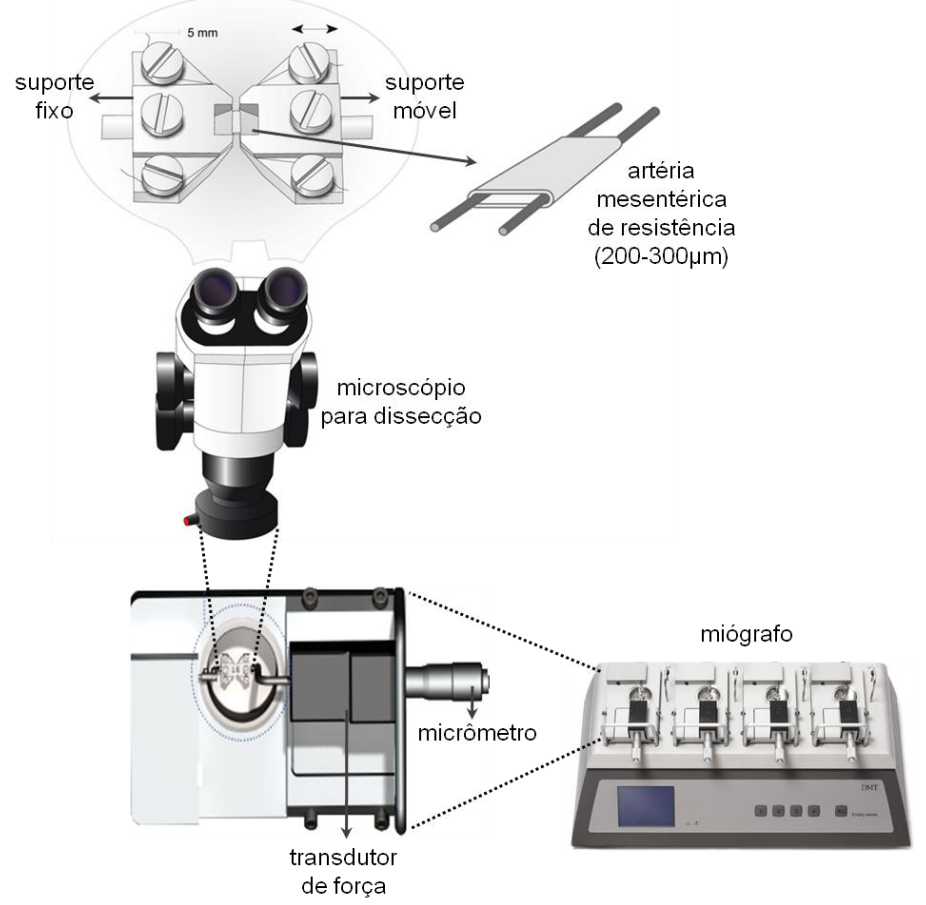

FONTE: Modificado de Mulvany e Halpern (1977). 


\subsubsection{Normalização das artérias de resistência}

O propósito do procedimento de normalização é distender o segmento vascular até que se atinja a chamada circunferência interna normalizada (IC1): definida como uma fração determinada da circunferência interna (IC100) que um segmento totalmente relaxado teria em uma determinada pressão transmural. Para artérias mesentéricas de resistência, a pressão transmural alvo é de $100 \mathrm{mmHg}$, que corresponde a $13,3 \mathrm{kPa}$.

Após o período de estabilização e aquecimento dos segmentos vasculares (15 minutos) em solução de Krebs-Henseleit ( $\mathrm{pH} 7,4$ e a $37^{\circ} \mathrm{C}$ ), as artérias mesentéricas foram distendidas de forma gradativa e a leitura da distância dos arames (micrômetro) e da força aplicada foram registrados a cada ponto (Figura 2). Estes dados foram então convertidos em valores de circunferência interna $(\mu \mathrm{m})$ e de tensão na parede vascular $\mathrm{T}(\mathrm{mN} / \mathrm{mm})$, respectivamente. A plotagem da tensão na parede do vaso contra a circunferência interna revela uma curva exponencial. Pela aplicação da curva isobárica correspondente a $100 \mathrm{mmHg}$, a IC100 é então calculada a partir do ponto de intersecção, utilizando o software específico para normalização de artérias de resistência (DMT Normalization Module, ADInstruments, Austrália) (Figura 3). A IC1 foi calculada a partir da IC100 por meio da fórmula IC1= $0,90 \times$ IC100, dando uma circunferência interna na qual a produção de força ativa bem como a sensibilidade do segmento a agonistas é máxima. $O$ diâmetro interno normalizado foi calculado dividindo-se IC1 por $\pi$.

Figura 2 - llustração do procedimento de normalização.

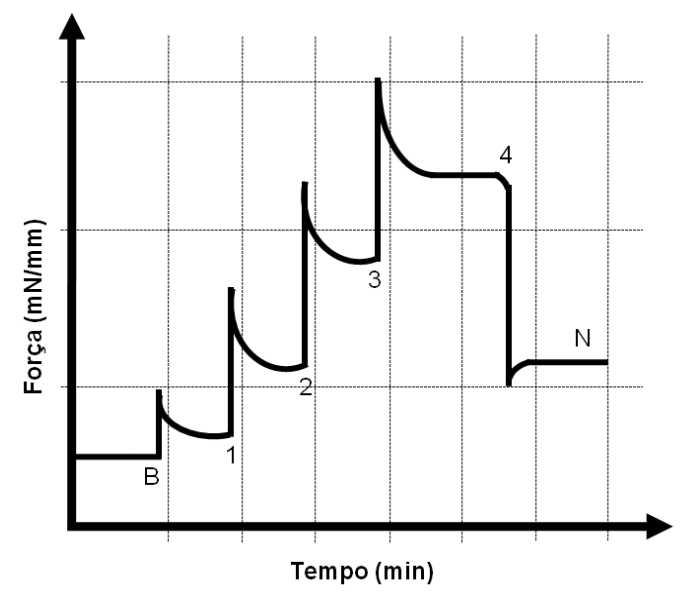

FONTE: Modificado de Mulvany e Halpern (1977). 


\subsubsection{Padronização das curvas concentração-resposta à Ang II em artérias} mesentéricas de resistência

A primeira etapa deste estudo foi dedicada à padronização da reatividade vascular para Ang II nas artérias mesentéricas de resistência. É importante mencionar que encontramos algumas dificuldades em realizar a curva concentração resposta a este agonista, uma vez que o mesmo induz dessensibilização de receptores. Deste modo, após o período de estabilização, os anéis foram précontraídos com NA na concentração que induz 30-50 \% da resposta máxima (concentração de $300 \mathrm{nM}$ ), determinada na curva concentração-resposta realizada previamente a este agonista (dados não demonstrados). O uso desse agonista evita a dessensibilização dos receptores para Ang II neste território vascular (Juul et al., 1987). Como não foi possível a realização de curva cumulativa, pois após a primeira dose de Ang II a artéria de resistência não respondia mais a este agonista, as quatro concentrações de Ang II foram testadas em quatro artérias de resistência do mesmo animal.

\subsubsection{Protocolo experimental}

Após 15 minutos do processo de normalização, as artérias foram contraídas com a administração de cloreto de potássio $(\mathrm{KCl}, 120 \mathrm{mM})$, com a finalidade de se avaliar a integridade funcional. Após um período de lavagem e estabilização por mais 15 minutos, a integridade do endotélio foi testada por meio da avaliação do relaxamento à acetilcolina ( $\mathrm{ACh}$ ) (vasodilatador dependente de endotélio) em vasos pré-contraídos com noradrenalina (NA, $1 \mu \mathrm{M})$. Para as curvas concentração resposta com endotélio $(E+)$, foram utilizados anéis com resposta vasodilatadora à $A C h$ superior à $90 \%$. Para os experimentos em anéis sem endotélio (E-), as artérias mesentéricas foram submetidas previamente à remoção mecânica do endotélio, com o auxílio de um fio de pêlo de rato, segundo protocolo descrito por Mulvany e Halpern (1977). Foram considerados sem endotélio apenas os anéis que apresentaram resposta vasodilatadora à ACh de no máximo $5 \%$.

Foram realizadas curvas concentração resposta à Ang II e à NA em segmentos vasculares com e sem endotélio. A participação dos receptores da Ang II foi avaliada pela realização de curvas concentração resposta na presença e na 
ausência dos antagonistas dos receptores AT1 e AT2, losartan (Los; $10 \mu \mathrm{M}$ ) (Franco et al., 2003) e o composto PD123,319 (1 $\mu \mathrm{M})$ (Isenovic et al., 2004), respectivamente. A participação do NO e das EROs foram avaliadas em curvas concentração resposta na ausência e na presença de inibidor da óxido nítrico sintase (L-NAME; $100 \mu \mathrm{M}$ ) (Lobato et al., 2011) e na ausência e na presença de inibidor da NADPH oxidase (apocinina; $10 \mu \mathrm{M})$ (Franco et al., 2007).

Com o objetivo de investigar a participação dos mediadores envolvidos na cascata de sinalização das MAPKs nas alterações da reatividade vascular observadas em ratos obesos, foram realizadas curvas concentração resposta à Ang II e à NA, na ausência e na presença de inibidores da ERK1/2 (PD 98059), da p38 MAPK (SB 203580) e da JNK (SP 600125). As doses usualmente utilizadas desses inibidores variam de 10 a 1 MM (Matrougui, et al. 2000; Zhou et al. 2010). Para a realização deste trabalho fizemos testes para as essas duas concentrações de inibidores (dados não demonstrados) e optamos por utilizar a dose de $1 \mu \mathrm{M}$ para todos os inibidores das MAPKs utilizados, pois a dose de $10 \mu \mathrm{M}$ mostrou-se muito alta, uma vez que aboliu a resposta contrátil à Ang II nos dois grupos estudados.

\subsection{Western Blotting}

Após anestesia (tiopental sódico, $5 \mathrm{mg} / 100 \mathrm{~g}$ peso corporal, sc.), as artérias mesentéricas de resistência foram removidas e incubadas em solução Krebs HEPES

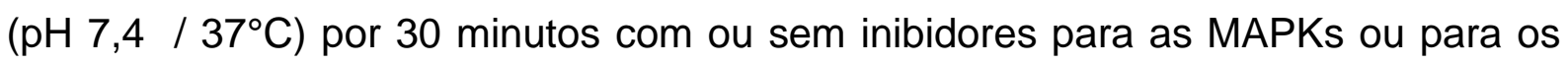
receptores AT1 ou AT2. Após o período de incubação, as artérias mesentéricas foram estimuladas ou não com Ang II $(10 \mu \mathrm{M})$ por 10 minutos $\left(37^{\circ} \mathrm{C}\right) \mathrm{e}$ imediatamente congeladas em nitrogênio líquido e armazenadas a $-80{ }^{\circ} \mathrm{C}$ até 0 momento da extração protéica. A concentração de Ang II e o tempo de incubação foram testados previamente (dados não demonstrados).

\subsubsection{Expressão proteica: AT1R e AT2R}

As artérias mesentéricas que estavam congeladas e armazenadas a $-80{ }^{\circ} \mathrm{C}$ foram trituradas em nitrogênio líquido com o auxílio de almofariz e pistilo de porcelana, homogeneizadas e incubadas no gelo por 30 minutos em $25 \mu \mathrm{L}$ de tampão de lise contendo Tris- $\mathrm{Cl}(50 \mathrm{mM} / \mathrm{pH} 7,4)$, EDTA (1 mM), sacarose $(10 \%)$, PMSF $(2 \mathrm{mM})$, leupeptina $(0,01 \mathrm{mg} / \mathrm{ml})$ e aprotinina $(0,01 \mathrm{mg} / \mathrm{ml})$. Os extratos 
teciduais foram centrifugados a $15000 \times$ g, a $4 \stackrel{\circ}{\mathrm{C}}$ por 20 minutos para remoção do material insolúvel. Após a centrifugação, o conteúdo protéico total foi quantificado pelo método de BCA protein assay (ácido bicincônínico, Thermo Scientific). O material insolúvel foi tratado com tampão de Laemmli contendo DTT (ditiotreitol, 350 $\mathrm{mM}$ ) e aquecido em água fervente por 5 minutos. Quarenta $\mu \mathrm{g}$ de proteína de cada amostra foram separadas por eletroforese em gel de poliacrilamida (SDS PAGE 10 $\%)$ em aparelho para mini gel (BioRad). Em cada gel foi aplicado também um marcador de peso molecular conhecido. A transferência (semi-dry) das proteínas separadas no gel foi feita eletricamente (Bio Rad) para uma membrana de nitrocelulose, por 40 minutos a $10 \mathrm{~V}$.

Após a transferência, as membranas de nitrocelulose foram incubadas com uma solução bloqueadora (PBS $1 \mathrm{X}$ e $1 \%$ de albumina) em temperatura ambiente por 3 horas, para reduzir a ligação inespecífica dos anticorpos na membrana.

Após o bloqueio, as membranas foram incubadas com anticorpos policlonais anti-AT1R (1:1000, Proteimax/PROTX04), anti-AT2R (1:1000, Proteimax/PROTX08) (diluídos em solução de PBS $1 \mathrm{X}$ e $1 \%$ de albumina) por 15 horas a $4^{\circ} \mathrm{C}$ em agitação. Em seguida, as membranas foram lavadas rapidamente por 3 vezes, seguida de 2 lavagens com intervalo de 10 minutos com solução tampão (PBS 1X e Tween 0,1\%). As membranas foram então incubadas por 2 horas, em temperatura ambiente, em agitação com anticorpo secundário anti-coelho conjugado com peroxidase (1:15000, Sigma). O procedimento de lavagem foi repetido novamente a cada 20 minutos por 1 hora e realizado conforme item $\underline{\mathbf{3 . 7 . 4}}$.

\subsubsection{Expressão proteica: ERK1/2 e eNOS}

As artérias mesentéricas que estavam congeladas e armazenadas a $-80^{\circ} \mathrm{C}$ foram trituradas em nitrogênio líquido e homogeinizadas em $25 \mu \mathrm{L}$ de tampão RIPA Lysis Buffer 1X (Millipore 20-188) com adição de pirofosfato de sódio (10 mM), fluoreto de sódio (100 mM), ortovanadato de sódio (10 mM), PMSF (1 mM) e PIC (coquetel inibidor de protease) $(2 \mathrm{mM})$.

Após 30 minutos no gelo, os extratos teciduais foram centrifugados a $12000 \mathrm{x}$ g a $4{ }^{\circ} \mathrm{C}$ por 30 minutos para a remoção do material insolúvel. Após a centrifugação, o conteúdo protéico total foi quantificado pelo método BCA protein assay (ácido bicincônínico, Thermo Scientific). O sobrenadante foi tratado com tampão de 
Laemmli contendo DTT (350 mM) e aquecido em água fervente por 5 minutos. Para a expressão protéica da ERK1/2 total e a fosforilada, $40 \mu \mathrm{g}$ de proteína foram separadas por eletroforese em gel de poliacrilamida (SDS-PAGE $10 \%$ ). Para a eNOS total e a fosforilada, $80 \mu \mathrm{g}$ de proteína foram separadas por eletroforese em gel de poliacrilamida (SDS-PAGE 7,5\%).

A transferência das proteínas separadas no gel foi feita eletricamente para uma membrana de nitrocelulose (BioRad) por 1 hora no caso da ERK1/2 e membrana de PVDF (previamente ativada em metanol por 20 minutos) por 1,5 hora no caso da eNOS, a $100 \mathrm{~V}$. Após a transferência, a membrana de nitrocelulose ou PVDF foi incubada com uma solução bloqueadora contendo leite desnatado Molico ${ }^{\circledR}$ (5 \%) para a ERK1/2, ou solução contendo albumina bovina (3 \%) para a eNOS, ambos dissolvidos em TTBS: Tris (10 mM), NaCl (150 mM) e Tween 20 (0,02 \%) por 1,5 hora em temperatura ambiente para reduzir a ligação inespecífica dos anticorpos às proteínas na membrana. Em seguida, as membranas foram lavadas com TTBS por 15 minutos e, então, incubadas com anticorpo para: Phospho ERK 1/2 (1:1000, Cell Signaling/9101S), ERK 1/2 (1:1000, Cell Signaling/9102), Phospho-eNOS (1:1000, Ser 1177-Cell Signaling/9571S), eNOS total (1:1000, BD Transduction Laboratories/610297), em solução contendo albumina bovina (3\%), Tris (10 mM), $\mathrm{NaCl}(150 \mathrm{mM})$ e Tween 20 (0,02 \%) em agitação por 15 horas a $4{ }^{\circ} \mathrm{C}$. Após este período, as membranas foram lavadas por 45 minutos em TTBS e incubadas com 0 segundo anticorpo (anti-coelho ou anti-camundongo 1:2000, Sigma) por 1,5 hora em temperatura ambiente e prosseguiu conforme item $\underline{\mathbf{3 . 7 . 4}}$.

\subsubsection{Expressão proteica: $\alpha$-actina}

As membranas que foram incubadas com anticorpos para ERK1/2 e eNOS, foram submetidas a processo de stripping para eliminar a fixação dos anticorpos na membrana. Posteriormente, elas foram incubadas com solução bloqueadora contendo leite desnatado Molico ${ }^{\circledR}(5 \%)$ por 1,5 hora. Em seguida, as membranas foram lavadas com TTBS por 15 minutos e, então, incubadas com anticorpo para $\alpha$ actina (1:10000, Sigma) por 2 horas em temperatura ambiente. Após este período, as membranas foram lavadas por 45 minutos em TTBS e seguida foram incubadas com o segundo anticorpo (anti-camundongo 10:20000, Sigma) por 1,5 hora em temperatura ambiente, prosseguindo conforme item $\underline{\mathbf{3 . 7 . 4}}$. 


\subsubsection{Quantificação da Intensidade de Quimioluminescência}

As membranas foram incubadas com solução quimioluminescente, como descrito no protocolo do kit (Super Signal West Pico Chemiluminescent, Thermo Scientific, Amersham). A quimioluminescência foi detectada e visualizada utilizando filmes fotográficos. A intensidade das bandas foi quantificada por densitometria óptica através da utilização do programa ImageJ (Wayne Rasband). No caso das proteínas fosforiladas, a quimioluminescência foi normalizada pela intensidade das bandas da proteína total. As proteínas totais e os receptores foram normalizados pela proteína $\alpha$-actina e calculados em relação ao controle de cada membrana.

\subsection{Análise Estatística}

Os resultados foram expressos como média \pm erro padrão da média (epm). Foi utilizado o teste "t" de Student no caso de comparação de duas médias; análise de variância de uma via (One-way ANOVA) seguido do teste de Tukey para o caso de comparação de mais de duas médias, ou análise de variância de duas vias (Twoway ANOVA) em medidas não repetidas, para o estudo da influência da obesidade e da Ang II seguido do teste de Bonferroni. O nível de significância mínima aceitável foi $p<0,05$.

\subsection{Drogas Utilizadas}

Tiopental sódico foi obtido da Cristália. noradrenalina, acetilcolina, glutamato monosódico, angiotensina II, losartan, apocinina, L-NAME, PD 98059, SB 203580, SP 600125, PD 123,319, foram obtidos da Sigma Chemical Co (St. Louis, MO). 


\section{RESULTADOS}

\subsection{Caracterização da Obesidade}

O tratamento de ratos neonatos com MSG induziu obesidade, caracterizada pelo aumento do índice de Lee e do peso relativo das gorduras periepididimal e retroperitoneal, sem alterar a massa magra (Figura 3: A, B, C, D e E respectivamente).

Figura 3 - Caracterização da obesidade
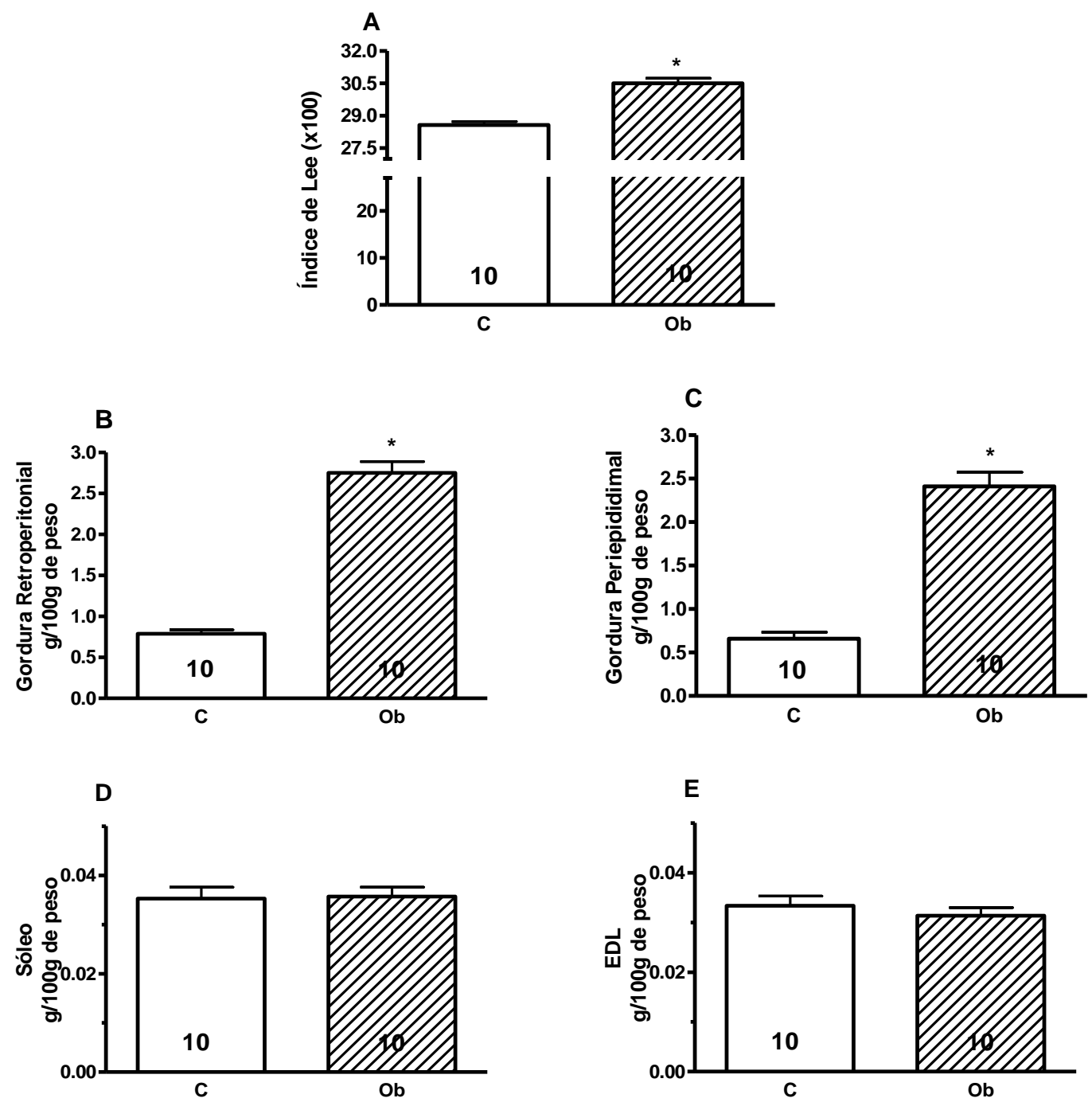

Índice de Lee [(peso corporal ${ }^{1 / 3}(\mathrm{~g}) /$ comprimento naso-anal $\left.(\mathrm{cm}) \times 100\right]$ (A), peso relativo das gorduras retroperitoneal $(B)$, periepididimal $(C)$ dos músculos sóleo (D) e extensor digital longo (EDL) (E) dos grupos controle (C) e obeso (Ob). Cada barra representa a média \pm epm. $O$ número de ratos usados em cada grupo encontra-se dentro das barras. ${ }^{*} p<0,05$ vs $C$.

FONTE: Hagihara, 2012. 


\subsection{Perfil Lipídico e Pressão Arterial}

As concentrações séricas de colesterol total e HDL-colesterol não foram diferentes entre os grupos. Entretanto, os ratos obesos apresentaram aumento das concentrações séricas de triglicerídeos, LDL e VLDL-colesterol quando comparados aos controles. Já a pressão arterial sistólica não diferiu entre os grupos analisados (Tabela 1).

Tabela 1 - Perfil lipídico e pressão arterial

\begin{tabular}{ccc}
\hline \hline Parâmetro & C & Ob \\
\hline Triglicerídeos $(\mathrm{mg} / \mathrm{dL})$ & $68,5 \pm 3,3$ & $122,8 \pm 6,5^{*}$ \\
Colesterol total $(\mathrm{mg} / \mathrm{dL})$ & $65,2 \pm 2,8$ & $67,0 \pm 3,3$ \\
HDL-colesterol $(\mathrm{mg} / \mathrm{dL})$ & $15,4 \pm 0,8$ & $16,4 \pm 1,5$ \\
LDL-colesterol $(\mathrm{mg} / \mathrm{dL})$ & $35,1 \pm 2,4$ & $45,5 \pm 4,2$ * \\
VLDL-colesterol $(\mathrm{mg} / \mathrm{dL})$ & $13,7 \pm 0,7$ & $24,5 \pm 1,3$ * \\
Pressão sanguínea $(\mathrm{mmHg})$ & $113,9 \pm 1,8$ & $112,8 \pm 2,8$ \\
\hline \hline
\end{tabular}

Perfil lipídico e pressão arterial dos grupos controle (C) e obeso (Ob). As frações do colesterol total foram representadas segundo as siglas em inglês: High Density Lipoprotein (HDL), Low Density Lipoprotein (LDL) e Very Low Density Lipoprotein (VLDL). Os valores foram expressos em média \pm epm. * $p<0,05$ vs $C . n=7-10 /$ grupo. FONTE: Hagihara, 2012.

\subsection{Reatividade Vascular}

Os anéis utilizados nos experimentos de reatividade vascular não apresentaram diferença estatística no que se refere ao diâmetro do vaso, tensão ativa (cálculo para verificar a integridade do músculo liso vascular: média da contração ao $\mathrm{KCl} /$ 2xcomprimento do vaso > 1,5) e à contração ao $\mathrm{KCl}$. Todos os resultados foram expressos em porcentagem de contração ao KCl (Tabela 2).

Tabela 2 - Características dos vasos utilizados na reatividade vascular

\begin{tabular}{ccc}
\hline \hline Parâmetro & $\mathrm{C}(\mathrm{n}=39)$ & $\mathrm{Ob}(\mathrm{n}=34)$ \\
\hline Diâmetro do vaso & $239,0 \pm 4,4$ & $236,7 \pm 4,2$ \\
Tensão ativa & $2,696 \pm 0,15$ & $2,653 \pm 0,11$ \\
Contração para KCl & $10,78 \pm 0,58$ & $10,61 \pm 0,45$ \\
\hline \hline
\end{tabular}

Os valores foram apresentados em média \pm epm. O número de animais utilizados em cada grupo encontra-se entre parênteses. Controle (C) e obesos (Ob). Cloreto de potássio $(\mathrm{KCl})$.

FONTE: Hagihara, 2012. 
Para as curvas concentração resposta em artérias com endotélio, foram utilizados anéis cuja resposta vasodilatadora à $A C h$ foi superior a $90 \%$. Já os experimentos em anéis sem endotélio foram realizados em artérias mesentéricas que apresentaram resposta vasodilatadora à $A C h$, de no máximo, 5 \% (Figura 6).

Figura 4 - Teste de viabilidade do endotélio
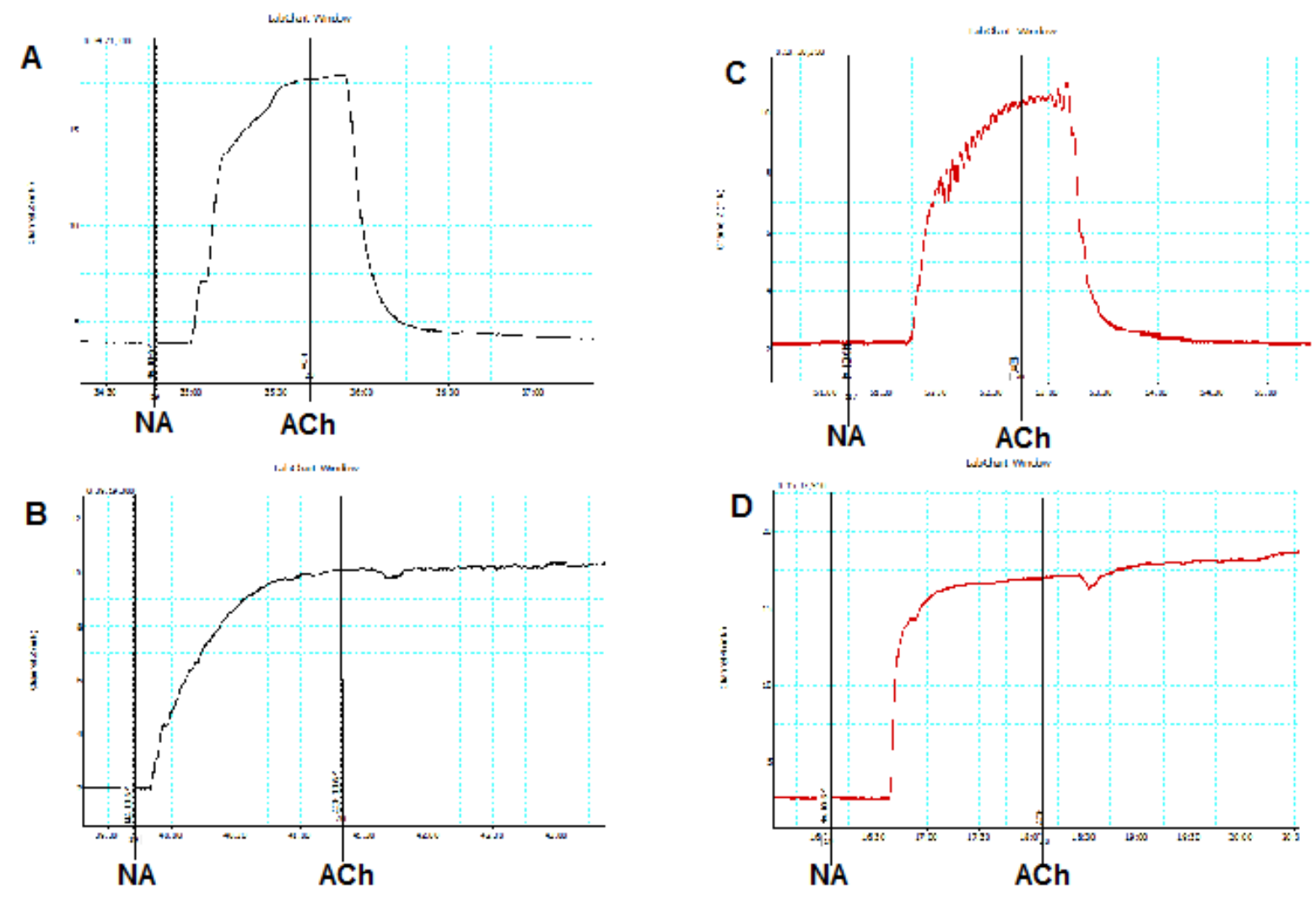

Experimentos realizados em anéis de ratos controle com endotélio $(\mathbf{A})$, controle sem endotélio (B), obeso com endotélio (C) e obeso sem endotélio (D) submetidos à précontração com noradrenalina (NA, $1 \mu \mathrm{M})$ e teste do endotélio com acetilcolina ( $\mathrm{ACh}$, $1 \mu \mathrm{M})$.

FONTE: Hagihara, 2012. 


\subsubsection{Avaliação da Resposta Vasoconstritora à Ang II}

Preparações com endotélio de ratos obesos apresentaram menor resposta vasoconstritora à Ang II quando comparados aos controles. Em preparações sem endotélio, essa diferença não foi mais observada, demonstrando que o endotélio participa da alteração constritora encontrada nos ratos obesos. Por essa razão, todas as demais curvas concentração resposta para esse agonista foram realizadas somente nos anéis com endotélio (Figura 5).

Figura 5 - Resposta contrátil à Ang II.
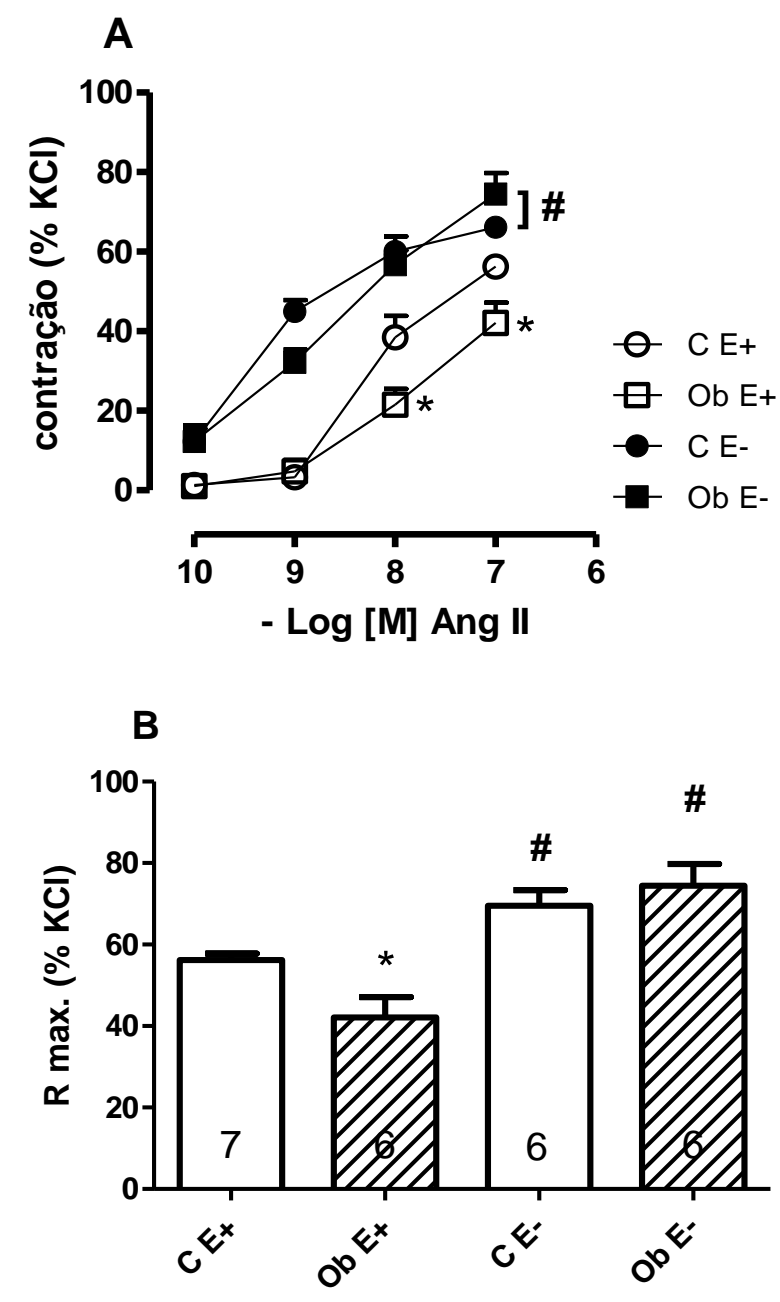

Curva concentração-efeito para à Ang II (A) e resposta máxima ( $\mathrm{R}$ máx.) (B) em artérias mesentérias de resistência de ratos controles com endotélio $(C E+)$, controles sem endotélio ( $\mathrm{C} \mathrm{E}$-), obesos com endotélio ( $\mathrm{Ob} \mathrm{E}+$ ) e obesos sem endotélio (Ob E-) com 16 semanas. Cada barra representa a média \pm epm. $O$ número de ratos utilizados em cada grupo encontra-se dentro das barras. ${ }^{*} p<0,05$ vs $\mathrm{C} E+e \# p<0,05$ vs $C \mathrm{E}+$ ou Ob E+.

FONTE: Hagihara, 2012. 
4.3.2 Avaliação da participação dos receptores AT1 na resposta vasoconstritora à Ang II

O antagonismo do AT1R na concentração de $10 \mu \mathrm{M}$ aboliu completamente a resposta contrátil à Ang II tanto nos ratos controles quanto nos obesos (Figura 6). Esses resultados confirmam que a ativação desse receptor é responsável pela vasoconstrição mediada pela Ang II. Doses menores do antagonista do AT1R foram utilizadas com o objetivo de verificar se a dose utilizada $(10 \mu \mathrm{M})$ era muito alta, podendo mascarar uma possível diferença entre os grupos estudados no que se refere à participação desse receptor. Na concentração de $1 \mu \mathrm{M}$ a contração à Ang II também foi abolida (dados não demonstrados), enquanto que a dose de $0,1 \mu \mathrm{M}$ mostrou-se muito baixa, uma vez que não alterou a resposta contrátil à Ang II (dados não demonstrados). Na dose intermediária às duas anteriores, de 0,3 $\mu \mathrm{M}, 0$ antagonista AT1R diminuição a resposta contrátil à Ang II nos dois grupos, entretanto, a contração à Ang II no grupo obeso com o antagonista foi estatisticamente maior do que no grupo controle com o mesmo antagonista. Esse dado levantou a hipótese de que os ratos obesos poderiam apresentar maior quantidade de AT1R (Figura 7). Para testar essa hipótese, realizamos experimentos de Western Blotting para AT1R e não encontramos diferença na quantidade desses receptores entre os grupos estudados (Figura 8).

Figura 6 - Losartan na concentração de $10 \mu \mathrm{M}$ aboliu a contração à Ang II

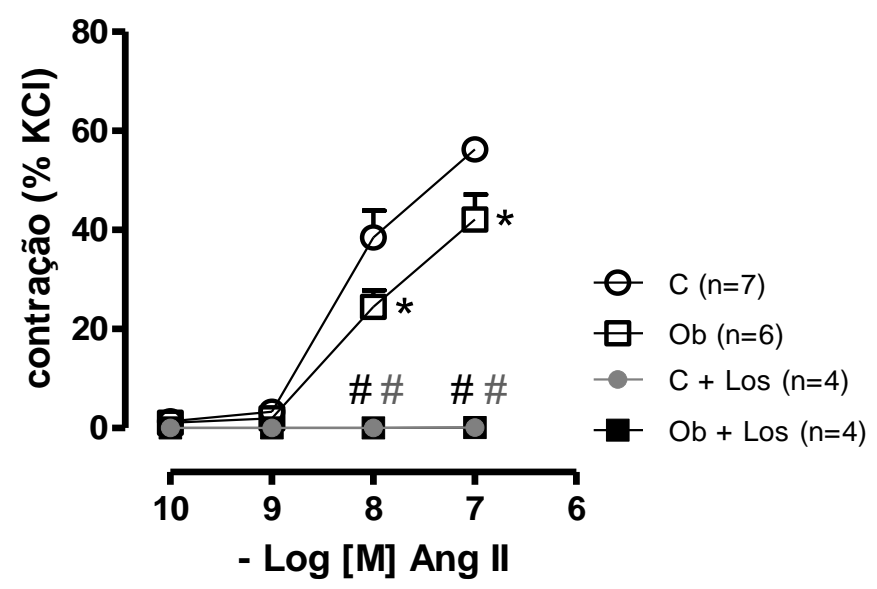

Curva concentração-efeito para Ang II em artérias mesentérias de resistência de ratos controles $(\mathrm{C})$ e obesos $(\mathrm{Ob})$ com 16 semanas, na ausência e na presença do antagonista AT1, losartan (Los). Cada ponto representa a média \pm epm. O número de ratos utilizados em cada grupo encontra-se entre parênteses. ${ }^{*} p<0,05$ vs $C$ e \# $p$ $<0,05$ vs respectivo grupo sem tratamento.

FONTE: Hagihara, 2012. 
Figura 7 - Participação do AT1R na contração à Ang II
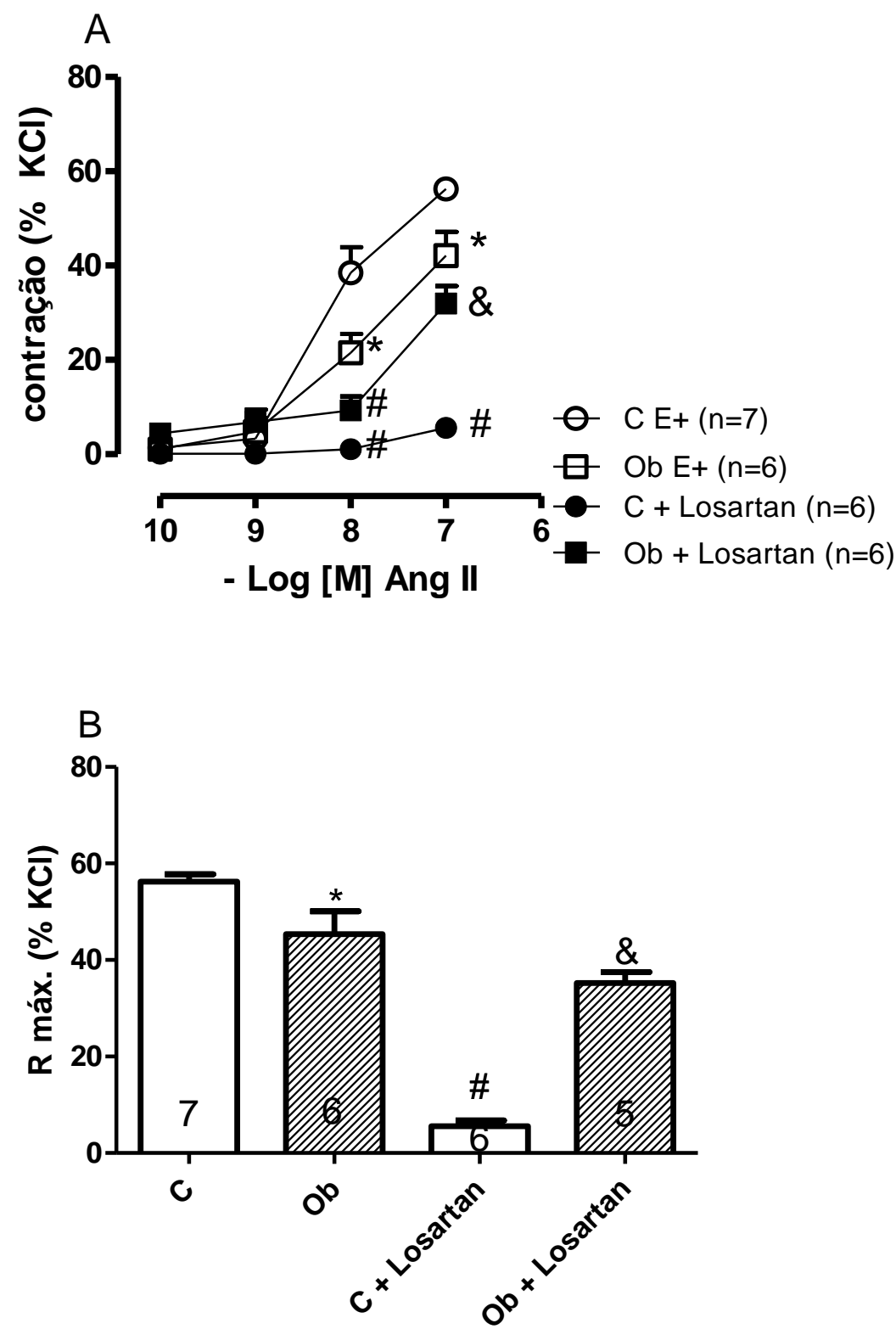

Curva concentração-efeito para a Ang II em artérias mesentérias de resistência de ratos controles $(\mathrm{C})$ e obesos $(\mathrm{Ob})$ com 16 semanas, na ausência e na presença do antagonista AT1, losartan (Los) na dose de $3 \times 10^{-7} \mathrm{M}$. Cada ponto representa a média \pm epm. O número de ratos utilizados em cada grupo encontra-se entre parênteses. * $p<0,05$ vs $C, \# p<0,05$ vs respectivo grupo sem tratamento e $\&<0,05$ vs $C$ tratado.

FONTE: Hagihara, 2012. 
Figura 8 - Conteúdo Proteico do AT1R em artérias mesentéricas de resistência
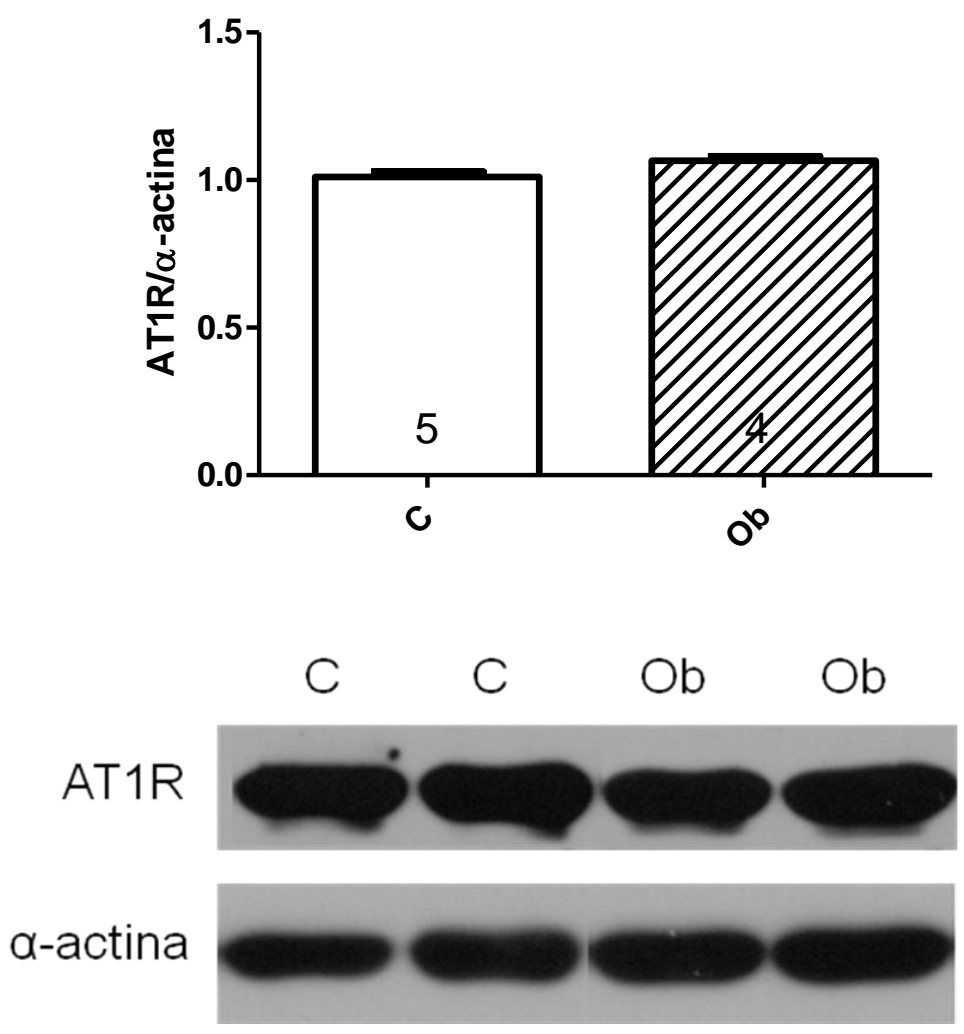

Western Blotting para receptores do tipo AT1 (AT1R) realizado em artérias mesentérias de resistência de ratos controles $(\mathrm{C})$ e obesos $(\mathrm{Ob})$ com 16 semanas, corrigido pela proteína controle $\alpha$-actina e pelo controle da membrana. Cada barra representa a média \pm epm. O número de ratos utilizados em cada grupo encontra-se dentro das barras.

FONTE: Hagihara, 2012.

\subsubsection{Avaliação da participação dos receptores AT2 na resposta vasoconstritora à} Ang II

A menor da resposta à Ang II nos ratos obesos poderia ser explicada pela redução do número de AT1R ou pelo aumento de AT2R. Conforme descrito anteriormente, o número de AT1R não está alterado nesses ratos, então fomos analisar a participação dos AT2R. O antagonismo do AT2R aumentou a resposta vasoconstritora à Ang II nos dois grupos, entretanto, parece que esse receptor desempenha um papel mais evidente nos ratos obesos, uma vez que o seu antagonismo aumentou a resposta contrátil em três doses de Ang II utilizadas (1, 10 e $100 \mathrm{nM}$ ), enquanto que os controles só apresentaram aumento significativo na dose de $1 \mathrm{nM}$ (Figura 9). 
Figura 9 - Participação do AT2R na contração à Ang II
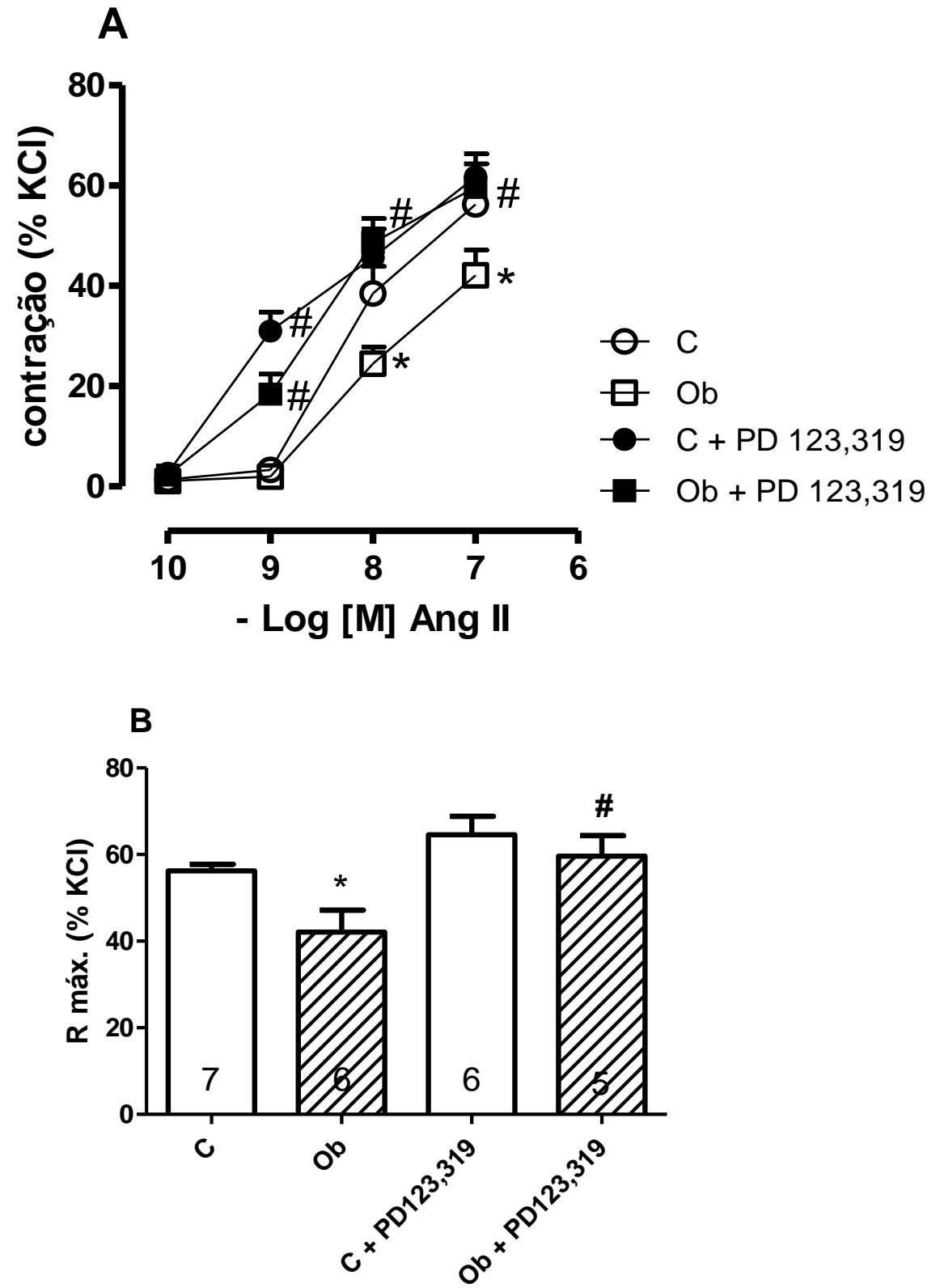

- Log [M] Ang II

Curva concentração-efeito para a Ang II (A) e resposta máxima (B) em artérias mesentérias de resistência de ratos controles $(\mathrm{C})$ e obesos (Ob) com 16 semanas, na ausência e na presença do antagonista AT2, o composto PD 123,319 (PD). Cada ponto ou barra representa a média \pm epm. $O$ número de ratos utilizados em cada grupo encontra-se dentro das barras. ${ }^{*} p<0,05$ vs $C \# p<0,05$ vs respectivo grupo sem tratamento.

FONTE: Hagihara, 2012. 
Para verificar se a menor da resposta à Ang II nos ratos obesos poderia ser explicada pelo aumento de AT2R. realizamos Western Blotting para AT2R e encontramos maior quantidade desses receptores nos ratos obesos (Figura 10).

Figura 10 - Conteúdo Proteico do AT2R em artérias mesentéricas de resistência
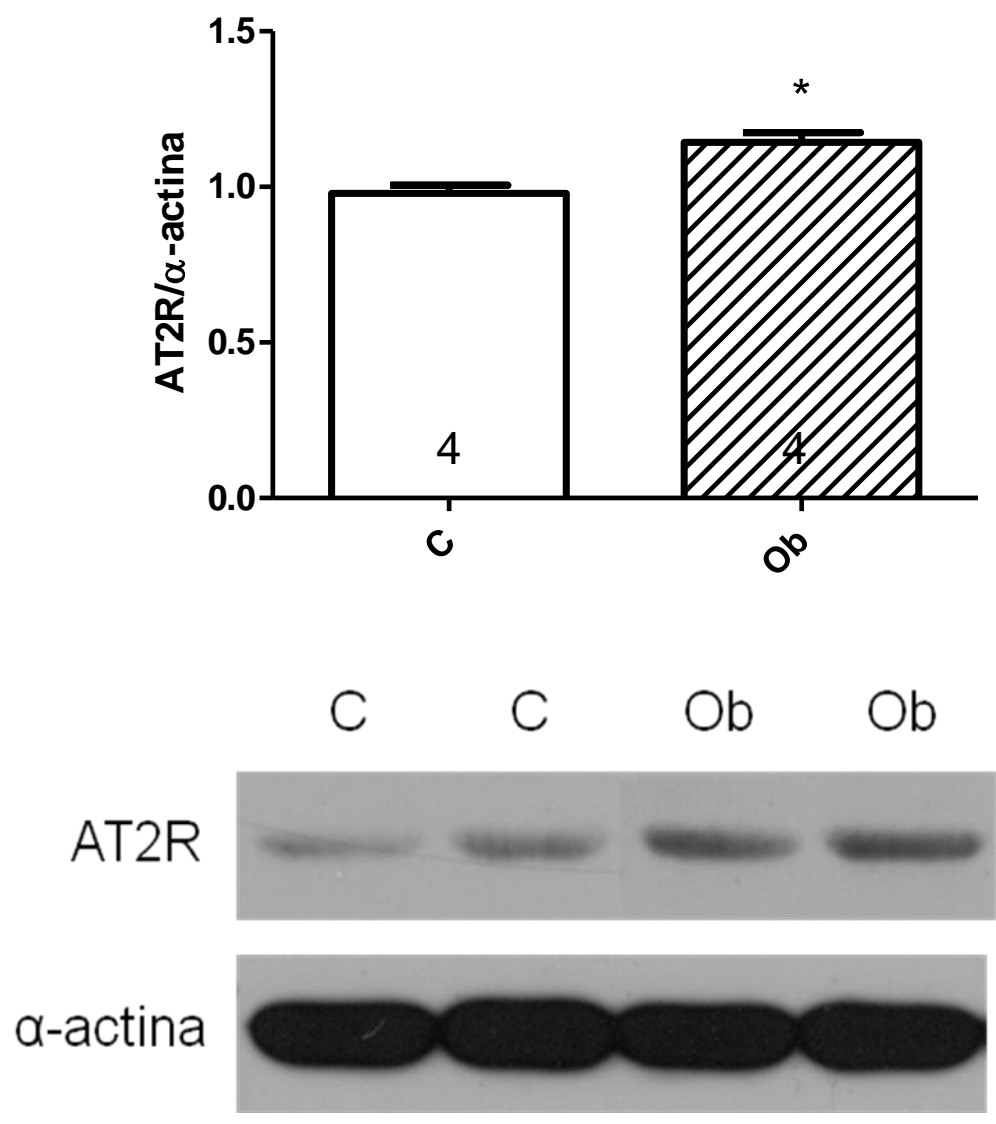

Western Blotting para receptores do tipo AT2 (AT2R) realizado em arteríolas mesentéricas de resistência de ratos controles (C) e obesos (Ob) com 16 semanas, corrigido pela proteína controle $\alpha$-actina e pelo controle da membrana. Cada barra representa a média \pm epm. $O$ número de ratos utilizados em cada grupo encontra-se dentro das barras.

FONTE: Hagihara, 2012. 


\subsubsection{Avaliação da participação do óxido nítrico na modulação da resposta} vasoconstritora à Ang II

Considerando que a alteração da resposta à Ang II é observada apenas em preparações com endotélio, analisamos a participação de um dos principais fatores derivados do endotélio, o óxido nítrico (NO). Para tanto, realizamos curvas concentração-efeito para Ang II na ausência e na presença do inibidor da óxido nítrico sintase, Nw-nitro-L-arginina metil éster (L-NAME) (Figura 11). O tratamento das preparações com o L-NAME deslocou as curvas concentração-efeito para a esquerda tanto em ratos obesos quanto em controles e a diferença entre os dois grupos não mais foi observada, à semelhança do que foi verificado quando avaliamos as preparações sem endotélio.

Figura 11 - Participação do NO na resposta à Ang II
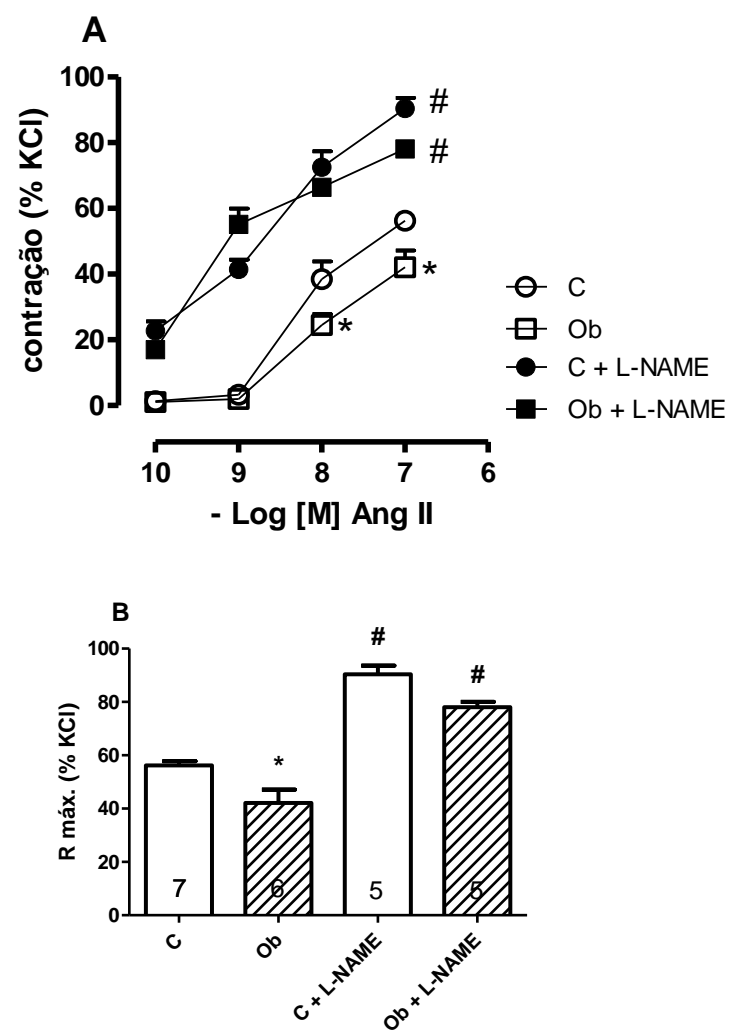

Curva concentração-efeito (A) e resposta máxima (B) para a Ang II em artérias mesentérias de resistência de ratos controles $(\mathrm{C})$ e obesos $(\mathrm{Ob})$ com 16 semanas, na ausência e na presença do inibidor da óxido nitrico sintase (C + L-NAME ou Ob + L-NAME). Cada ponto representa a média \pm epm. O número de ratos utilizados foi de 5 a $7 .{ }^{*} p<0,05$ vs $C$ e \# $p<0,05$ vs respectivo grupo sem tratamento.

FONTE: Hagihara, 2012. 
4.3.5 Avaliação da participação das espécies reativas de oxigênio na modulação da resposta vasoconstritora à Ang II

As curvas concentração-efeito para Ang II na ausência e na presença do inibidor da NADPH oxidase, a apocinina (Apo), reduziu a resposta à Ang II nos dois grupos estudados (Figura 12). O tratamento com apocinina diminuiu mais a resposta à Ang II na dose de $10 \mathrm{nM}$ nos obesos do que nos controles. Esses resultados nos demonstram que as EROs não participam da menor contração à Ang II nos ratos obesos.

Figura 12 - Participação das EROs na resposta à Ang II
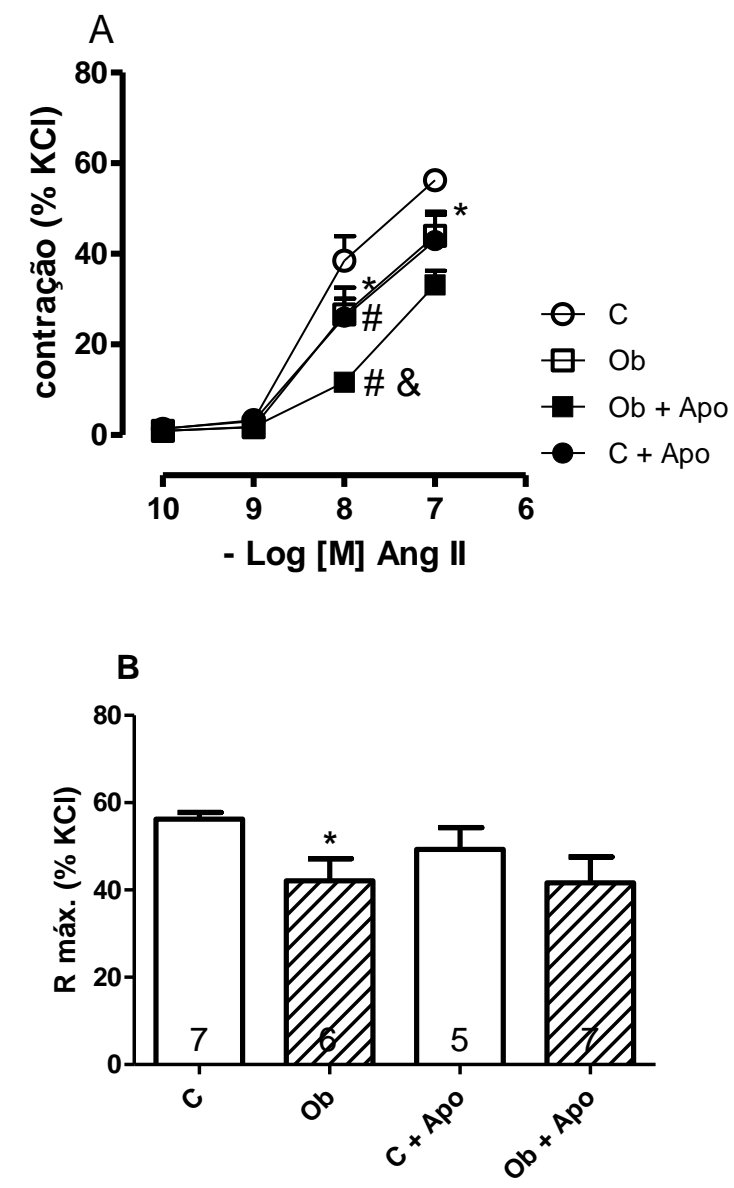

Curva concentração-efeito (A) e resposta máxima (B) para a Ang II em artérias mesentérias de resistência de ratos controles $(C)$ e obesos $(\mathrm{Ob})$ com 16 semanas, na ausência e na presença do inibidor da NADPH oxidase, apocinina $(C+A p o$ ou $\mathrm{Ob}+\mathrm{Apo})$. Cada ponto representa a média \pm epm. $\mathrm{O}$ número de ratos utilizados foi de 5 a $7 .{ }^{*} p<0,05$ vs $C$ e \# $p<0,05$ vs respectivo grupo sem tratamento e $\&<0,05$ vs $\mathrm{C}$ tratado.

FONTE: Hagihara, 2012. 
4.3.6 Avaliação da Participação das Vias das MAPKs na Resposta Vasoconstritora à Ang II

O tratamento das preparações com o inibidor da ERK1/2 pelo composto PD98059 corrigiu a resposta diminuída à Ang II encontrada nos ratos obesos, sem alterar a resposta constritora dos controles (Figura 13). Este resultado nos leva a sugerir que a ERK 1/2 está favorecendo a vasodilatação nos ratos obesos. Com este resultado surgiu a hipótese de que a hiporeatividade à Ang II nos ratos obesos poderia também ser explicada pelo aumento da fosforilação da ERK 1/2 que neste caso atua promovendo vasodilatação.

Figura 13 - Participação da ERK1/2 na resposta à Ang II
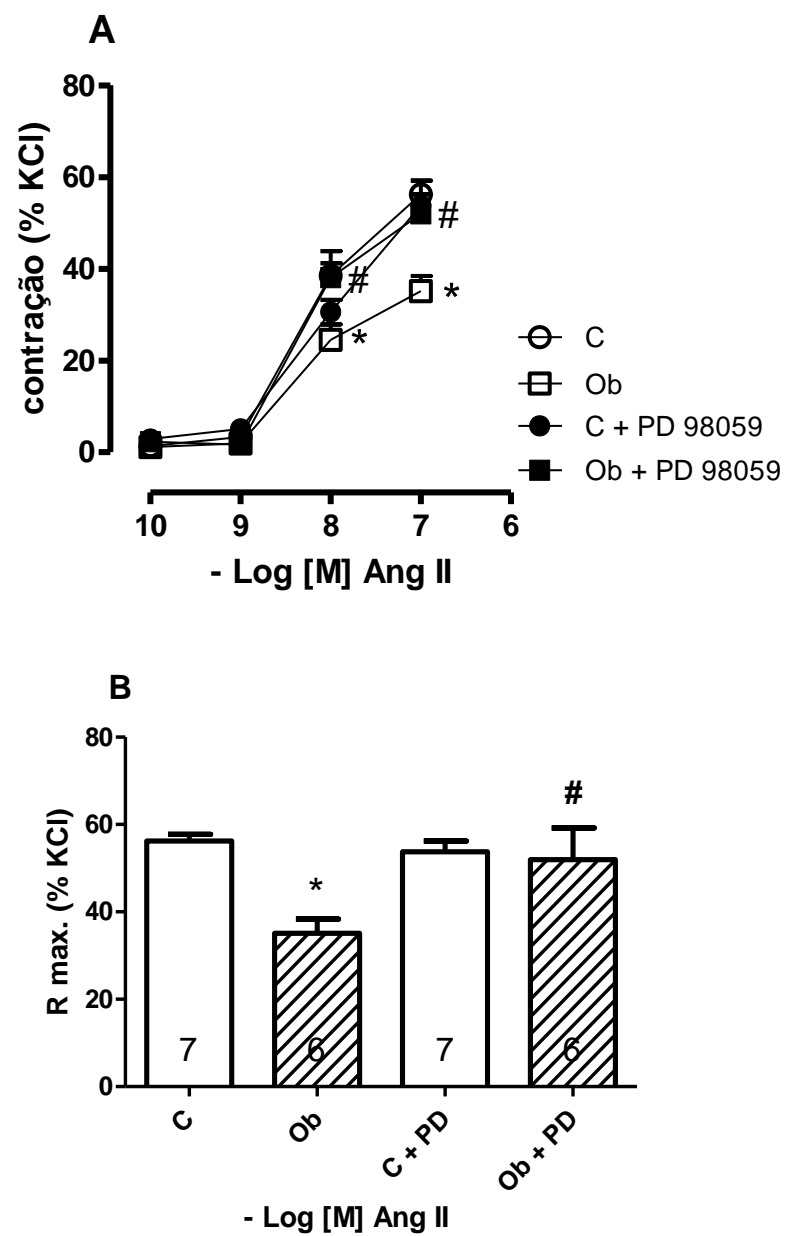

Curva concentração-efeito para Ang II (A) e resposta máxima (B) em artérias mesentérias de resistência de ratos controles $(C)$ e obesos $(\mathrm{Ob})$ com 16 semanas, na ausência e na presença do inibidor da via ERK 1/2 (C + PD ou Ob + PD). Cada ponto representa a média \pm epm. $O$ número de ratos utilizados em cada grupo encontra-se dentro das barras. ${ }^{*} p<0,05$ vs $\mathrm{C}$ e e \# $p<0,05$ vs respectivo grupo sem tratamento.

FONTE: Hagihara, 2012. 
O estudo da expressão da ERK 1/2 nos mostrou que essa MAPK, no estado basal, já se encontra mais fosforilada nos ratos obesos do que nos controles. $O$ estímulo com Ang II aumentou ainda mais a fosforilação da ERK 1/2 nesses animais (Figura 14).

Figura 14 - Expressão proteica da ERK1/2 em artérias mesentéricas de resistência
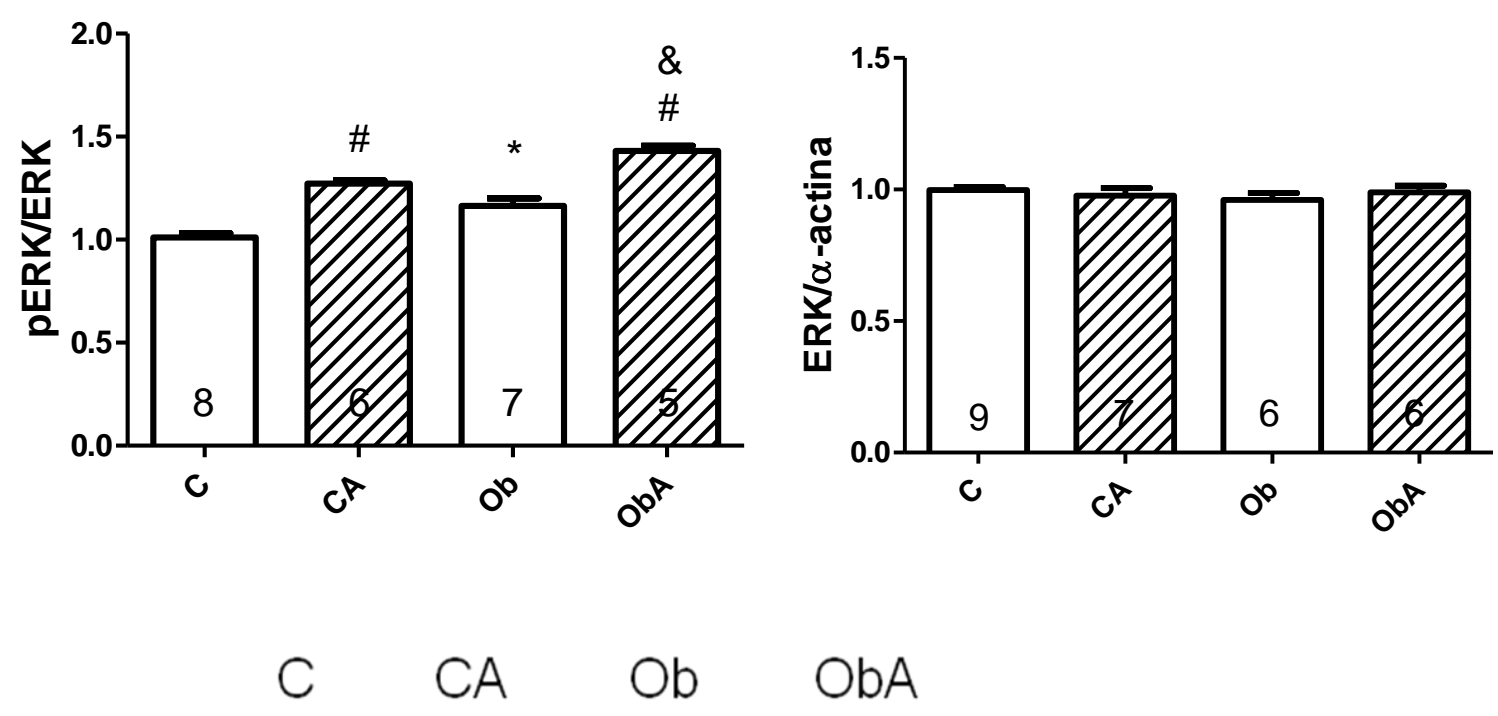

pERK

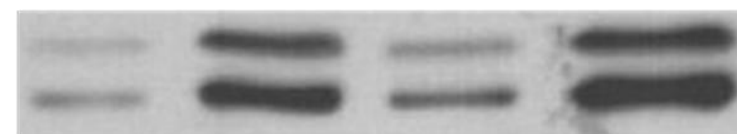

ERK

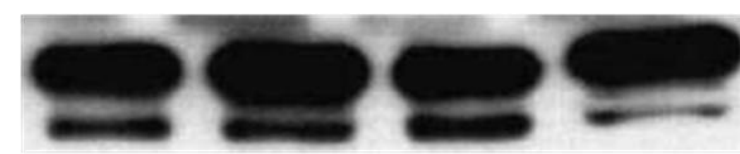

a-actina

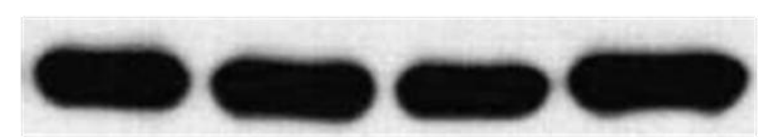

Western Blotting para ERK 1/2 em artérias mesentérias de resistência de ratos controles (C) e obesos (Ob) com 16 semanas, sem estímulo e com estímulo da Ang II (CA ou ObA). Cada barra representa a média \pm epm. O número de ratos utilizados em cada grupo encontra-se dentro das barras. ${ }^{*} p<0,05$ vs $C ; \# p<0,05$ vs respectivo grupo sem tratamento e $\& p<0,05$ vs controle tratado.

FONTE: Hagihara, 2012. 
Tanto a inibição da via da JNK quanto da p38, diminuíram ainda mais a resposta vasoconstritora à Ang II nos ratos obesos sem alterar a resposta constritora nos controles (Figuras 15 e 16, respectivamente).

Figura 15 - Participação da JNK na resposta à Ang II
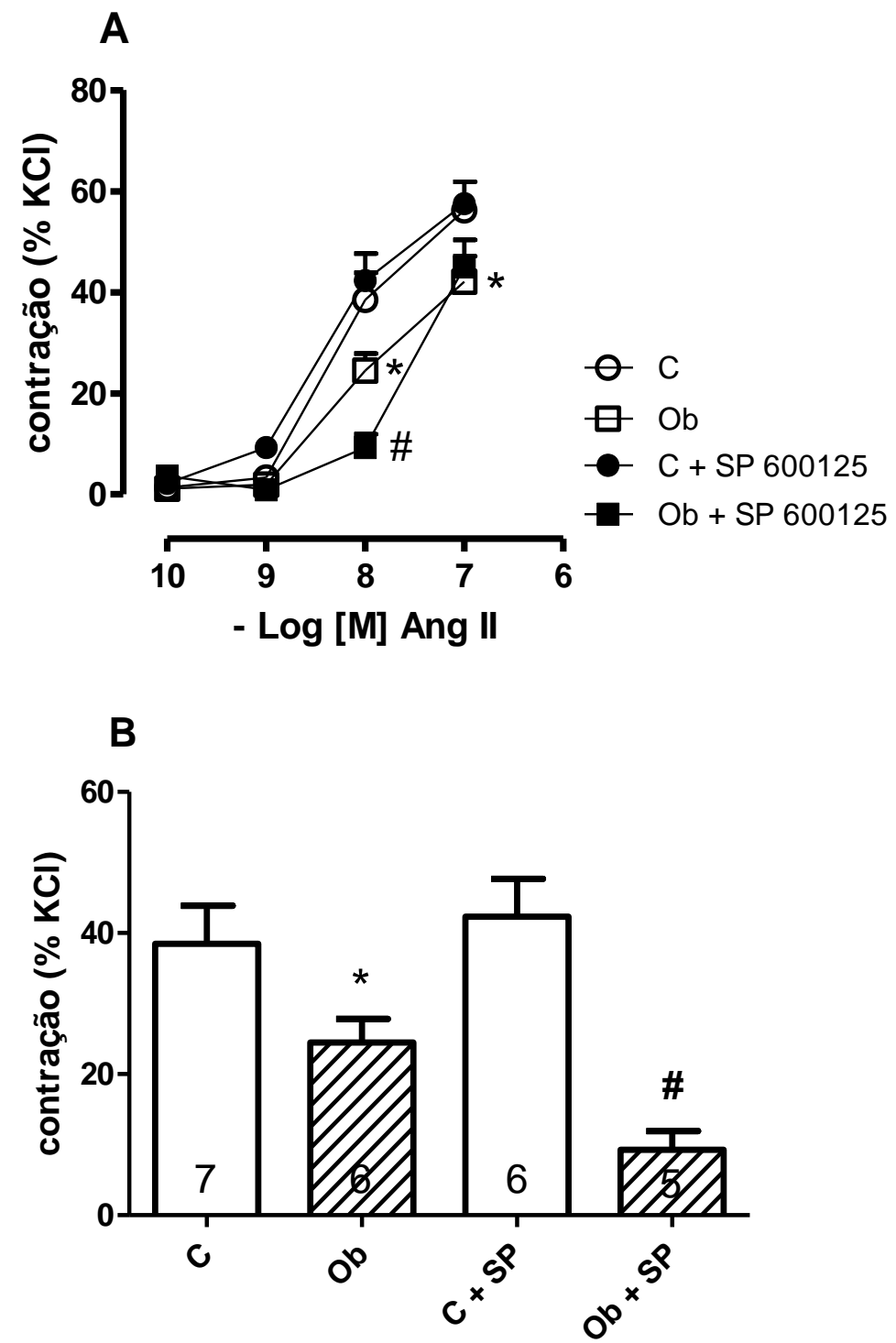

- Log [M] Ang II

Curva concentração-efeito para a Ang II (A) e resposta na dose de $10^{-8} \mathrm{M}$ (B) em artérias mesentérias de resistência de ratos controles $(\mathrm{C})$ e obesos $(\mathrm{Ob})$ com 16 semanas, sem inibidor e com inibidor da via JNK (C + SP ou Ob + SP). Cada ponto representa a média \pm epm. $O$ número de ratos utilizados em cada grupo encontra-se dentro das barras. ${ }^{*} p<0,05$ vs $C$ e e \# $p<0,05$ vs respectivo grupo sem tratamento. FONTE: Hagihara, 2012. 
Figura 16 - Participação da p38 MAPK na resposta à Ang II
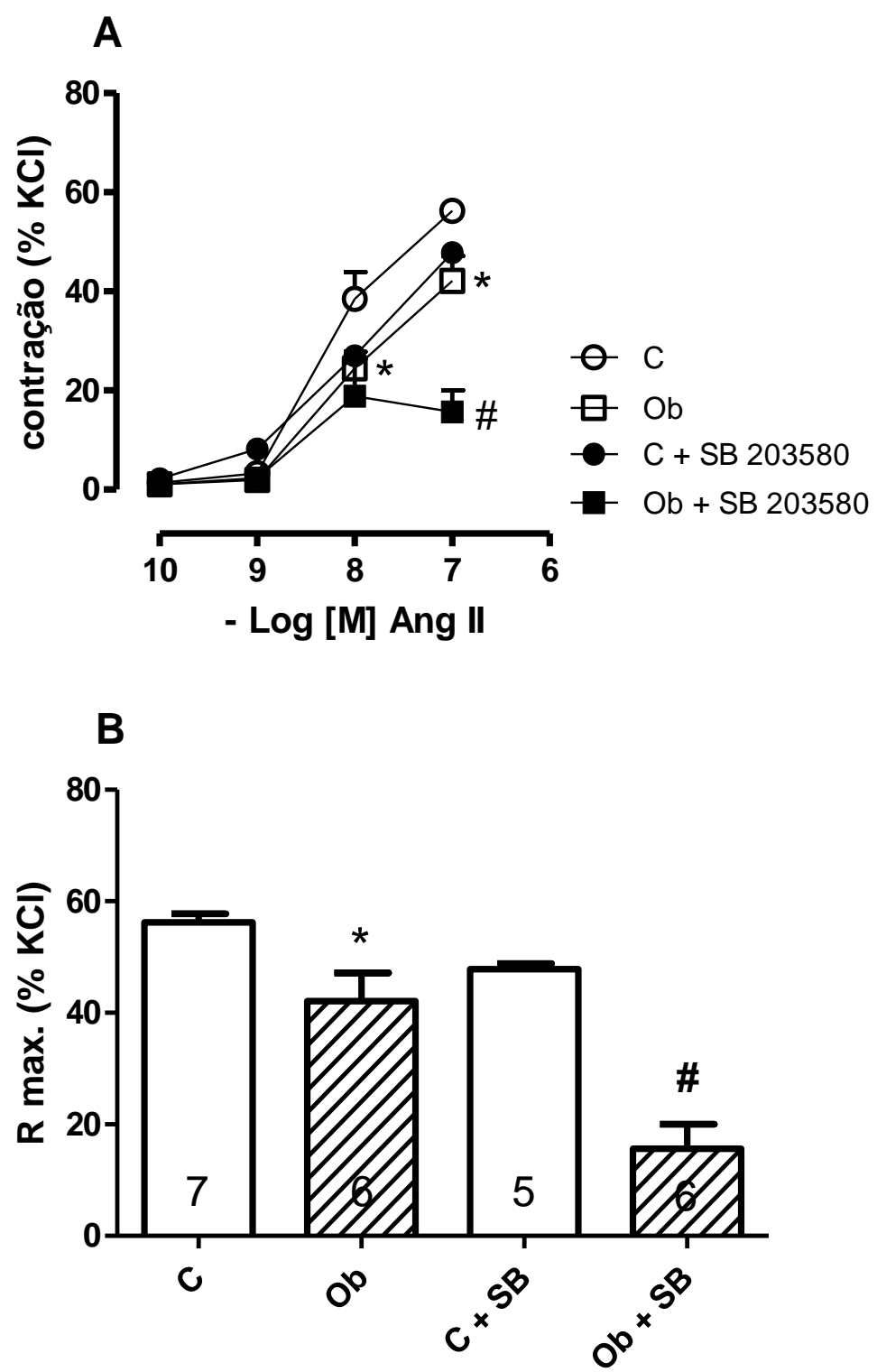

- Log [M] Ang II

Curva concentração-efeito para a Ang II (A) e resposta máxima (B) em artérias mesentérias de resistência de ratos controles $(\mathrm{C})$ e obesos (Ob) com 16 semanas, sem inibidor e com inibidor da via p38 ( $\mathrm{C}+\mathrm{SB}$ ou Ob + SB).Cada ponto representa a média \pm epm. $O$ número de ratos utilizados em cada grupo encontra-se dentro das barras. ${ }^{*} p<0,05$ vs $C$ e e \# $p<0,05$ vs respectivo grupo sem tratamento.

FONTE: Hagihara, 2012. 
Os bloqueios do AT2R, da ERK 1/2 e da NOS corrigiram a resposta diminuída à Ang II nos ratos obesos. A partir deste fato, surgiu a hipótese de que o receptor AT2 poderia ativar a ERK1/2 e esta, por sua vez, fosforilaria a eNOS, resultando em aumento de $\mathrm{NO}$ e consequente diminuição da resposta vasoconstritora à Ang II. O estudo da expressão protéica de ERK $1 / 2$ mostrou que o bloqueio tanto do AT2R quanto do AT1R diminuiu a fosforilação dessa MAPK, demonstrando que esses dois receptores participam da fosforilação da ERK 1/2 nos ratos obesos (Figura 17).

Figura 17 - Expressão proteica da ERK1/2 com antagonistas de AT1R e AT2R
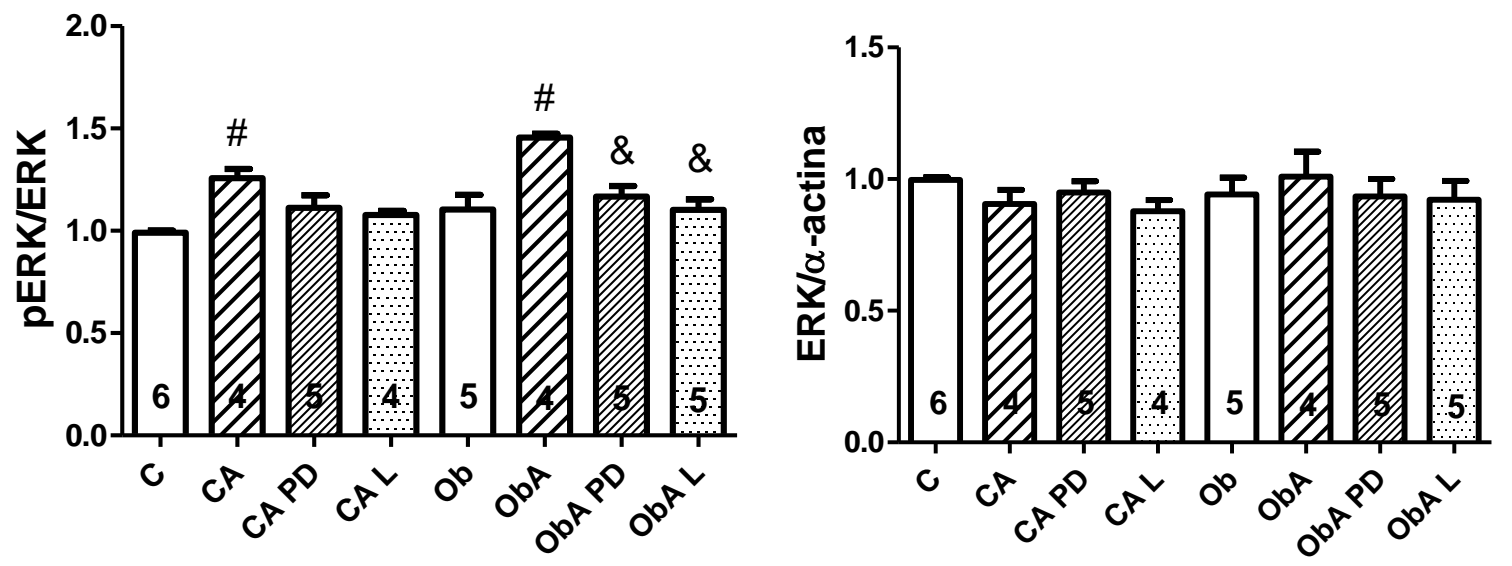

\section{C $\quad$ CA $\quad$ CPD $\quad \mathrm{CL}$ Ob ObA ObPD ObL}

pERK

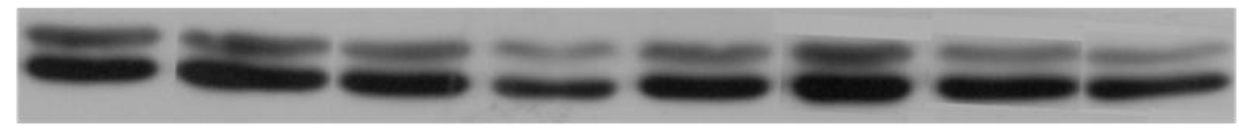

ERK

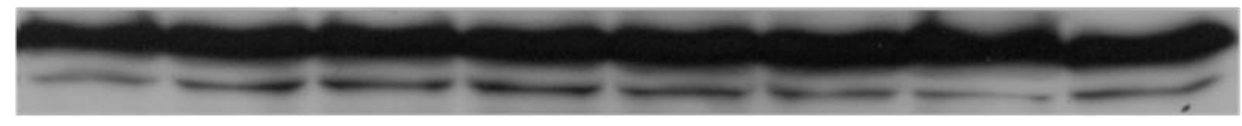

a-actina

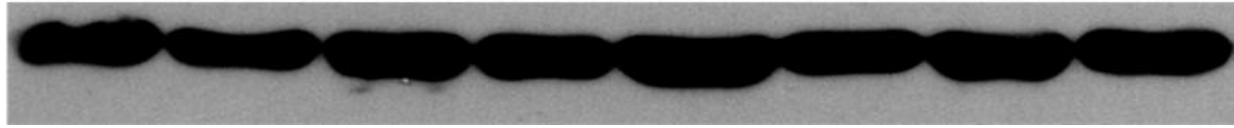

Western Blotting para ERK $1 / 2$ em artérias mesentérias de resistência de ratos controles $(\mathrm{C})$ e obesos $(\mathrm{Ob})$ com 16 semanas, sem estímulo e com estímulo da Ang II (CA ou ObA), na ausência ou na presença do antagonista AT2R (CPD ou ObPD) ou antagonista do AT1R (CL ou ObL). Cada barra representa a média \pm epm. $O$ número de ratos utilizados em cada grupo encontra-se dentro das barras. ${ }^{*} p<0,05$ vs $C$; \# $p<0,05$ vs respectivo grupo sem tratamento e \& $p<0,05$ vs controle tratado. FONTE: Hagihara, 2012. 
Para testarmos a hipótese de que o aumento da fosforilação da ERK $1 / 2$ se devia a uma maior ativação do AT2R, realizamos curva concentração-efeito na presença de antagonista do AT2R (PD123,319) e inibidor da ERK 1/2 (PD98059) obtendo assim um duplo bloqueio.

O duplo bloqueio aumentou mais ainda a resposta contrátil à Ang II no grupo Ob, havendo efeito somatório e não antagonismo como esperado (Figura 18). Esse resultado permite sugerir que a ativação da ERK 1/2 não envolve apenas a via do receptor AT2.

Figura 18 - Resposta à Ang II com bloqueio de AT2R e inibição da ERK1/2

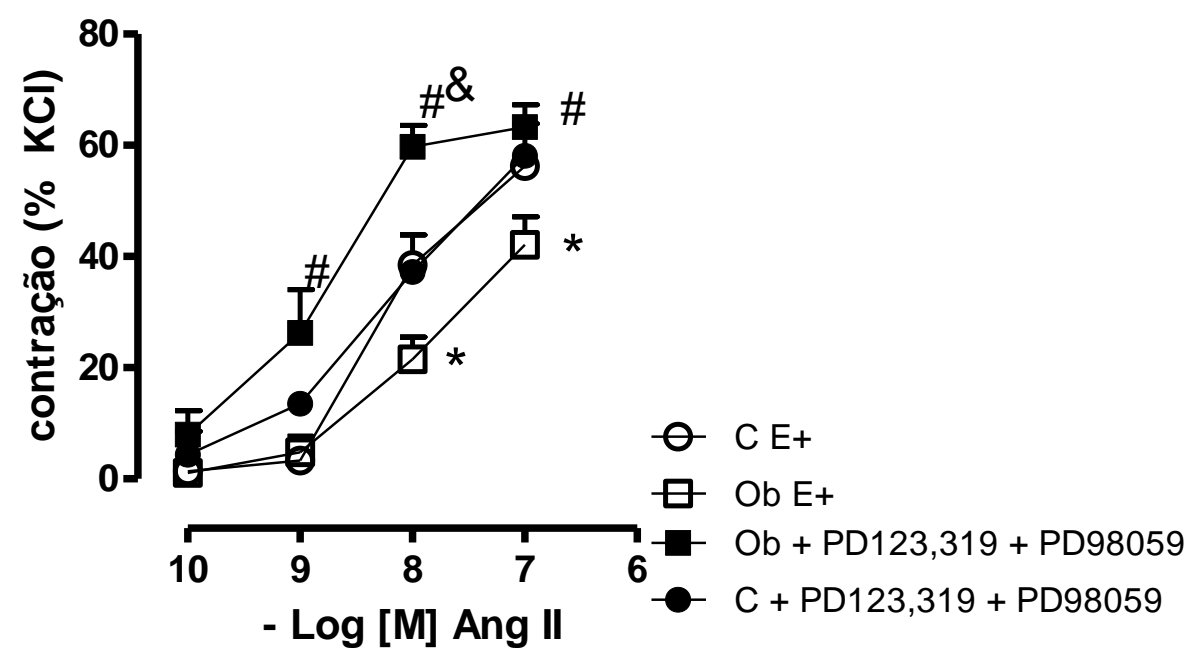

Curva concentração-efeito para a Ang II em artérias mesentérias de resistência de ratos controles $(\mathrm{C})$ e obesos $(\mathrm{Ob})$ com 16 semanas, na ausência e na presença do antagonista AT2, composto PD 123,319 e do inibidor da ERK 1/2, PD98059 . Cada ponto representa a média \pm epm. O número de ratos utilizados variou de 4 a 7 . $^{*} \mathrm{p}<$ 0,05 vs $C, \# p<0,05$ vs respectivo grupo sem tratamento e $\& p<0,05$ vs $C$ tratado. FONTE: Hagihara, 2012.

Para avaliar se a ERK $1 / 2$ está fosforilando a eNOS e desta forma contribuindo para o aumento de NO, diminuindo a contração à Ang II, realizamos Western Blotting para eNOS, avaliando a sua expressão no estado basal, após estímulo com Ang II e após inibição da ERK 1/2.

Em relação aos controles, os ratos obesos já apresentaram aumento da fosforilação da eNOS no estado basal. O estímulo de Ang II não foi capaz de alterar esse resultado tanto em obesos quanto em controles. A inibição da via da ERK 1/2 
levou a uma diminuição da fosforilação da eNOS apenas em ratos obesos. Este resultado demonstra que a ERK 1/2 é capaz de fosforilar a eNOS somente nos ratos obesos, enquanto que nos controles não houve diferença estatisticamente significativa entre a fosforilação da eNOS estado basal, estimulado com Ang II e com o inibidor da ERK1/2 (Figura 19).

Figura 18 - Expressão proteica da eNOS após inibição da ERK1/2

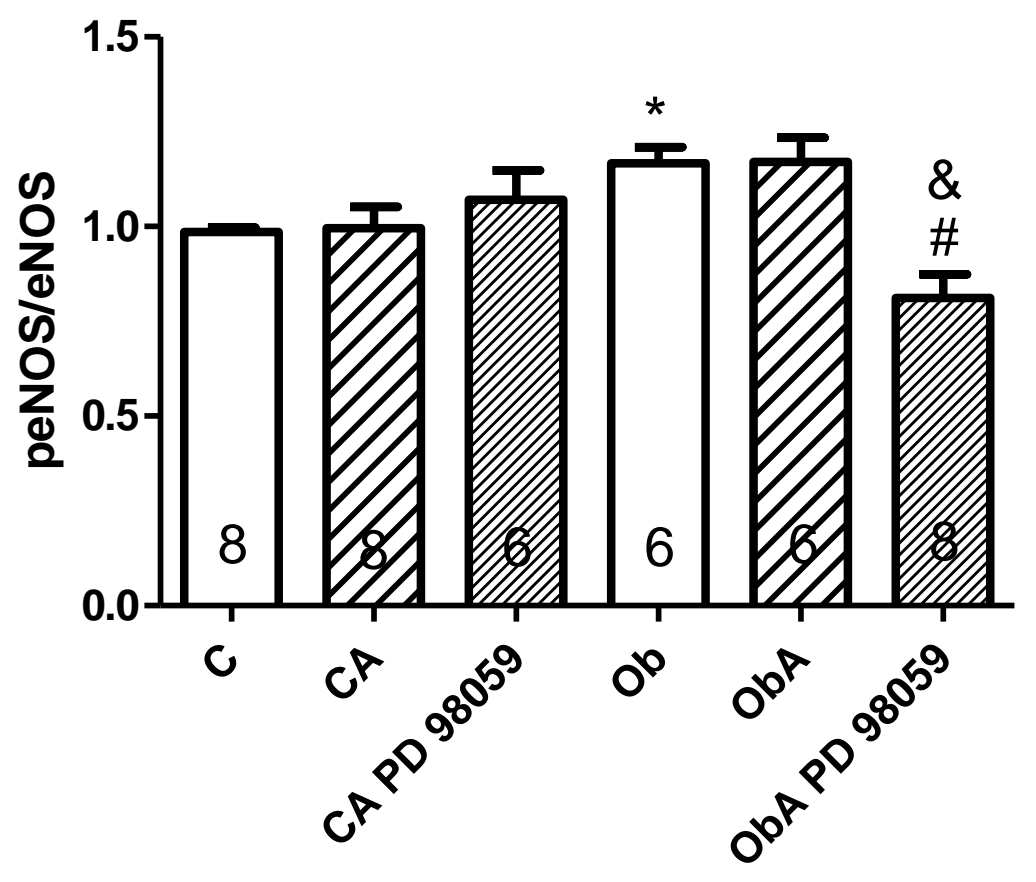

C CA CE Ob ObA ObE

peNOS Ser 1177

eNOS

a-actina

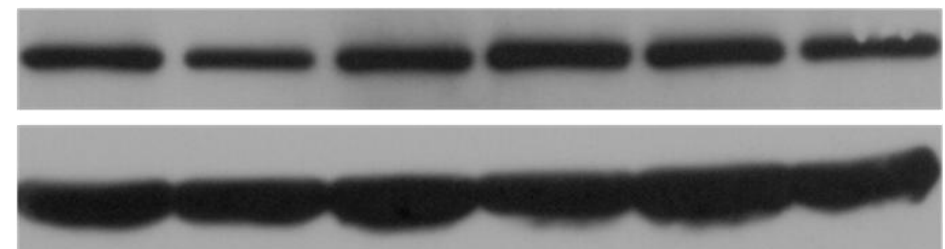

Western Blotting para eNOS em artérias mesentérias de resistência de ratos controles $(\mathrm{C})$ e obesos (Ob) com 16 semanas, sem estímulo ou com estímulo da Ang II (CA ou ObA) e sem inibidor ou com inibidor da ERK 1/2 (CE ou ObE). Cada barra representa a média \pm epm. O número de ratos utilizados em cada grupo encontra-se dentro das barras. ${ }^{*} \mathrm{p}<0,05$ vs $\mathrm{C}$; \# $\mathrm{p}<0,05$ vs respectivo grupo sem tratamento $\mathrm{e}$ $\& p<0,05$ vs $C$ tratado.

FONTE: Hagihara, 2012. 


\subsubsection{Avaliação da resposta vasoconstritora à NA}

Não houve diferença nas respostas máximas de ratos controles com e sem endotélio e de ratos obesos com e sem endotélio; entretanto, as preparações sem endotélio de ambos os grupos, controles e obesos, apresentaram curvas concentração-efeito deslocadas para a esquerda quando comparadas às preparações com endotélio. Portanto, que a retirada do endotélio tornou as preparações mais sensíveis ao agonista estudado (Figura 20 e tabela 3).

Figura 20 - Resposta contrátil à NA

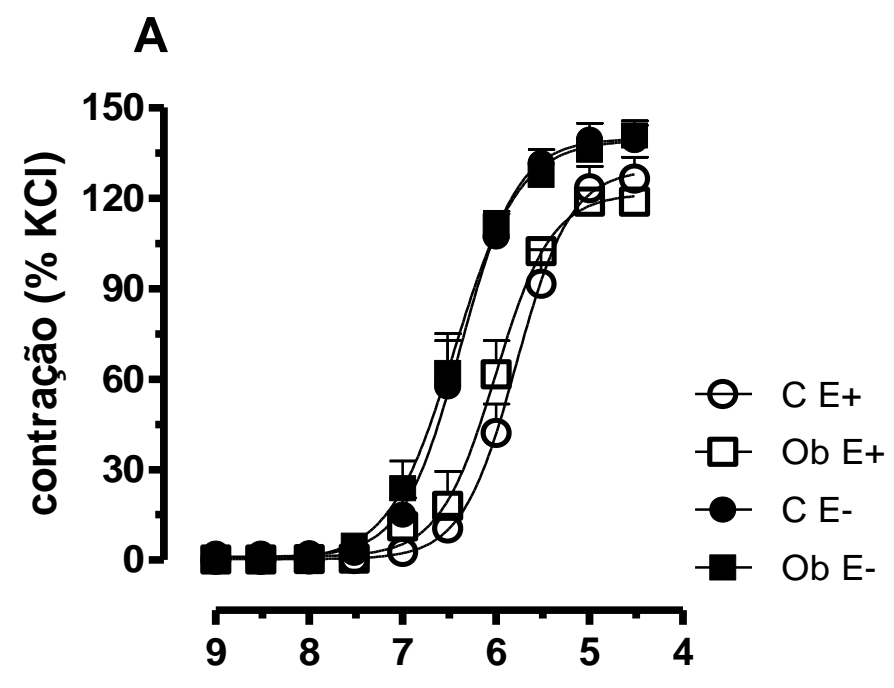

- Log [M] noradrenalina

B

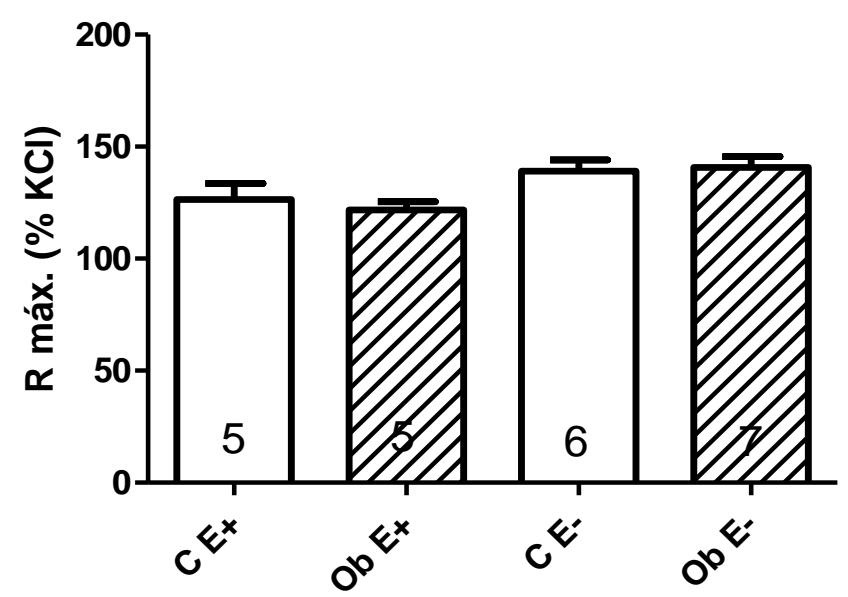

Curva concentração-efeito cumulativa para NA (A) e resposta máxima (B) em artérias mesentérias de resistência de ratos controles $(\mathrm{C})$ e obesos $(\mathrm{Ob})$ com 16 semanas, com endotélio $(\mathrm{E}+)$ e sem endotélio ( $\mathrm{E}-$ ). Cada ponto representa a média \pm epm. O número de ratos utilizados em cada grupo encontra-se dentro das barras.

FONTE: Hagihara, 2012. 
Tabela 3 - Resposta máxima ( $R$ máx.) e sensibilidade $\left(\mathrm{pD}_{2}\right)$ à $N A$ das artérias mesentéricas com $(E+)$ e sem endotélio $(E-)$

\begin{tabular}{ccc}
\hline \hline Grupo & R máx. $(\% \mathrm{KCl})$ & $\mathrm{pD}_{2}$ \\
\hline C E+ $(\mathrm{n}=5)$ & $126,4 \pm 7,7$ & $5,89 \pm 0,17$ \\
Ob E+ $(\mathrm{n}=5)$ & $121,7 \pm 3,62$ & $5,90 \pm 0,19$ \\
C E- $(n=5)$ & $135,7 \pm 5,27$ & $6,37 \pm 0,23^{\#}$ \\
Ob E- $(n=6)$ & $140,8 \pm 7,84$ & $6,54 \pm 0,23^{\#}$ \\
\hline \hline
\end{tabular}

Os valores foram expressos em média \pm epm. Em parênteses o número de animais. Resposta máxima ( $\mathrm{R}$ máx.), porcentagem de contração ao cloreto de potássio (\% $\mathrm{KCl})$, sensibilidade ao agonista $\left(\mathrm{pD}_{2}\right)$. $\# \mathrm{p}<0,5$ vs $\mathrm{C} \mathrm{E}+$ ou $\mathrm{Ob} \mathrm{E}+$.

FONTE: Hagihara, 2012. 
4.3.8 Avaliação da participação das vias das MAPKs na resposta vasoconstritora à noradrenalina

A inibição da via da ERK 1/2, da p38 e JNK não alteraram a resposta vasoconstritora a NA nos dois grupos, demonstrando que essas vias não participam da resposta contrátil a esse agonista (Figuras 20,21 e 22; Tabelas 4, 5 e 6).

Figura 21 - Participação da ERK1/2 na contração à NA

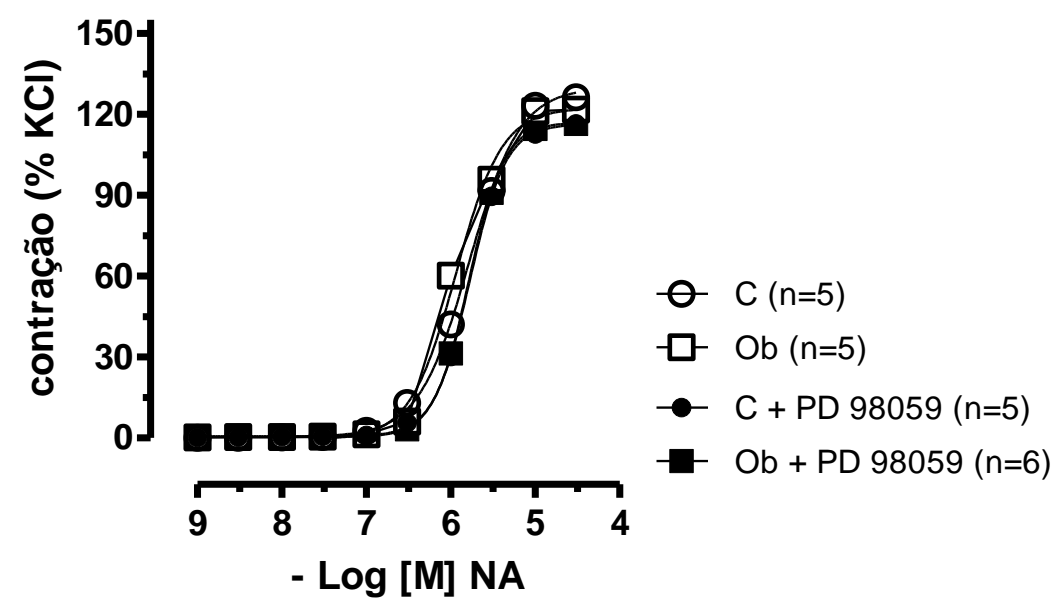

Curva concentração-efeito cumulativa para NA em artérias mesentérias de resistência de ratos controles $(\mathrm{C})$ e obesos $(\mathrm{Ob})$ com 16 semanas, com endotélio sem inibidor e com inibidor da via ERK 1/2 (C + PD ou Ob + PD). Cada ponto representa a média \pm epm. $O$ número de ratos utilizados em cada grupo encontra-se entre parênteses.

FONTE: Hagihara, 2012.

Tabela 4 - Resposta máxima (R máx.) e sensibilidade $\left(\mathrm{pD}_{2}\right)$ a NA das artérias mesentéricas com endotélio, sem inibidor e com inibidor da via ERK 1/2 $(\mathrm{C}+\mathrm{PD}$ ou $\mathrm{Ob}+\mathrm{PD})$

\begin{tabular}{ccc}
\hline \hline Grupo & R máx. $(\% \mathrm{KCl})$ & $\mathrm{pD}_{2}$ \\
\hline C $(\mathrm{n}=5)$ & $126,4 \pm 7,7$ & $5,89 \pm 0,17$ \\
Ob $(\mathrm{n}=5)$ & $121,7 \pm 3,62$ & $5,90 \pm 0,19$ \\
C + PD (n=5) & $116,4 \pm 0,29$ & $5,76 \pm 0,10$ \\
Ob + PD $(n=6)$ & $120,5 \pm 3,13$ & $5,72 \pm 0,16$ \\
\hline \hline
\end{tabular}

Os valores foram expressos em média \pm epm. O número de ratos utilizados em cada grupo encontra-se entre parênteses. Porcentagem de contração ao cloreto de potássio $(\% \mathrm{KCl})$, sensibilidade ao agonista $\left(\mathrm{pD}_{2}\right)$.

FONTE: Hagihara, 2012. 
Figura 22 - Participação da JNK na contração à NA

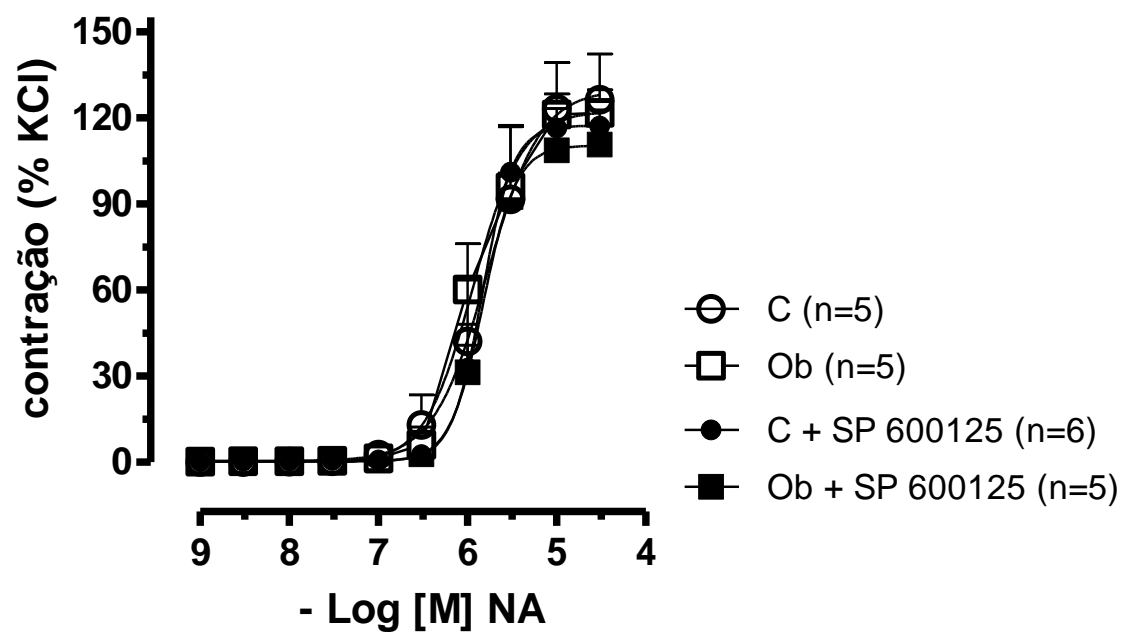

Curva concentração-efeito cumulativa para NA em artérias mesentérias de resistência de ratos controles $(\mathrm{C})$ e obesos $(\mathrm{Ob})$ com 16 semanas, com endotélio, sem inibidor e com inibidor da via JNK (C + Sp ou Ob + Sp). Cada ponto representa a média \pm epm. $O$ número de ratos utilizados em cada grupo encontra-se entre parênteses.

FONTE: Hagihara, 2012.

Tabela 5 - Resposta máxima ( $R$ max.) e sensibilidade $\left(\mathrm{pD}_{2}\right)$ a $N A$ das artérias mesentéricas com endotélio, sem inibidor e com inibidor da via JNK $(C+$ $\mathrm{SP}$ ou $\mathrm{Ob}+\mathrm{SP}$ )

\begin{tabular}{ccc}
\hline \hline Grupo & R máx. $(\% \mathrm{KCl})$ & $\mathrm{pD}_{2}$ \\
\hline $\mathrm{C}(\mathrm{n}=5)$ & $126,4 \pm 7,7$ & $5,89 \pm 0,17$ \\
Ob $(\mathrm{n}=5)$ & $121,7 \pm 3,62$ & $5,90 \pm 0,19$ \\
$\mathrm{C}+\mathrm{SP}(\mathrm{n}=6)$ & $117,2 \pm 2,49$ & $5,84 \pm 0,29$ \\
$\mathrm{Ob}+\mathrm{SP}(\mathrm{n}=5)$ & $115,0 \pm 3,07$ & $5,81 \pm 0,06$ \\
\hline \hline
\end{tabular}

Os valores foram expressos em média \pm epm. O número de ratos utilizados em cada grupo encontra-se entre parênteses. Porcentagem de contração ao cloreto de potássio $(\% \mathrm{KCl})$, sensibilidade ao agonista $\left(\mathrm{pD}_{2}\right)$.

FONTE: Hagihara, 2012. 
Figura 23 - Participação da p38 MAPK na contração à NA

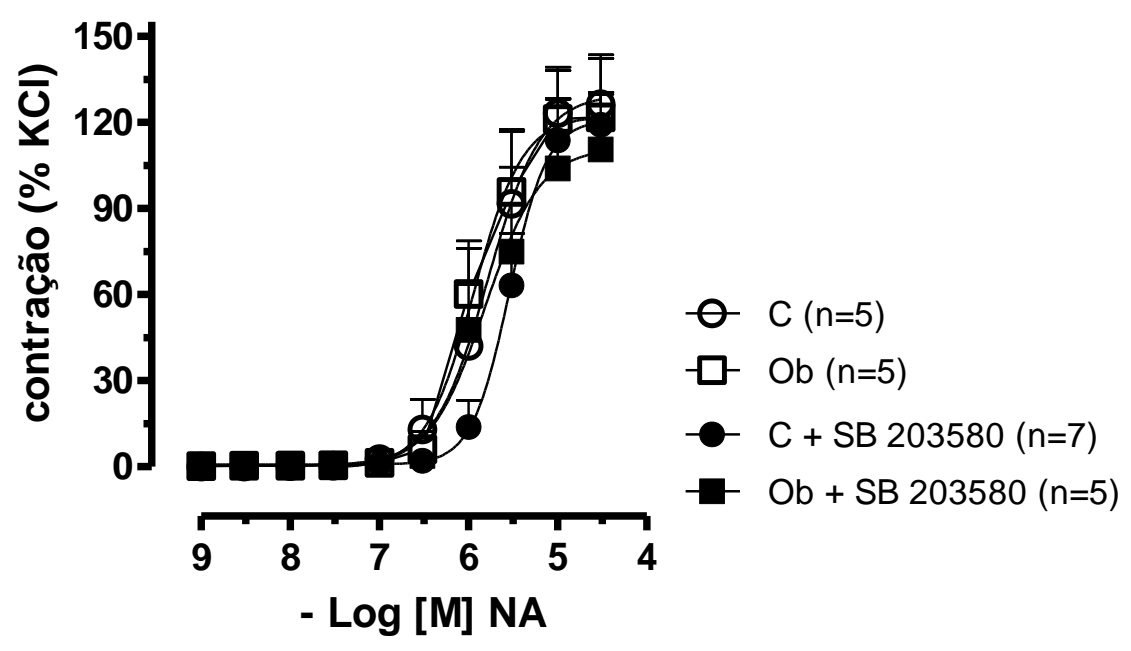

Curva concentração-efeito cumulativa para NA (A), resposta máxima (B) e EC50 (C) em artérias mesentérias de resistência de ratos controles (C) e obesos (Ob) com 16 semanas, com endotélio, sem inibidor e com inibidor da via p38 $(\mathrm{C}+\mathrm{Sb}$ ou Ob + $\mathrm{Sb})$. Cada ponto representa a média \pm epm. $\mathrm{O}$ número de ratos utilizados em cada grupo encontra-se entre parênteses.

FONTE: Hagihara, 2012.

Tabela 6 - Resposta máxima ( $R$ max.) e sensibilidade (pD2) a NA das artérias mesentéricas, com endotélio, sem inibidor e com inibidor da via p38 $(C+$ $\mathrm{Sb}$ ou $\mathrm{Ob}+\mathrm{Sb})$

\begin{tabular}{ccc}
\hline \hline Grupo & R máx. $(\% \mathrm{KCl})$ & $\mathrm{pD}_{2}$ \\
\hline C (n=5) & $126,4 \pm 7,7$ & $5,89 \pm 0,17$ \\
Ob $(\mathrm{n}=5)$ & $121,7 \pm 3,62$ & $5,90 \pm 0,19$ \\
$\mathrm{C}+$ SB $(\mathrm{n}=7)$ & $110,9 \pm 4,78$ & $5,65 \pm 0,14$ \\
Ob + SB $(\mathrm{n}=5)$ & $119 \pm 7,10$ & $5,65 \pm 0,31$ \\
\hline \hline
\end{tabular}

Os valores foram expressos em média \pm epm $\mathrm{O}$ número de ratos utilizados em cada grupo encontra-se entre parênteses. Porcentagem de contração ao cloreto de potássio $(\% \mathrm{KCl})$, sensibilidade ao agonista $\left(\mathrm{pD}_{2}\right)$.

FONTE: Hagihara, 2012. 


\section{DISCUSSÃO}

No presente trabalho, demonstramos que artérias mesentéricas de resistência de ratos obesos apresentaram menor resposta vasoconstritora à Ang II quando comparadas aos controles. Essa menor resposta está diretamente relacionada a alterações no endotélio. Além disso, demonstramos que a menor contração não atinge todos os agentes contráteis uma vez que as respostas constritoras pelo agonista adrenérgico $\mathrm{NA}$ e pelo agonista $\mathrm{KCl}$, não diferiram entre os grupos estudados. Demonstramos também que as alterações envolvem maior participação de AT2R e alterações nas vias de sinalização intracelular ativadas pela Ang II, mais especificamente as vias das MAPKs.

A obesidade é caracterizada por acúmulo de gordura corporal e/ou visceral, alterações no perfil lipídico e resistência à insulina que é definida como diminuição da capacidade desse hormônio de promover a captação da glicose sanguínea pelo músculo e tecido adiposo bem como diminuição da capacidade de inibir a produção de glicose pelo fígado (Kopelman, 2000). Além disso, a obesidade, mais precisamente a obesidade abdominal, predispõe ao desenvolvimento de doenças cardiovasculares em humanos (Park, Kim, 2012).

Neste trabalho utilizamos o modelo de obesidade por injeção de glutamato monossódico (MSG), que foi inicialmente descrito em camundongos por Olney em 1969. O glutamato monossódico é um aminoácido que ao ser administrado no período neonatal lesiona a região do núcleo arqueado do hipotálamo, resultando em menor secreção do hormônio do crescimento $(\mathrm{GH})$ fato que explica o menor tamanho desses animais (Nemeroff et al., 1977), além de menor atividade da proteína translocadora de glicose GLUT-4, menor atividade do tecido adiposo marrom, menor termogênese, hiperleptinemia, hipercorticosteronemia e normofagia (Hirata et al., 1997). Além disso, estudos demonstraram que os animais obesos por injeção de MSG apresentaram redução da ativação do sistema simpático com possível aumento da ativação do sistema parassimpático (Dulloo, Young, 1991; Morris et al., 1998), fatos que justificam a manutenção dos níveis normais da pressão arterial sistólica nesses animais.

Em nosso estudo, o tratamento com MSG foi efetivo em induzir obesidade, levando a aumento do índice de Lee, do peso relativo das gorduras periepididimal e retroperitoneal, sem alterar a massa magra, além de induzir quadro de 
hipertrigliceridemia, aumento das frações VLDL e LDL, sem alteração no colesterol total, nos níveis de HDL e na pressão arterial sistólica. Além disso, foi demonstrado em trabalho anterior do nosso laboratório que esses ratos apresentam resistência à insulina, hiperinsulinemia e são normoglicêmicos (Lobato et al., 2011; 2012). Além disso, também já foi demonstrado por outros autores que os ratos obesos por injeção de MSG, com 16 semanas, constituem excelente modelo não diabético de resistência à insulina e hiperinsulinemia (Tokarev et al., 1997; Messina et al.,2005; Toledo, 2005). Em trabalho que avaliou a influência da idade no desenvolvimento do diabetes nesse modelo relatou-se que até 32 semanas de idade, os ratos obesos por injeção de MSG eram intolerantes à glicose e ainda não eram diabéticos (Morrison et al., 2007). A nossa escolha de trabalhar com esse modelo na faixa etária de 16 semanas garantiu que os ratos submetidos ao tratamento com MSG fossem obesos, normotensos e não diabéticos. Isso permitiu estudar a obesidade sem a influência da hipertensão e da hiperglicemia.

$\mathrm{Na}$ obesidade há alterações metabólicas importantes, como o aumento de ácidos graxos circulantes, aumento da liberação de citocinas pró-inflamatórias, disfunção endotelial e resistência à insulina (Weiss, 2007). Já foi descrito que a insulina é capaz de aumentar a expressão de angiotensinogênio, um importante constituinte do SRA, em tecido adiposo subcutâneo de humanos (Harte et al., 2003). Diversos estudos têm demonstrado de modo bastante consistente que na obesidade ocorre aumento da ativação do SRA, com níveis elevados de angiotensinogênio, de ECA, de renina e da Ang II no plasma e em diversos tecidos, incluindo o tecido adiposo (Formiguera, Cantón, 2004; Carvalho-Filho et al., 2007; Jonk et al., 2007), favorecendo o desenvolvimento de alterações cardiovasculares (Yvan-Charvet, Quignard-Boulange, 2011).

O aumento agudo de Ang II na circulação provoca aumento da ativação dos AT1R (Dinh et al., 2001). Entretanto, em condições em que há aumento crônico da exposição à Ang II, como na obesidade, pode ocorrer o fenômeno de regulação negativa desses receptores, além da regulação positiva dos AT2R (Metha, Griendling, 2007; Kloet et al., 2010). Com base nestes estudos e de acordo com os resultados obtidos no presente trabalho, podemos sugerir que a menor resposta à Ang II em artérias mesentéricas de resistência dos ratos obesos pode ter ocorrido como mecanismo compensatório frente ao aumento da síntese e liberação de elementos do SRA local e sistêmico. 
A reatividade vascular em artérias mesentéricas sem o endotélio resultou em curvas concentração resposta à Ang II e NA deslocadas para a esquerda, demonstrando que na ausência do endotélio há aumento da sensibilidade aos agonistas estudados. Além disso, não houve diferença na resposta à Ang II entre ratos obesos e controles nas preparações sem endotélio demonstrando a participação do endotélio na menor resposta à Ang II em ratos obesos. O fato da resposta à $\mathrm{NA}$ e ao $\mathrm{KCl}$ não estarem alteradas nos ratos obesos indica que o comprometimento da resposta contrátil não afeta todo o processo contrátil, sendo relativamente específico.

O endotélio desempenha importante papel na regulação do tônus vascular. As células endoteliais secretam diversas substâncias de ação vascular. Dentre elas podemos destacar o NO, a prostaciclina e o fator hiperpolarizante derivado do endotélio. Já os agentes contráteis incluem a ET-1, os ânions superóxido, prostanóides e a geração local de Ang II. O desequilíbrio entre os fatores contráteis e relaxantes resulta em disfunção endotelial (Toda et al., 2007). Em nosso estudo, parece haver aumento dos fatores relaxantes como tentativa de conter o aumento da ativação do SRA.

A Ang II tem a maioria de suas ações conhecidas e extensamente estudadas desencadeada pela ligação ao AT1R, que uma vez ativado pode estimular múltiplas vias intracelulares de transdução de sinal, levando a diversas ações biológicas dentre elas a contração vascular (Touyz, Schiffrin, 2000).

Além do AT1R, a Ang II pode ativar o AT2R que, apesar de possuir afinidade para Ang II similar à do AT1R, foi menos estudado e suas ações ainda não foram tão bem descritas quanto as ações do AT1R (Jones et al., 2008). O AT2R é expresso em diversos tecidos, incluindo o endotélio e músculo liso vascular de adultos (Jonk et al., 2007 e Steckelings et al., 2005). A ligação da Ang II ao AT2R induz a ativação de cascatas intracelulares que resultam em regulação negativa de diversas respostas iniciadas pela ativação do $A T 1 R$, destacando-se a vasodilatação (Fleming et al., 2006). Entretanto, os mecanismos pelos quais o AT2R exerce essas funções ainda não foram totalmente esclarecidos.

Em nosso trabalho, estudamos a participação desses dois receptores na resposta vasoconstritora à Ang II. O estudo do AT1R confirmou que esse é de fato o receptor envolvido na contração induzida pela Ang II tanto em controles como em obesos. Alterações na expressão desse receptor foram relatadas em modelos 
animais, indicando que o estímulo de Ang II pode tanto regular positivamente (Xu et al., 2005) como negativamente o AT1R (Lassègue et al., 1995). A menor resposta contrátil à Ang II dos ratos obesos descrita em nosso trabalho poderia, então, ser explicada pela redução do número de AT1R. Os experimentos de reatividade vascular na presença do antagonista de AT1R fizeram-nos levantar outra hipótese, a de que os ratos obesos teriam maior número desse receptor, uma vez que a mesma dose do antagonista utilizado quase aboliu a resposta contrátil à Ang II nos controles e apenas reduziu a contração à Ang II nos obesos. A regulação positiva de AT1R já foi descrita em ratos obesos Zucker e o tratamento com bloqueador AT1R melhorou algumas complicações que ocorrem nesse modelo como a nefropatia ( $\mathrm{Xu}$ et al., 2005). Para testarmos a nossa hipótese de que a alteração na quantidade de AT1R estaria envolvida na menor resposta à Ang II realizamos os experimentos de western blotting e verificamos que os ratos obesos e controles não apresentaram diferença no conteúdo proteico de AT1R, descartando essa hipótese.

O aumento da quantidade de AT2R poderia explicar a menor resposta à Ang II dos ratos obesos. De fato, os ratos obesos apresentam aumento do conteúdo proteico de AT2R quando comparados aos controles. A ativação desse receptor poderia assim estar se contrapondo às ações do AT1R, favorecendo o relaxamento vascular, o que em nosso caso pode ser traduzido como menor resposta contrátil à Ang II. Embora estudos recentes tenham demonstrado que no infarto do miocárdio, na nefropatia diabética, na falência renal, em quadro de isquemia e reperfusão, na hipertensão e na inflamação há aumento do conteúdo proteico de AT2R como tentativa de se manter a homeostase (Sabuhi et al.,2011; Wang et al., 2011), o mesmo ainda não havia sido demonstrado em artérias mesentéricas de resistência de ratos obesos MSG.

Dentre os mecanismos intracelulares envolvidos na vasodilatação promovida pela ativação do AT2R, está o aumento da produção de NO, importante agente vasodilatador produzido pelo endotélio. O NO ativa a guanilato ciclase solúvel (sGC), que por sua vez leva à ativação do segundo mensageiro guanina 3',5'-monofosfato cíclico (cGMP). Este ativa uma proteína quinase dependente de cGMP (PKG) que pode reduzir a concentração do $\mathrm{Ca}^{2+}$ livre e diminuir a sensibilidade vascular ao $\mathrm{Ca}^{2+}$ induzindo, consequentemente, efeito vasodilatador (Doronzo et al., 2011).

O aumento da quantidade e da ativação dos AT2R poderia, então, levar à maior liberação de NO e desta forma, favorecer o relaxamento vascular. De fato, 
verificamos que a inibição da óxido nítrico sintase pelo L-NAME corrigiu a menor resposta à Ang II nos obesos. As curvas concentração resposta à Ang II com o LNAME foram muito semelhantes às curvas realizadas em preparações sem endotélio indicando que a substância liberada pelo endotélio que estaria envolvida na hiporreatividade à Ang II nos obesos é o NO.

A NAPH oxidase pode ser ativada em células do músculo liso vascular e no endotélio por diferentes estímulos como aumento da Ang II circulante, pela exposição a metais pesados, por aumento plasmático de lipoproteínas oxidadas, pela tensão de cisalhamento, por aumento das citocinas pró-inflamatórias (Jiang et al., 2011). Ela é uma enzima que induz a produção de EROs e participa da modulação de diferentes vias de sinalização intracelular podendo inibir ou ativar fosfatases e fatores de transcrição, desempenhando um importante papel na manutenção da função celular (Lambeth, 2004).

Demonstramos que as EROs participam da contração à Ang II em ratos obesos e controles pois a inibição da NADPH oxidase pela apocinina reduziu a resposta contrátil à Ang II nos dois grupos. Entretanto, como a diferença na resposta à Ang II foi mantida pode-se sugerir que as EROS não estão envolvidas na menor resposta à Ang II nos ratos obesos.

A ligação da Ang II ao AT1R pode levar à ativação das vias das MAPKs, dentre elas as mais estudadas são a ERK1/2, JNK e p38 MAPKs (Metha, Griendling, 2007). A via de sinalização mediada pela ERK1/2 é a mais bem caracterizada das MAPKs. Em nosso estudo, demonstramos que no modelo de obesidade induzido por MSG a ativação da via da ERK1/2 pode ocorrer tanto pela ligação da Ang II ao AT1R quanto pela ligação ao AT2R. Alguns estudos descrevem que a ativação do AT1R pela Ang II leva à fosforilação da ERK1/2, promovendo contração vascular, aparentemente por mecanismos dependentes de $\mathrm{Ca}^{2+}$ e da proteína quinase $\mathrm{C}$ (PKC) (Touyz, Schiffrin, 2000). Entretanto, também já foi descrito em cultura de células neuronais quiescentes (células $\mathrm{PC} 12 \mathrm{~W}$ ) que a ativação do AT2R resulta em aumento da fosforilação da ERK1/2 resultando em vasodilatação (Stroth et al., 2000). O fato do bloqueio desse receptor ter inibido a ativação da ERK1/2 comprova que o AT2R também pode contribuir para o aumento da ativação dessa via de sinalização intracelular, que em nosso caso, contribuiu para a menor resposta à Ang II. 
A participação da ERK1/2 na vasodilatação ainda foi pouco estudada. Em estudo realizado em cultura de células endoteliais de artérias fetoplacentárias, foi demonstrado que a Ang II induz aumento da fosforilação da eNOS e que a inibição da ERK1/2 reduz a ativação aumentada da eNOS, indicando que ERK1/2 pode ativar a eNOS nas células estudadas (Zheng et al., 2005). Isso pode levar à vasodilatação e explicar a menor resposta à Ang $\mathrm{II}$ em obesos.

$\mathrm{Na}$ obesidade pode haver aumento crônico da produção local e sistêmica de Ang II (Jonk et al., 2007), o que pode ter contribuído para o aumento da ativação da ERK1/2 no estado basal dos ratos obesos, assim como no aumento da ativação da eNOS. Resultado semelhante foi encontrado em artérias coronárias de ratos obesos Zucker (Contreras et al., 2011). Além disso, também demonstramos que a Ang II ativa mais a ERK1/2 nos ratos obesos do que nos controles e que a sua inibição corrigiu a menor resposta a esse agente, indicando o envolvimento da via ERK1/2 na redução da resposta à Ang II.

Enquanto a via de sinalização intracelular da ERK1/2 favoreceu a vasodilatação nos ratos obesos, as vias da JNK e da p38 MAPKs participaram da manutenção da contração à Ang II. De fato, já foi descrito que a ERK1/2 pode exercer funções contrárias a aquelas exercidas pelas JNK e p38 MAPKs, indicando um possível mecanismo de regulação entre essas três MAPKs a fim de manter o equilíbrio celular frente a situações de intensa injúria celular (Staples et al., 2010). Em nosso caso, isso se traduziria em maior ativação da ERK1/2 como mecanismo compensatório frente ao possível aumento da ativação de mecanismos contráteis via JNK e p38 MAPKs.

Uma das hipóteses para explicar a participação da ERK1/2 na vasodilatação envolve o aumento da fosforilação da eNOS, levando à maior liberação de $\mathrm{NO} e$ desta forma promovendo relaxamento vascular. De fato, demonstramos aumento da ativação da ERK1/2 e da eNOS já no estado basal de ratos obesos. Além disso, a inibição da ERK1/2 diminuiu a ativação da eNOS, reduzindo-a a níveis abaixo do encontrado em estado basal. Esses dados levam a sugerir que o aumento basal da eNOS se deve à maior ativação da ERK1/2 nos ratos obesos. Mecanismo semelhante foi descrito em artérias mesentéricas e em aorta de ratos Wistar com endotoxemia (Korkmaz et al., 2006; Tunctan et al., 2007).

Considerando nossos achados de que a menor resposta contrátil à Ang $\mathrm{II}$ em artérias mesentéricas de ratos obesos ocorreu por aumento da atividade e da 
expressão proteica de AT2R, pelo aumento da expressão da ERK1/2 e da eNOS, e que o AT2R pode ativar a ERK1/2 e esta, pode ativar a eNOS podemos sugerir que a Ang II se ligaria mais ao AT2R do que ao AT1R promovendo a ativação de vias de sinalização intracelular que culminariam na maior ativação da ERK1/2. Entretanto, o duplo bloqueio do AT2R e a inibição da ERK1/2 potencializou o efeito contrátil à Ang II em artérias mesentéricas de ratos obesos, indicando que a via de sinalização ativada pelo $A T 2 R$ e a via ativada pela ERK1/2 são distintas e tiveram efeitos somatórios, resultando na menor resposta à Ang II em ratos obesos.

Em artérias mesentéricas de ratos controles demonstramos que as MAPKs não participam da resposta contrátil induzida por Ang II e NA. A participação das MAPKs na resposta contrátil de animais não obesos ainda é pouco estudada e os resultados são divergentes. Em estudo realizado em artérias mesentéricas de ratas Sprague-Dowley demonstrou-se que a p38MAPK participa da contração à NA, mas não na resposta contrátil à ET-1 (Ohanian et al., 2001). Em outro estudo, realizado em aortas de ratos Sprague-Dowley, demonstrou-se a participação da JNK na contração à Ang II, NA e ET1 (Zhou et al., 2010). Quanto à participação da via da ERK1/2 na resposta contrátil à Ang II em controles foi demonstrado, em artérias mesentéricas de resistência de ratos Wistar com 12 semanas, redução da resposta contrátil com a inibição da ERK1/2 mostrando, ao contrário do nosso trabalho, que essa via participa da contração nos ratos Wistar (Matrougui et al., 2000). Neste caso, a idade dos ratos utilizados era diferente daquela do nosso estudo bem como o equipamento utilizado, miógrafo pressurizado, (que mede alterações na pressão interna do vaso), era diferente daquele utilizado por nós, miógrafo de arame (que mede a variação da tensão isométrica do vaso). Este sistema mostrou-se mais adequado ao nosso estudo por não apresentar a interferência da tensão de cisalhamento.

Experimentos de reatividade vascular à NA em ratos obesos pela injeção de MSG foram realizados em nosso laboratório por Lobato et al. (2011) em leito arteriolar mesentérico, demonstrando aumento da resposta contrátil à NA. O mesmo não foi encontrado em nosso estudo. Essa diferença de resultados pode ser explicada pelo tipo de preparação vascular utilizado no primeiro estudo, em que artérias e arteríolas de diferentes calibres são avaliadas em conjunto. Neste caso, a hiperreatividade à NA pode ter se dado por alterações em vasos de calibres maiores daqueles utilizados no presente trabalho (200 a $250 \mu \mathrm{m})$ e também pela influência 
do tecido adiposo perivascular, que foi retirado em nosso caso. Sabe-se que o tecido adiposo desempenha ações fisiológicas muito mais abrangentes e importantes do que inicialmente se acreditava. $O$ tecido adiposo deixou de ser considerado apenas um simples reservatório energético para ser descrito como órgão endócrino capaz de responder a sinais hormonais e neurais, bem como de secretar substâncias vasoativas (Ahima, 2000; Houben et al., 2012). Entretanto, ainda não há um consenso quanto ao seu papel na resposta contrátil, sendo relatados tanto efeitos facilitadores ou inibidores da contração (Verlohren et al., 2001; Szasz, Webb, 2012).

Em resumo, no presente trabalho demonstramos que as três vias das MAPKs estudadas participam da resposta à Ang II nos ratos obesos com 16 semanas, seja favorecendo a contração a esse agonista, como no caso da JNK e p38 MAPKs ou então, favorecendo mecanismos de relaxamento, como no caso da ERK 1/2. Demonstramos que a menor resposta contrátil à Ang II encontrada nos ratos obesos não está relacionada a alteração no número de AT1R e sim ao aumento de AT2R, que ao ser ativado favoreceu vias intracelulares de vasodilatação. Dentre essas vias, comprovamos o importante papel desempenhado pela ERK 1/2 nos ratos obesos, demonstrando que na obesidade há aumento da ativação dessa via e que neste caso, esta MAPK contribuiu para o aumento basal da eNOS nos ratos obesos. Desta forma, comprovamos que na obesidade ocorrem alterações vasculares e intracelulares importantes e que as MAPKs passam a desempenhar um papel extremamente importante na tentativa de manter os processos fisiológicos em equilíbrio. 


\section{CONCLUSÃO}

> Ratos obesos com 16 semanas apresentam menor resposta vasoconstritora à Ang II, sugerindo mecanismo compensatório para o possível aumento da ativação do SRA;

> A alteração contrátil à Ang II nos ratos obesos é dependente do endotélio e específica a este agente pois não houve alteração na contração à NA e ao $\mathrm{KCl}$;

> Os ratos obesos não apresentaram alteração no número de receptores do tipo AT1, entretanto, eles apresentaram maior quantidade de receptores do tipo AT2, promovendo respostas que favorecem a vasodilatação, que no nosso trabalho é demonstrado pela diminuição da resposta à Ang II;

A hiporreatividade à Ang II está relacionada à maior liberação NO;

As EROs participam da resposta contrátil à Ang II nos dois grupos estudados, entretanto, parecem não contribuir para a menor resposta à Ang II em ratos obesos;

$>$ A via da ERK1/2 parece favorecer mecanismos de relaxamento nos ratos obesos, estando associada à maior fosforilação da eNOS e, desta forma, ao aumento do $\mathrm{NO}$ e consequente menor contração à Ang II; enquanto que as vias da JNK e p38 MAPK atuam na manutenção da vasoconstrição a esse agente;

> O maior número de receptores AT2 e a maior fosforilação da ERK 1/2 são fatores que se somam para resultar na diminuição da resposta à Ang II.

As MAPKs não constituem o principal mecanismo de contração vascular nos ratos controles; 


\section{REFERÊCIAS*}

Ahima RS, Flier JS. Adipose tissue as an endocrine organ. Trends Endocrinol Metab. 2000;11:327-32.

Avogaro A, Kreutzenberg SV. Mechanisms of endothelial dysfunction in obesity. Clin Chim Acta. 2005;360:9-26.

Barton M, Carmona R, Ortmann J, et al. Obesity-associated activation of angiotensin and endothelin in the cardiovascular system. Int J Biochem Cell Biol. 2003;35:82637.

Caballero AE. Endothelial dysfunction in obesity and insulin resistance: a road to diabetes and heart disease. Obes Res. 2003;11:1278-89.

Carvalho-Filho MA, Carvalheira JC, Velloso LA, et al. Cross-talk das vias de sinalização de insulina e angiotensina II: implicações com a associação entre diabetes mellitus e hipertensão arterial e doença cardiovascular. Arq Bras Endocrinol Metab. 2007;51/2:195-203.

Chen $\mathrm{H}$, Montagnani $\mathrm{M}$, Funahashi $\mathrm{T}$, et al. Adiponectin stimulates production of nitric oxide in vascular endothelial cells, J Biol Chem. 2003;278:45021-6.

Contreras $\mathrm{C}$, et al. Preserved insulin vasorelaxation and up-regulation of the Akt/eNOS pathway in coronary arteries from insulin resistant obese Zucker rats. Atherosclerosis. 2011;217(2):331-9.

Dinh DT, et al. Angiotensin receptors: distribution, signaling and function. Clinical Science. 2001;100:481-92.

Doronzo G, Viretto M, Russo I, et al. Nitric oxide activates PI3-K and MAPK signaling pathways in human and rat vascular smooth muscle cells: influence of insulin resistance and oxidative stress. Atherosclerosis. 2011;216(1):44-53.

Dulloo AG, Young JB. Effects of monosodium glutamate and gold thioglucose on dietary regulation of sympathetic nervous system activity in rodents. Metabolism. 1991;40(2):113-21.

Fernández-Sánchez A, et al. Inflammation, oxidative stress, and obesity. Int J Mol Sci. 2011;12:3117-32.

Fleming I, Kohlstedt K, Busse R. The tissue renin- angiotensin system and intracellular signalling. Curr Opin Nephrol Hypertens. 2006;15:8-13.

Formiguera X, Cantón A. Obesity: epidemiology and clinical aspects. Best Pract Res Clin Gastroenterol. 2004;18(6):1125-46.

* De acordo com: International Committee of Medical Journal Editors. Uniform requirements for manuscripts submitted to Miomedical Journal: sample references.

Available from: http://www.icmje.org [2007 May 22]. 
Franco Mdo C, Akamine EH, Di Marco GS, et al. NADPH oxidase and enhanced superoxide generation in intrauterine undernourished rats: involviment of the reninangiotensin system. Cardiovasc Res. 2003;1(3):767-75.

Franco Mdo C, Akamine EH, Rebouças N, et al. Long-term effects of intrauterine malnutrition on vascular function in female offspring: implications of oxidative stress. Life Sci. 2007;80(8):709-15.

Freidenberg GR, Reichart D, Olefsky JM, Henry RR. Reversibility of defective adipocyte insulin receptor kinase activity in non-insulin-dependent diabetes mellitus. Effect of weight loss. J Clin Invest. 1988;82(4):1398-406.

Fruhbeck $\mathrm{G}$. The adipose tissue as a source of vasoactive factors. Curr Med Chem. 2004;2:197-208.

Furchgott RF, Vanhoutte PM. Endothelium-derived relaxing and contracting factors. FASEB J. 1989;3(9):2007-18.

Ghatta S, Ramarao P. Increased contractile responses to 5-Hydroxytryptamine and Angiotensin II in high fat diet fed rat thoracic aorta. Lipids Health Dis. 2004;2:3-19.

Giachini FR, Sullivan JC, Lima VV, Carneiro FS, Fortes ZB, Pollock DM, Carvalho $\mathrm{MHC}$, Webb RC, Tostes RC. Extracellular signal-regulated kinase 1/2 activation, via downregulation of mitogen-activated protein kinase phosphatase-1, mediates sex differences in desoxycorticosterone acetate-salt hypertension vascular reactivity. Hypertension. 2010;55:172-9.

Greenfield J, Campbell L. Insulin resistance and obesity. Clin Derm. 2004;22(4):28995.

Harker CT, O’Donnell MP, Kasiske BL, Keane WF, Katz SA. The renin-angiotensin system in the type II diabetic obese Zucker rat. J Am Soc Nephrol. 1993;4:1354-61.

Harte AL et al. Insulin increases angiotensinogen expression in human abdominal subcutaneous adipocytes. Diabetes Obes Metab. 2003;5(6):462-7.

Hill JO. Understanding and addressing the epidemic of obesity: an energy balance perspective. Endocr Rev. 2006;27(7):750-61.

Hirata $A E$, et al. Monosodium glutamate (MSG)-obese rats develop glucose intolerance and insulin resistance to peripheral glucose. Braz $\mathrm{J}$ Med Biol Res. 1997;30:671-4.

Hirosumi J, Tuncman G, Chang L, et al. A central role for JNK in obesity and insulin resistance. Nature. 2002;21:420(6913):333-6.

Houben AJ et al. Perivascular fat and the microcirculation: relevance to insulin resistance, diabetes and cardiovascular disease. Curr Cardiovasc Risc Rep. 2012;6:80-90. 
Isenovic $\mathrm{ER}$, Jacobs $\mathrm{DB}$, Kedees $\mathrm{MH}$, et al. Angiotensin II regulation of the $\mathrm{Na}^{+}$pump involves the phosphatidylinositol-3 kinase and p42/44 mitogen-activated protein kinase signaling pathways in vascular smooth muscle cells. Endocrinology. 2004;145(3):1151-60.

Jiang $\mathrm{F}$, et al. NADPH oxidase-mediated redox signaling: roles in cellular response, stress tolerance, and tissue repair. Am Soc Pharmacol Exp Therap. 2011;63:218-42.

Jones EM, Vinh A, McCarthy CA, et al. AT2 receptors: functional relevance in cardiovascular disease. Pharmacol Ther. 2008;120(3):292-316.

Jonk AM, Houben AJ, de Jongh RT, et al. Microvascular dysfunction in obesity: a potential mechanism in the pathogenesis of obesity-associated insulin resistence and hypertension. Physiology. 2007;22:252-60.

Juul B, Aalkjaer C, Mulvany MJ. Responses of femoral resistance vessels to angiotensin in vitro. Eur. J. Pharmacol. 1987;135(1):61-8.

Kloet $A D$, et al. The renin angiotensin system and metabolic syndrome. 2010;100(5):525-34.

Kopelman PG. Obesity as a medical problem. Nature. 2000;404(6778):635-43.

Korkmaz B, et al. Extracellular signal-regulated kinase (ERK1/2) contributes to endotoxin-induced hyporeactivity via nitric oxide and protacyclin production in rat aorta. Pharmacology. 2006;78(3):123-8.

Kurtz TW, Pravenec M. Antidiabetic mechanisms of angiotensin-converting enzyme inhibitors and angiotensin II receptor antagonists: beyond the renin-angiotensin system. J Hypertens. 2004;22:2253-61.

Kwon S, Fang LH, Kim B, et al. p38 Mitogen-Activated Protein Kinase Regulates Vasoconstriction in Spontaneously Hypertensive Rats. Journal of Pharmacological Sciences. 2004;95(2):267-72.

Lambeth JD. NOX enzymes and the biology of reactive oxygen. Nat Rev Immunol. 2004;4:181-9.

Larson B, Svardsudd K, Welin L, et al. Abdominal adipose tissue distribution, obesity, and risk of cardiovascular disease and death: 13 year follow up of participants in the study of men born in 1913. Br Med J. 1984;288:1401-4.

Lassègue $B$ et al., Angiotensin down-regulates the vascular smooth muscle AT1 receptor by transcriptional and post-transcriptional mechanisms: evidence for homologous and heterologous regulation. Mol Pharmacol. 1995;48:601-9.

Lee MA, Böhm M, Paul M, Ganten D. Tissue renin-angiotensin systems. Their role in cardiovascular disease. Circulation. 1993;87(Suppl.5): IV7-13.

Lobato NS, Filgueira FP, Hagihara GN, Akamine EH, Pariz JR, Tostes RC, Carvalho $\mathrm{MHC}$, Fortes ZB. Improvement of metabolic parameters and vascular function by metformin in obese non-diabetic rats. Life Sci. 2012;90:228-35. 
Lobato NS, et al. Obesity Induced by Neonatal Treatment with Monosodium Glutamate Impairs Microvascular Reactivity in Adult Rats: Role of $\mathrm{NO}$ and Prostanoids. Nutr Metab Cardiovasc Dis. 2011;21:808-16.

Mather KJ, Mirzamohammadi B, Lteif A, et al. Endothelin Contributes to Basal Vascular Tone and Endothelial Dysfunction in Human Obesity and Type 2 Diabetes. Diabetes. 2002;51(12):3517-23.

Matrougui K, Eskildsen-Helmond Y, Fiebeler A, et al. Angiotensin II stimulates Extracellular Signal-Regulated Kinase activity in intact pressurized rat mesenteric resistance arteries. Hypertension. 2000;36:617-21.

Messina MM, et al. Perinatal MSG treatment attenuates fasting-induced bradycardia and metabolic suppression. Physiol Behav. 2005;86(3):324-30.

Metha PK, Griendling KK. Angiotensin II cell signaling: physiological and pathological effects in the cardiovascular system. Am J Physiol Cell Physiol. 2007;292:C82-C97.

Morris MJ, et al. Reduced BAT function as a mechanism for obesity in the hypophagic, neuropeptide $\mathrm{Y}$ deficient monosodium glutamate-treated rat. Regul Pept. 1998;25(75):441-7.

Morrison JFB, et al. Sensory and autonomic nerve changes in the monosodium glutamate-treated rat: a model of type II diabetes. Exp Physiol. 2007;93(2):213-22.

Mulvany MJ, Halpern W. Contractile properties of small arterial resistance vessels in spontaneously hypertensive and normotensive rats. Circ Res. 1977;41(1):19-26.

Muslin AJ. MAPK signaling in cardiovascular health and disease: molecular mechanisms and therapeutic targets. Clin Sci (Lond). 2008;115(7):203-18.

Nemeroff CB et al. Growth, endocrinological and behavioral deficits after monosodium L-glutamato in the neonatal rat: possible involvement of arcuate dopamine neuron damage. Psychoneuroendocrinology. 1997;2:179-96.

Nishimatsu $H$, Suzuki $E$, Takeda $R$, et al. Endothelial dysfunction and hypercontractility of vascular myocytes are ameliorated by Fluvastatin in Obese Zucker Rats. Am J Physiol Heart Circ Physiol. 2005;288:H1770-6.

Ohanian J, Cunliffe P, Ceppi E, et al. Activation of p38 mitogen-activated protein kinases by endothelin and noradrenaline in small arteries, regulation by calcium influx and tyrosine kinases, and their role in contraction. Arterioscler Thromb Vasc Biol. 2001;21:19-21.

Olney JW. Brain lesions, obesity, and other disturbances in mice treated with monosodium glutamate. Science. 1969;164:719-21.

Park YS, Kim JS. Obesityy phenotype ando coronary heart disease risk as estimated by the Framingham risk score. J Korean Med Sci. 2012;27(3):243-9. 
Perticone $F$, Ceravolo $R$, Candigliota $M$, et al. Obesity and body fat distribution linduce endothelial dysfunction by oxidative stress: protective effect of vitamin $\mathrm{C}$. Diabetes. 2001;50:159-65.

Puigserver P, Rhee J, Wu ZU, Yoon JC, et al. Cytokine stimulation of energy expenditure through p38 MAP kinase activation of PPARgamma coactivator-1. Mol Cell. $2001 ; 8(5): 971-82$.

Qatanani M, Lazar MA. Mechanisms of obesity-associated insulin resistance: many choices on the menu. Genes Dev. 2007;21(12):1443-55.

Rahmouni K, Correia ML, Haynes WG, Mark AL. Obesity-associated hypertension: new insights into mechanisms. Hypertension. 2005;45:9-14.

Rodriguez-Sierra JF, et al. Monosodium glutamate disruption of behavioral and endocrine function in the female rat. Neuroendocrinology. 1980;31(3):228-35.

Sabuhi R, et al. Role of the angiotensin II AT2 in inflammation and oxidative stress: opposing effects in lean and obese Zucker rats. Am J Physiol Renal Physil. 2011; 300:F700-F6.

Saltiel AR, Kahn CR. Insulin signalling and the regulation of glucose and lipid metabolism. Nature. 2001;414:799-806.

Sánchez A, et al. Altered arachidonic acid metabolism via COX-1 and COX-2 contributes to endothelial dysfunction of penile arteries from obese Zucker rats. $\mathrm{Br} \mathrm{J}$ Pharmacol. 2010;159(3):604-16.

Schiffrin EL. Oxidative stress, nitric oxide synthase, and superoxide dismutase: a matter of imbalance underlies endothelial dysfunction in the human coronary. Hypertension. 2008;51:31-2.

Seger R, Krebs EG. The MAPK signaling cascade. FASEB J. 1995;9(9):726-35.

Siddiqui $A H$, Hussain $T$. Enhaced AT1 receptor-mediated vasocontractile response to ANG II in endothelium-denuded aorta of obese Zucher rats. Am J Physiol Heart Circ Physiol. 2007;292:H722-H7.

Sprague $\mathrm{AH}$, Khalil RA. Inflamatory cytokines in vascular dysfunction and vascular disease. Biochem Pharmacol. 2009;15:78(6):539-52.

Staples CJ, et al. Cross-talk between the p38alpha and JNK MAPK pathways mediated by MAP kinase phosphatase-1 determines cellular sensitivity to UV radiation. J Biol Chem. 2010;285(34):25928-40.

Steckelings UM, et al., The AT2 receptor - a matter of love and hate. Peptides. 2005; 26:1401-9.

Steinberg $\mathrm{HO}$, Chaker $\mathrm{H}$, Leaming $\mathrm{R}$, et al. Obesity/insulin resistance is associated with endothelial dysfunction. J Clin Invest. 1996;97:2601-10. 
Stroth U, Blume A, Mielke K, et al. Angiotensin AT2 receptor stimulates ERK1 and ERK2 in quiescent but not inhibits ERK in NGF-stimulated PC12W cells. Brain Res Mol Brain Res. 2000;78(1-2):175-80.

Szasz T, Webb RC. Perivascular adipose tissue: more than just structural support. Clinical Science. 2012;122:1-12.

Toda N, et al. Interaction of endothelial nitric oxide and angiotensin in the circulation. Pharmacol Rev. 2007;59:54-9.

Tokarev D, et al. Treatment of neonatal rats with monossodium glutamate attenuates the cardiovascular reactivity to phenylephrine and angiotensin II. Physiol Res. 1997;46(3):165-71.

Toledo DP. Estudo da resposta inflamatória aguda e crônica e reatividade microvascular em modelo de resistência à insulina (obesidade em ratos). 2005. Tese de doutorado. Instituto de Ciências Biomédicas, Universidade de São Paulo.

Touyz RM e Schiffrin EL. Signal transduction mechanisms mediating the physiological and pathophysiological actions of angiotensin II in vascular smooth muscle cells. 2000; 52:639-72.

Touyz RM, He G, Deng Ly, Schiffrin EL. Role of extracellular signal-regulated kinases in angiotensin II-stimulated contraction of smooth muscle cells from human resistance arteries. Circulation. 1999;99:392-9.

Tunctan B, et al. Inhibition of extracellular signal-regulated kinase (ERK1/2) activity reverses endotoxin-induced hypotension via decreased nitric oxide production in rats. Pharmacol Res. 2007;56(1):54-6.

Verlohren S, Dubrovska G, Tsang SY, et al. Visceral periadventitial adipose tissue regulates arterial tone of mesenteric arteries. Hypertension. 2004;44:271-6.

Wang $\mathrm{X}$, et al. LOX-1 and angiotensin receptors, and their interplay. Cardiovasc Drugs Ther. 2011; 25:401-17.

Weiss R. Fat distribution and storage: how much, where, and how? Eur J Endocrinol. 2007;157(1):S39-S45.

Wilcox G Insulin and insulin resistance. Clin Biochem Rev. 2005;26:19-27.

Wild S, Roglic G, Green A, et al. Global prevalence of diabetes: estimates for the year 2000 and projections for 2030. Diabetes Care. 2004;27:1047-53.

$\mathrm{Xu} Z$ et al. Upregulation of angiotensin II type 1 receptor, inflamatory mediators, and enzymes of arachidonate metabolism in obese Zucker rats kidney: reversal by angiotensin II type 1 receptor blockade. Circulation. 2005;111:1962-9.

Yvan-Charvet L, Quignard-Boulange A. Role of adipose tissue rennin-angiotensin system in metabolic and inflammatory diseases associated with obesity. Hidney International. 2011; 79:162-8. 
Zheng $\mathrm{J}$ et al. Angiotensin II elevates nitric oxide synthase 3 express and nitric oxide production via a mitogen-activated protein kinase cascade in ovine fetoplacental artery endothelial cells. Biol Reprod. 0005;72:1421-8.

Zhou MS, Shulman IH, Chadipiralla K, et al. Role of $\mathrm{c}$-jun n-terminal kinase in the regulation of vascular tone. J Cardiovasc Pharmacol Ther. 2010;15(1):78-83.

Zimet P, et al. Global and societal implications of the diabetes epidemic. Nature. 2001;414:782-7. 
ANEXO A: Lobato NS, Filgueira FP, Hagihara GN, Akamine EH, Pariz JR, Tostes RC, Carvalho MHC, Fortes ZB. Improvement of metabolic parameters and vascular function by metformin in obese nondiabetic rats. Life Sci. 2012;90:228-35. 


\title{
Improvement of metabolic parameters and vascular function by metformin in obese non-diabetic rats
}

\author{
N.S. Lobato ${ }^{\text {a,b }}$, F.P. Filgueira ${ }^{\text {a }}$, G.N. Hagihara ${ }^{\text {a }}$, E.H. Akamine ${ }^{\text {a }}$, J.R. Pariz ${ }^{\text {a }}$, R.C. Tostes ${ }^{\text {a,c }}$, \\ M.H.C. Carvalho ${ }^{a}$, Z.B. Fortes ${ }^{a}, *$ \\ a Department of Pharmacology, Institute of Biomedical Sciences, University of Sao Paulo, Sao Paulo, Brazil \\ ${ }^{\mathrm{b}}$ Department of Biological Sciences, University of Goias, Jatai, Brazil \\ c Department of Pharmacology, University of Sao Paulo, Ribeirao Preto, Brazil
}

\section{A R T I C L E I N F O}

\section{Article history:}

Received 3 August 2011

Accepted 14 November 2011

Keywords:

Obesity

Metformin

Monosodium glutamate

Vascular dysfunction

\begin{abstract}
A B S T R A C T
Aims: Metformin is an insulin sensitizing agent with beneficial effects in diabetic patients on glycemic levels and in the cardiovascular system. We examined whether the metabolic changes and the vascular dysfunction in monosodium glutamate-induced obese non-diabetic (MSG) rats might be improved by metformin. Main methods: 16 week-old MSG rats were treated with metformin for 15 days and compared with agematched untreated MSG and non-obese non-diabetic rats (control). Blood pressure, insulin sensitivity, vascular reactivity and prostanoid release in the perfused mesenteric arteriolar bed as well as nitric oxide production and reactive oxygen species generation in isolated mesenteric arteries were analyzed.

Key findings: 18-week-old MSG rats displayed higher Lee index, fat accumulation, dyslipidemia, insulin resistance and hyperinsulinemia. Metformin treatment improved these alterations. The norepinephrine-induced response, increased in the mesenteric arteriolar bed from MSG rats, was corrected by metformin. Indomethacin corrected the enhanced contractile response in MSG rats but did not affect metformin effects. The sensitivity to acetylcholine, reduced in MSG rats, was also corrected by metformin. Indomethacin corrected the reduced sensitivity to acetylcholine in MSG rats but did not affect metformin effects. The sensitivity to sodium nitroprusside was increased in preparations from metformin-treated rats. Metformin treatment restored both the reduced PGI2/TXA2 ratio and the increased reactive oxygen species generation in preparations from MSG rats.

Significance: Metformin improved the vascular function in MSG rats through reduction in reactive oxygen species generation, modulation of membrane hyperpolarization, correction of the unbalanced prostanoids release and increase in the sensitivity of the smooth muscle to nitric oxide.
\end{abstract}

(c) 2011 Elsevier Inc. All rights reserved.

\section{Introduction}

Obesity represents a major public health problem (Hill, 2006). This condition is associated with increased risk of type 2 diabetes (Goran et al., 2003). Epidemiological and observational studies have shown that overweight/obese individuals tend to be insulin resistant and become more insulin sensitive with weight loss (Lionetti et al., 2009). These findings suggest that insulin resistance is the link between obesity and the related clinical syndromes, such as type 2 diabetes.

Obesity is associated with endothelial dysfunction (Stapleton et al., 2008), which in turn can be considered the first step in the progression of cardiovascular diseases (Lerman and Zeiher, 2005). A

\footnotetext{
* Corresponding author at: Department of Pharmacology, Institute of Biomedical Sciences, University of Sao Paulo, Sao Paulo 05508-900, Brazil. Tel./fax: +55 113091 7317.

E-mail address: zbfortes@icb.usp.br (Z.B. Fortes).
}

number of experimental and clinical studies have consistently demonstrated impaired arterial function manifested by reduced endothelium-dependent vasodilatation in obesity (Tziomalos et al., 2010; Lobato et al., 2010; Zalesin et al., 2008). We have previously demonstrated that obesity induced by monosodium glutamate (MSG) impairs microvascular reactivity in rats. An altered ability of the endothelium to maintain the vascular homeostasis through the release of endothelium-derived relaxing factors (EDRFs) and endothelium-derived contracting factors (EDCFs) was demonstrated in MSG-induced obese rats (Lobato et al., 2010).

The biguanide metformin (dimethylguanidine) is one of the most commonly used drugs for type 2 diabetes treatment (Nathan et al., 2006). There are evidences for a potential role of metformin in the prevention of type 2 diabetes in obese patients (Diabetes Prevention Program Research Group, 2002). Metformin has also been associated with reduction in the progression of the cardiovascular repercussions of obesity (UKPDS, 1998; Kurukulasuriya et al., 1999; Grant, 2003). Therefore, we hypothesized that metformin could have beneficial 
effects on the vascular function in obesity independently of the presence of a diabetic condition. Considering that obesity and insulin resistance impair the vascular function before the onset of type 2 diabetes (Goran et al., 2003; Lobato et al., 2010), the aim of the present study was to investigate the effects of metformin on metabolic and vascular alterations in obesity. We used non-diabetic MSG obese rats, that manifests obesity and vascular dysfunction (Lobato et al., 2010), providing a suitable model to investigate the effects of metformin in obesity before the onset of diabetes.

\section{Methods}

\section{Animals}

The investigation was approved by the Ethical Committee for Animal Research of the Institute of Biomedical Sciences, University of Sao Paulo (Protocol no. 007/04), conformed to the Guide for the Care and Use of Laboratory Animals published by the US National Institutes of Health (NIH Publication No. 85-23, revised 1996). Male Wistar rats received subcutaneous injections of MSG [4.0 g/ $\mathrm{kg}$ body weight; Sigma-Aldrich, Germany] dissolved in $0.9 \% \mathrm{NaCl}$ (MSG rats) or an equivalent volume of vehicle (control rats), from the second to the sixth day after birth. The breeding conditions were followed as previously described (Akamine et al., 2006).

After 16 weeks, rats from the MSG group were divided into two subgroups: 1 - rats from this subgroup received a daily dose of metformin (300 $\mathrm{mg} / \mathrm{kg}$, for 15 days), by gavage; 2 - rats from this subgroup received the same volume of vehicle (water) by the same route and for the same period, and will be identified as MSG rats. All experimental groups were studied at 18 weeks of age.

Assessment of water and food consumption was performed by placing the animals in metabolic cages. Rats were acclimated for $72 \mathrm{~h}$ and data were collected over the next $24 \mathrm{~h}$.

\section{Blood pressure - tail-cuff method}

Blood pressure (BP) was measured in unanesthetized animals by an indirect tail-cuff method (PowerLab 4/S, ADInstruments, Australia). Rats were maintained at $37^{\circ} \mathrm{C}$ for $10 \mathrm{~min}$, and then three consecutive stable measurements were averaged.

\section{Intravenous insulin tolerance test}

Tail blood samples were collected before ( $0 \mathrm{~min}$ ) and 4, 8, 12 and $16 \mathrm{~min}$ after an intravenous injection of regular insulin $(0.75 \mathrm{U} / \mathrm{kg}$ b.w., Biobras, Brazil). The constant rate for blood glucose disappearance during the Insulin Tolerance Test (kITT) was calculated based on the linear regression of the neperian logarithm of blood glucose concentrations obtained during the test.

\section{Blood biochemical assays}

For biochemical assays, rats were submitted to food deprivation $(5 \mathrm{~h})$ and weighted. After sodium thiopental $(50 \mathrm{mg} / \mathrm{kg}$, intraperitoneally, Cristália, Brazil) anesthesia and laparotomy, blood samples were taken from the descending aorta. Glucose levels and the lipid profile were assessed spectrophotometrically using colorimetric method (Celm, Brazil). Insulin was determined using radioimmunoassay (Linco, USA). The Homeostasis Model Assessment (HOMA-IR), an index of insulin resistance (Matsuda, 2010), was calculated from glucose and insulin levels, using the equation: HOMA-IR = fasting insulin (in $\mu \mathrm{U} / \mathrm{mL}$ ) $\times$ fasting glucose (in $\mathrm{mmol} / \mathrm{L}$ ) $/ 22.5$. The Lee's obesity index was calculated as follows: body weight ${ }^{1 / 3}(\mathrm{~g}) /$ nasal-anal length $(\mathrm{cm}) \times 100$. Visceral adipose tissue (periepididymal and retroperitoneal) and the lean mass (soleus and extensor digitorum longus) were removed from each animal. The tissues were weighted after dissection and separation from vessels and other connective tissues.

\section{Vascular reactivity in the perfused mesenteric arteriolar bed}

The perfused mesenteric arteriolar bed was prepared as previously described (Lobato et al., 2010). Under anesthesia, the abdominal cavity was opened and a polyethylene cannula was inserted into the superior mesenteric artery. The whole preparation was cut close to the intestinal border and transferred to an organ bath at $37^{\circ} \mathrm{C}$ and perfused at a constant flow rate $(2 \mathrm{~mL} / \mathrm{min})$ by a peristaltic pump with Krebs-Henseleit solution (pH 7.4) containing $5 \% \mathrm{CO}_{2}$ and $95 \%$ $\mathrm{O}_{2}$. The composition of the solution was (in $\mathrm{mM}$ ): $\mathrm{NaCl} 130.0, \mathrm{KCl}$ 4.7, $\mathrm{CaCl}_{2}$ 1.6, $\mathrm{NaHCO}_{3}$ 14.9, $\mathrm{MgSO}_{4} 1.17, \mathrm{KH}_{2} \mathrm{PO}_{4} 1.18$, EDTA disodium salt 0.026 and glucose 5.5. Vascular responses were evaluated as changes in the perfusion pressure, measured with a pressure transducer (BP Transducer, ADInstruments, Australia) and recorded on a digital acquisition system (Power Lab, ADInstruments).

After a 45-min equilibration period, concentration-effect curves to norepinephrine $(\mathrm{NE}, 0.1-100 \mu \mathrm{M})$, potassium chloride $(\mathrm{KCl}$, 5-225 mM), a direct acting smooth muscle contracting agent, acetylcholine (ACh, 0.001-30 $\mu \mathrm{M}$ ), an endothelium-dependent vasodilator, and sodium nitroprusside (SNP, 0.001-10 $\mu \mathrm{M}$ ), a NO donor, were obtained. All curves were performed in the presence of desipramine (inhibitor of NE uptake, $10 \mathrm{nM}$ ). The vasodilator responses to ACh and SNP were determined in NE-contracted preparations in a concentration that produced $80 \%$ of the maximal contractile response.

In order to determine the role of NO, prostanoids and EDHF on the $\mathrm{NE}$ and ACh responses, N $\omega$-Nitro-L-arginine Methyl Ester (L-NAME, $100 \mu \mathrm{M})$, a NO synthase inhibitor, indomethacin $(10 \mu \mathrm{M})$, a cyclooxygenase (COX) inhibitor, or tetraethylammonium (TEA, 2 mM), a nonselective $\mathrm{K}^{+}$-channel blocker, were used. Each drug was added to the perfusing solution $30 \mathrm{~min}$ before the concentration-effect curves were performed and was maintained throughout the experiment. The concentrations of the agents used were based on the data in the literature (Lobato et al., 2010).

\section{Prostanoid release measurements}

The isolated mesenteric arteriolar bed was allowed to equilibrate for $30 \mathrm{~min}$. The ability of the preparations to release $\mathrm{TXA}_{2}$ (estimated from measurements of 11-dehydro- $\mathrm{TXB}_{2}$ ) and $\mathrm{PGI}_{2}$ (estimated from measurements of 6 -keto- $\mathrm{PGF}_{1 \alpha}$ ) was assessed in $1 \mathrm{~mL}$ samples of perfusate collected before and after stimulation with $\mathrm{NE}$ $(100 \mathrm{nM})$ or ACh (30 nM) using enzyme immunoassay kits (Cayman Chemical, USA).

\section{Measurement of nitric oxide production in mesenteric arteries}

Nitric oxide (NO) production was determined using 4,5-diaminofluorescein diacetate (DAF-2), a NO-sensitive fluorescent dye (Lobato et al., 2010). Mesenteric arteries were dissected, embedded in a freezing medium and frozen. Transverse arteriolar cryostat sections $(20 \mu \mathrm{m})$ were collected on glass slides and incubated at $37^{\circ} \mathrm{C}$ with $8 \mu \mathrm{M}$ DAF-2 in phosphate buffer $(0.1 \mathrm{M}, \mathrm{pH} 7.4)$ containing $\mathrm{CaCl}_{2}$ $(0.45 \mathrm{mM})$. After $30 \mathrm{~min}$, the sections were stimulated with $\mathrm{ACh}$ $(100 \mu \mathrm{M})$ in the absence/presence of $\mathrm{BH}_{4}(1 \mu \mathrm{M})$. Digital images were collected on a microscope (Carl Zeiss, Germany) equipped for epifluorescence and with a fluorescein filter. The images were analyzed with the Image software (KS-300, Zeiss) by measuring the mean optical density of the fluorescence in the endothelium.

\section{Reactive oxygen species generation in mesenteric arteries}

Reactive oxygen species (ROS) generation was determined by hydroethidine (Lobato et al., 2010). Transverse mesenteric arteries 
were obtained as described for measurement of NO production and incubated at $37^{\circ} \mathrm{C}$ with hydroethidine $(2.5 \mu \mathrm{M})$ in phosphate buffer (0.1 M, pH 7.4). Images were collected on a microscope equipped for epifluorescence and with a rhodamine filter. The mean optical density of the fluorescence in the vessel wall was measured. To evaluate superoxide $\left(\mathrm{O}_{2}^{-}\right)$production and the participation of NOS in the ROS generation, mesenteric arteries were treated with SOD $(150 \mathrm{IU} / \mathrm{mL})$ or L-NAME $(100 \mu \mathrm{M})$, respectively, $30 \mathrm{~min}$ before the tissues were frozen.

\section{Drugs}

Metformin (Glifage ${ }^{\circledR}$ ) was purchased from Merck (Rio de Janeiro, Brazil); MSG, NE, ACh, desipramine, sodium nitroprusside, indomethacin, L-NAME, SOD and TEA were purchased from Sigma Chemical (USA); Hydroethidine was purchased from Polysciences (USA) and DAF-2 was purchased from Alexis (USA).

\section{Data analyses}

Contraction is expressed as the $\mathrm{KCl}$ - and NE-induced perfusion pressure subtracted from the baseline pressure, and vasodilatation is represented as a percentage of the maximal response to NE. $\mathrm{pD}_{2}$ $\left(-\log \mathrm{EC}_{50}\right)$ and the maximum response $\left(\mathrm{R}_{\mathrm{MAX}}\right)$ were calculated by non-linear regression analysis. Data are represented as mean \pm SEM and compared by one-way ANOVA. p Values less than 0.05 were considered significant.

\section{Results}

\section{General characteristics of metformin-treated rats}

General and biochemical characteristics of the different groups are presented in Table 1 . The food intake was not different among groups. The higher Lee index and fat mass weight found in MSG rats were significantly reduced by metformin treatment. The lean mass weight of metformin-treated MSG rats was not different from that of control rats or from MSG rats. The levels of cholesterol,

Table 1

General characteristics of monosodium glutamate-induced obese rats subjected to metformin treatment.

\begin{tabular}{lccc}
\hline Parameter & Control $(\mathrm{n}=10)$ & MSG $(\mathrm{n}=10)$ & MSG-MET $(\mathrm{n}=10)$ \\
\hline Lee index $(\times 100)$ & $29.5 \pm 0.15$ & $31.1 \pm 0.22^{*}$ & $30.2 \pm 0.15^{*}, \#$ \\
Retroperitoneal & $1.0 \pm 0.07$ & $3.0 \pm 0.1^{*}$ & $2.1 \pm 0.1^{*}, \#$ \\
$\quad$ WAT $(\mathrm{g} / 100 \mathrm{~g})$ & & \\
Periepididymal & $1.2 \pm 0.04$ & $2.8 \pm 0.1^{*}$ & $1.9 \pm 0.08^{*}, \#$ \\
$\quad$ WAT $(\mathrm{g} / 100 \mathrm{~g})$ & & \\
Soleus muscle $(\mathrm{g} / 100 \mathrm{~g})$ & $0.04 \pm 0.001$ & $0.04 \pm 0.001$ & $0.04 \pm 0.001$ \\
EDL muscle $(\mathrm{g} / 100 \mathrm{~g})$ & $0.04 \pm 0.001$ & $0.03 \pm 0.002$ & $0.04 \pm 0.001$ \\
Food intake $(\mathrm{g} / 100 \mathrm{~g} / \mathrm{day})$ & $6.1 \pm 0.2$ & $6.3 \pm 0.2$ & $6.18 \pm 0.1$ \\
Water intake & $8.1 \pm 0.1$ & $8.3 \pm 0.1$ & $8.3 \pm 0.2$ \\
$\quad(\mathrm{~mL} / 100 \mathrm{~g} / \mathrm{day})$ & & & \\
Total cholesterol $(\mathrm{mg} / \mathrm{dL})$ & $74.8 \pm 4.2$ & $108.7 \pm 8.0^{*}$ & $59.8 \pm 3.1^{\#}$ \\
Triacylglycerols $(\mathrm{mg} / \mathrm{dL})$ & $40.7 \pm 8.0$ & $124.7 \pm 9.9^{*}$ & $68.6 \pm 10.0^{\#}$ \\
LDL-cholesterol $(\mathrm{mg} / \mathrm{dL})$ & $48.5 \pm 2.9$ & $78.0 \pm 4.6^{*}$ & $50.6 \pm 6.1^{\#}$ \\
VLDL-cholesterol $(\mathrm{mg} / \mathrm{dL})$ & $7.6 \pm 1.5$ & $24.4 \pm 2.0^{*}$ & $10.6 \pm 2.6^{\#}$ \\
HDL-cholesterol $(\mathrm{mg} / \mathrm{dL})$ & $43.4 \pm 1.9$ & $18.5 \pm 2.1^{*}$ & $53.5 \pm 3.1^{*}, \#$ \\
Glucose $(\mathrm{mg} / \mathrm{dL})$ & $121.0 \pm 3.2$ & $120.1 \pm 5.5$ & $118.1 \pm 2.8$ \\
Insulin $(\mathrm{ng} / \mathrm{mL})$ & $2.5 \pm 0.2$ & $5.9 \pm 0.4^{*}$ & $3.0 \pm 0.2^{\#}$ \\
$k$ ITT $(\% / m i n)$ & $3.9 \pm 0.20$ & $2.3 \pm 0.1^{*}$ & $4.1 \pm 0.09^{*}, \#$ \\
HOMA-IR index & $15.5 \pm 1.5$ & $36.2 \pm 2.6^{*}$ & $17.9 \pm 1.3^{*}, \#$ \\
Blood pressure $(\mathrm{mm} \mathrm{Hg})$ & $115.5 \pm 1.8$ & $122.3 \pm 2.3$ & $117.9 \pm 1.6$ \\
\hline
\end{tabular}

Values are mean \pm SEM; WAT, white adipose tissue; EDL, extensor digitorum longus; LDL, low density lipoprotein; kITT, constant rate for blood glucose disappearance; HOMA-IR, homeostasis model assessment-insulin resistance; n, number of animals tested. * $\mathrm{p}<0.05$ vs. control.

\# $\mathrm{p}<0.05$ vs. MSG. triglycerides and low density lipoprotein (LDL) cholesterol, increased in MSG rats, were restored to the control levels after metformin treatment. In addition, metformin treatment promoted increase in high density lipoprotein (HDL) cholesterol, restoring the levels of this lipoprotein to values observed in control rats. Although similar serum glucose levels were found among groups, MSG rats displayed enhanced HOMA-IR index, and hyperinsulinemia. Metformin treatment restored these parameters to values observed in control rats. No difference in BP levels was found among groups.

\section{Vascular reactivity in the mesenteric arteriolar bed}

Similar basal perfusion pressure was found in preparations from all experimental groups (around $20 \mathrm{~mm} \mathrm{Hg}$ ). Metformin treatment did not alter the contractile response induced by $\mathrm{KCl}$ (in $\mathrm{mm} \mathrm{Hg}$, control $=75.2 \pm 4.1$, MSG $=76.2 \pm 5.7$, MSG-Met = 78.6 \pm 6.1 ). However, the vasoconstrictor response to NE, significantly increased in MSG rats, was corrected by metformin (Fig. 1A). Perfusion of the mesenteric arteriolar bed with Krebs-Henseleit solution containing L-NAME or TEA for 30 min further increased the response to NE in all experimental groups (Fig. 1B and C). Indomethacin corrected the enhanced contractile response to NE in MSG rats. The effect of metformin correcting the enhanced contractile response observed in MSG rats was not altered by indomethacin (Fig. 1D).

Metformin treatment restored the reduced sensitivity (lower pD2) to ACh observed in the mesenteric arteriolar bed from MSG rats. Perfusion of the preparations with L-NAME decreased the maximum response to ACh in all experimental groups (Fig. 2B). Perfusion with TEA decreased significantly the maximal vasodilator response to ACh in MSG rats. On the other hand, in preparations from metformin-treated rats, similar to that observed in control rats, TEA did not reduce the response to ACh (Fig. 2C). The sensitivity to ACh in the mesenteric arteriolar bed from control rats was not modified by indomethacin $\left(\mathrm{pD}_{2}\right.$, control $=7.7 \pm 0.1$, Control + Indo $=7.6 \pm 0.2$, Fig. 2D), however, in MSG rats this agent was able to correct the reduced sensitivity to ACh (MSG $=7.0 \pm 0.1, \mathrm{MSG}+$ Indo $=7.8 \pm 0.05, \mathrm{p}<0.05 \mathrm{vs}$. respective group in the absence of the inhibitor, Fig. 2D). In preparations from metformin-treated rats, similar to that observed in control rats, the response to ACh was not affected by perfusion with indomethacin (MSG-MET $=7.6 \pm 0.1$, $\mathrm{MET}+$ Indo $=7.9 \pm 0.1$, Fig. 2D).

The mesenteric arteriolar bed from metformin-treated rats was more sensitive (lower $\mathrm{EC}_{50}$, represented by $\mathrm{pD} 2$ values) to SNP when compared to both MSG and control preparations $(\mathrm{pD} 2, \quad$ control $=6.6 \pm 0.1, \quad \mathrm{MSG}=6.5 \pm 0.2, \quad$ MSG-MET $=7.1 \pm 0.1$, $\mathrm{p}<0.05$, Fig. 2E).

\section{Prostanoid release from the mesenteric arteriolar bed}

Metformin treatment restored the reduced $\mathrm{PGI}_{2} / \mathrm{TXA}_{2}$ ratio observed in unstimulated, NE- and ACh-stimulated preparations from MSG rats (Fig. 3).

\section{Measurement of nitric oxide production in mesenteric arteries}

The reduced basal and ACh-stimulated NO production found in arteries from MSG rats was not affected by metformin treatment (Fig. 4). The addition of exogenous $\mathrm{BH}_{4}$, an $\mathrm{NO}$ synthase cofactor that enhances NO production or L-NAME, an NO synthase inhibitor, to preparations from MSG rats and MSG-MET rats stimulated with ACh, fully corrected NO production (Fig. 4).

\section{Superoxide anion generation in mesenteric arteries}

The increased ROS generation observed in mesenteric arteries from MSG rats was corrected by metformin treatment. The incubation 
A

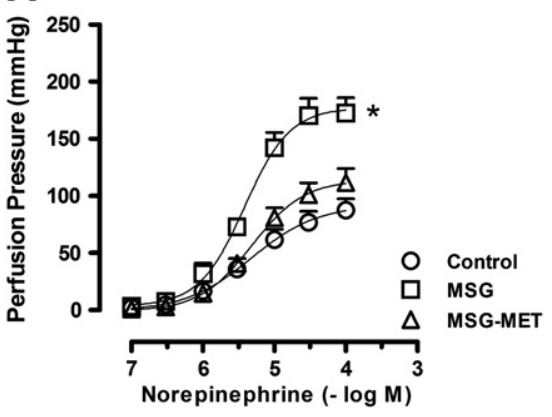

C

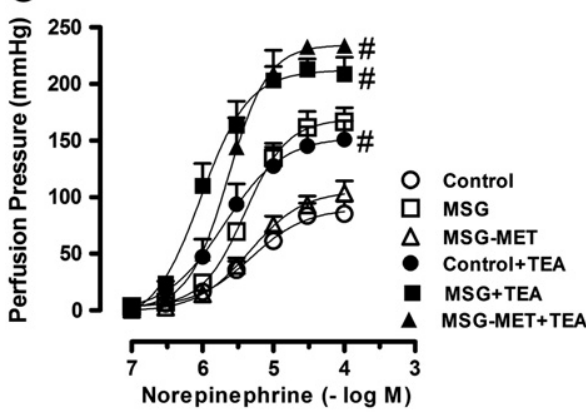

B
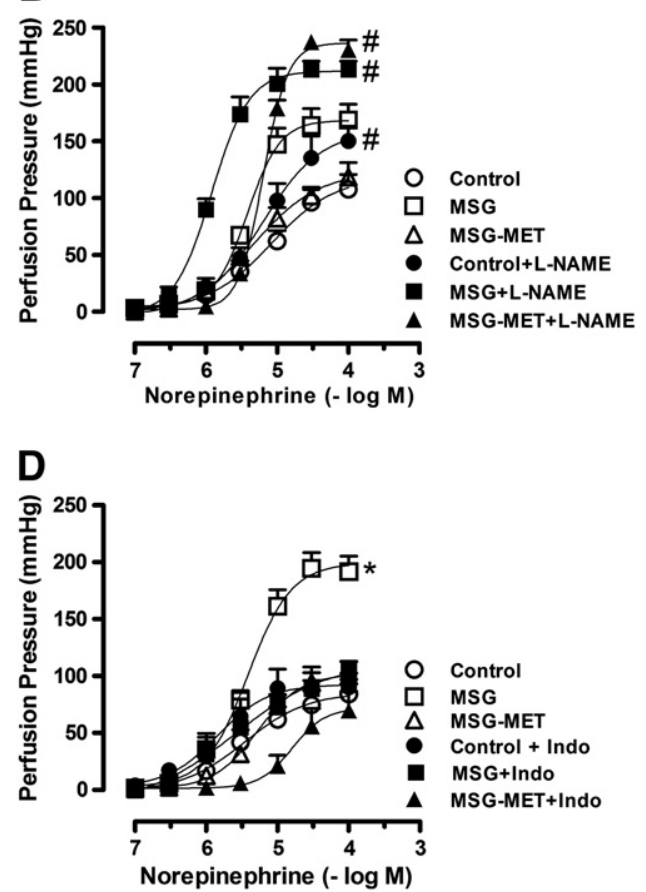

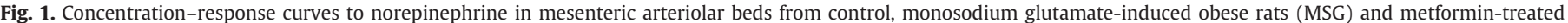

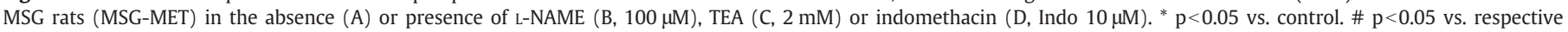
group in the absence of blockade. Perfusion pressure increase is presented as the mean \pm S.E.M of eight independent experiments.

with L-NAME or SOD reduced the ROS generation in MSG rats to values similar to those obtained in MSG-MET rats (Fig. 5).

\section{Discussion}

In the present study we demonstrated that metformin had beneficial effects in non-diabetic MSG rats correcting the insulin resistance, the hyperinsulinemia and the altered lipid profile. We also demonstrated that metformin treatment was associated with reduction in Lee Index as well as in visceral fat accumulation. Previous studies performed in both humans or in experimental models of type 2 diabetes have demonstrated improvement of metabolic parameters as well as reduction in body weight after metformin treatment (Diabetes Prevention Program Research Group, 2002; UKPDS, 1998; Hundal et al., 2000), reinforcing the potential role of this drug as an early therapeutic intervention to prevent the development of the comorbidities associated with type 2 diabetes.

Oral treatment with metformin led to a decrease in Lee index, an accurate Index that correlates highly with body fat. This effect is not related to the food intake since we did not observe difference in this parameter among groups. Metformin is widely recognized to have either little effect on body weight or to facilitate modest weight loss in type 2 diabetic patients (UKPDS, 1998; Hundal et al., 2000). Similarly, metformin has shown to induce weight loss in obese non-diabetic individuals (Nichols and Gomez-Caminero, 2007; Glueck et al., 2001), although long duration studies in this population are scarce. The weight loss by metformin treatment in diabetic patients has been related to reduction in fat mass (Kurukulasuriya et al., 1999). Accordingly, we observed that metformin treatment was able to reduce the fat accumulation observed in MSG rats along with reduction in the Lee Index, an accurate index that determines the body mass gain corrected by the length.

Metformin had also advantageous effects on lipid profile besides its effects on whole-body insulin sensitivity in MSG rats. In type 2 diabetic patients the correction of the dyslipidemia after metformin treatment has been associated with decreased synthesis and increased clearance of VLDL. This may provide an indirect mechanism by which metformin improves the metabolic changes in these patients as described by Wiernsperger and Bailey (1999). Considering that fat accumulation can contribute to changes of lipid profile in obesity by increasing the release of free fatty acids (FFAs), the effect of metformin reducing visceral fat and its insulin sensitizer effect in MSG rats might contribute to the correction of the dyslipidemia observed. Another notable effect of metformin was the increase in HDL cholesterol levels in MSG rats. Even in patients, it has been shown that metformin increases HDL cholesterol levels in overweight, diet-controlled type 2 diabetic patients (Lawrence et al., 2004). Low fasting plasma HDL cholesterol has been reported to be associated with insulin resistance (Abbasi et al., 1999). Based on this, the correction of the insulin resistance after metformin treatment might also be involved in the increase of HDL cholesterol in MSG rats.

A substantial amount of evidence has consistently demonstrated that obesity is closely related to impaired endothelial function either in animals (Lobato et al., 2010), or in patients (Stapleton et al., 2008; Lerman and Zeiher, 2005; Tziomalos et al., 2010). Considering that metformin has beneficial effects on vascular function in type 2 diabetes (Bailey, 2008), we evaluated in metformin-treated MSG rats, the endothelium-dependent vasodilator response, tested with $\mathrm{ACh}$, and the vasoconstriction induced by $\mathrm{NE}$, that has its response negatively modulated by the endothelium. In fact, metformin promoted beneficial effects in MSG rats correcting the increased response to NE and the lower response to ACh observed in the mesenteric arteriolar bed.

Endothelial dysfunction is usually associated with reduction in NO production and/or increase in NO metabolism (Feletou and Vanhoutte, 2006). It has been suggested that the vasculoprotective effects of metformin are mainly due to improvement of NO signaling (Bailey, 2008). Interestingly, an important finding in our study was that the correction of the endothelial dysfunction with metformin treatment in MSG rats is not due to improvements in NO signaling. This is supported by the fact that metformin did not correct the reduced endothelium-dependent NO production in mesenteric arteries from MSG rats. 
A
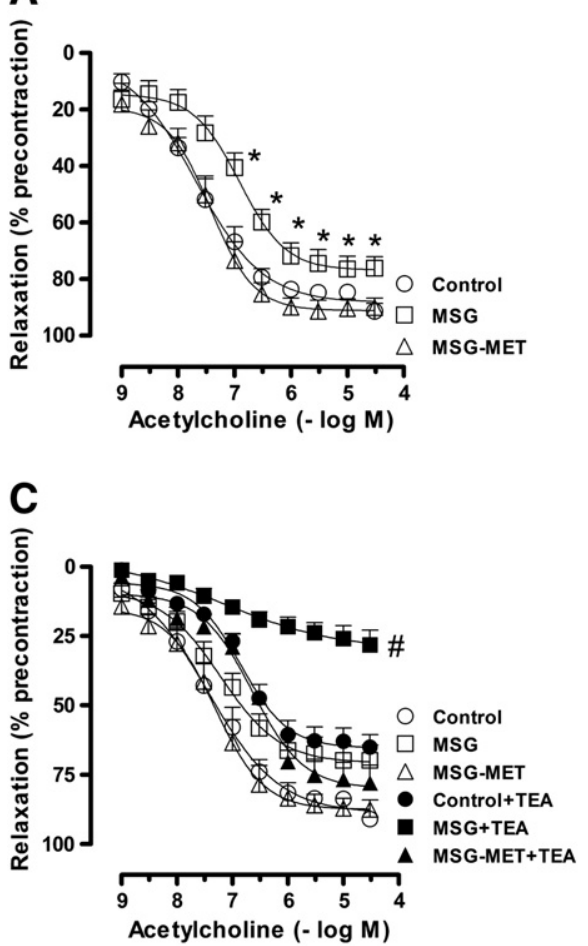

B

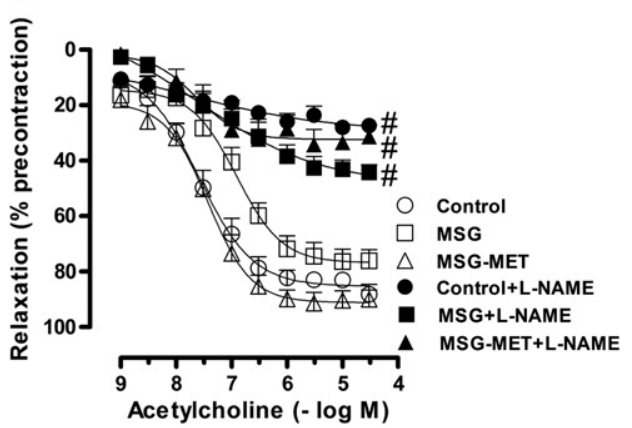

D

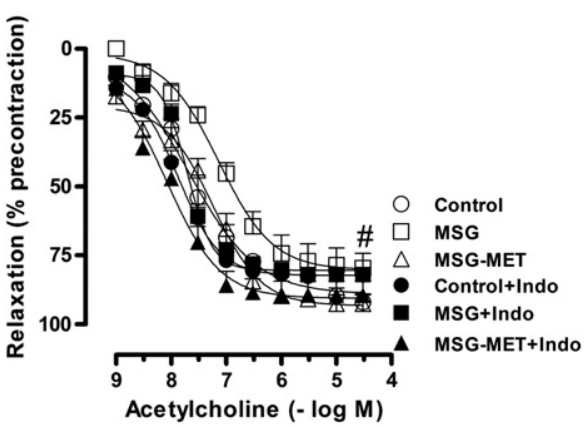

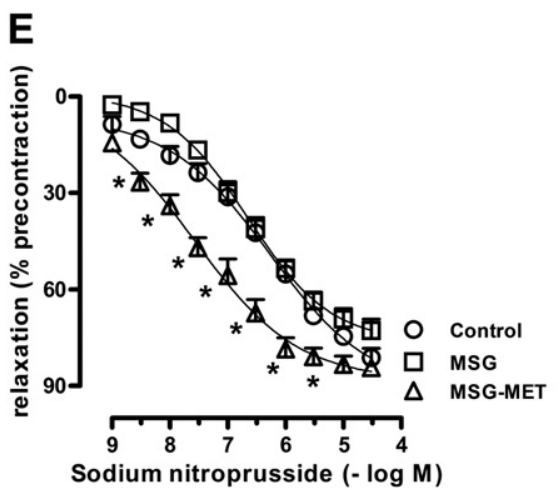

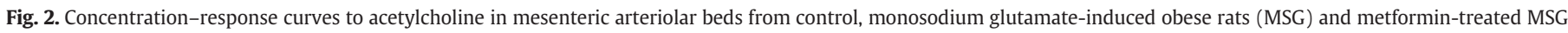

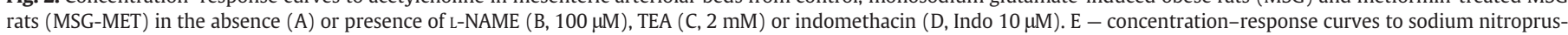

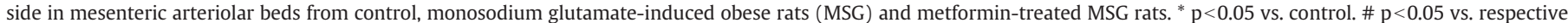
group in the absence of blockade. Relaxation (measured by percentage of contraction reduction) is presented as the mean \pm S.E.M of eight independent experiments.

It is well documented that endothelial NO synthase (eNOS) uncoupling, a process in which eNOS generates $\mathrm{O}_{2}^{-}$instead of NO when the concentrations of either L-arginine, the substrate of NOS, or tetrahydrobiopterin (BH4), a cofactor of the enzyme, are depleted, may mediate decrease in NO bioavailability (Förstermann and Münzel, 2006). $\mathrm{O}_{2}^{-}$generation can be involved in the reduction of endothelium-dependent vasodilatation, by impairing NO bioavailability (Hopps et al., 2010). We have previously demonstrated uncoupling of eNOS in mesenteric arteries from 16-week-old MSG rats (Lobato et al., 2010). In 18-week-old MSG rats, incubation of mesenteric arteries with $\mathrm{BH}_{4}$ corrected the reduced $\mathrm{NO}$ production. Furthermore, the treatment of these arteries with either SOD, an $\mathrm{O}_{2}^{-}$ scavenger or L-NAME, a NOS inhibitor, reduced ROS generation, confirming the role of eNOS as a source of $\mathrm{O}_{2}^{-}$production. Interestingly, although metformin did not correct the reduced NO production in MSG rats, it exerted an antioxidant effect by decreasing the $\mathrm{O}_{2}^{-}$production. Taking the above findings together, we speculate that metformin's beneficial effects on endothelial dysfunction in MSG rats may be at least partly due to the suppression of the oxidative stress. The antioxidant effect of metformin has been demonstrated in previous studies (Gallo et al., 2005; Mahrouf et al., 2006; Ouslimani et al., 2005); however, the role of it on the beneficial effects of metformin in obesity has not been described before.

In the present study, an additional mechanism involved in metformin effects appears to be the modulation of membrane hyperpolarization. The substantial decrease of the ACh-induced relaxation after perfusion of the mesenteric arteriolar bed from MSG rats with TEA, $\mathrm{a} \mathrm{K}^{+}$channel blocker, revealed the major participation of the hyperpolarization for the vasodilator response, which could be a compensatory mechanism for the reduced NO production observed in this model. The correction of this alteration might be suggested in our study, since TEA was not able to decrease the ACh-induced response in metformin-treated rats, similarly to that observed in control rats.

Accumulating evidences suggest that alterations in the production/release of prostanoids by the endothelium directly contribute to the endothelial dysfunction in vascular diseases (Yuhki et al., 2010; Iñiguez et al., 2008). In fact, the increased vasoconstriction and the reduced vasodilatation in MSG rats were corrected after COX inhibition. Additionally, MSG rats displayed decreased $\mathrm{PGI}_{2} / \mathrm{TX}_{2}$ ratio in the mesenteric arteriolar bed. Therefore, the unbalanced 


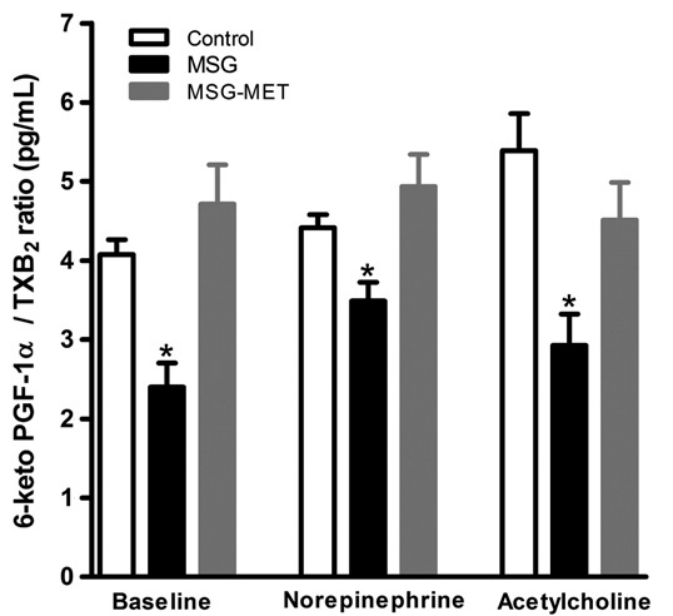

Fig. 3. Basal, norepinephrine- and acetylcholine-induced release of 6-keto-PGF- $1 \alpha$ and TXB2 from the mesenteric arteriolar bed perfusate of control, monosodium glutamateinduced obese rats (MSG) and metformin-treated MSG rats (MSG-MET). ${ }^{*} \mathrm{p}<0.05$ vs. control. 6-keto-PGF- $1 \alpha$ and TXB2 levels ratio are presented as the mean \pm S.E.M of twelve independent experiments.

release of vasodilator/vasoconstrictor prostanoids derived from COX might explain the endothelial dysfunction in MSG rats. Interestingly, an important finding in this study was that the decreased $\mathrm{PGI}_{2} / \mathrm{TXA}_{2}$ ratio in MSG rats was not detected after metformin treatment, indicating that metformin improves the endothelial function in MSG rats by restoring the balance in the synthesis/release of prostanoids.
Although the accurate mechanisms involved in metformin effects on the endothelium have not been elucidated, recent studies point to the role of COX-2 (Matsumoto et al., 2008). In fact, we have demonstrated that 16-week-old MSG rats displayed increased expression of COX-2 that contributed to the increased contractile response to $\mathrm{NE}$ as well as to the decreased relaxation in MSG rats (Lobato et al., 2010). Considering that metformin corrected the decreased ratio PGI2/TXA2 observed in the mesenteric arteriolar bed from MSG rats, we suggest that metformin restored the COX-2-derived production of prostanoids in this model of obesity.

The correction of the insulin resistance can also contribute to explain metformin effect on COX-derived vasoactive products, because insulin resistance, increasing endothelial FFAs, can reduce arterial prostacyclin synthase activity. FFAs commonly observed in insulin resistant patients promote increased $\mathrm{O}_{2}^{-}$production in endothelial cells, by providing increased electron donors (NADH and FADH2) to the mitochondrial electron transport chain. The FFA-induced overproduction of $\mathrm{O}_{2}^{-}$activates a variety of proinflammatory signals and inactivates two important enzymes, PGI2 synthase and eNOS (Du et al., 2006; Kuboki et al., 2000), thus decreasing the endotheliumdependent vascular relaxation.

Restoration of endothelium-derived factors release might not be the only factor that accounted for metformin effect since SNP, which acts via direct stimulation of vascular smooth muscle cells independently of an intact endothelium, had its response increased by metformin treatment. SNP and NO, which is released by endothelialdependent vasodilators, share a final common pathway to produce vasodilatation, stimulating guanylate cyclase and increasing cGMP levels. Thus, it is possible that a direct effect of metformin on vascular

A

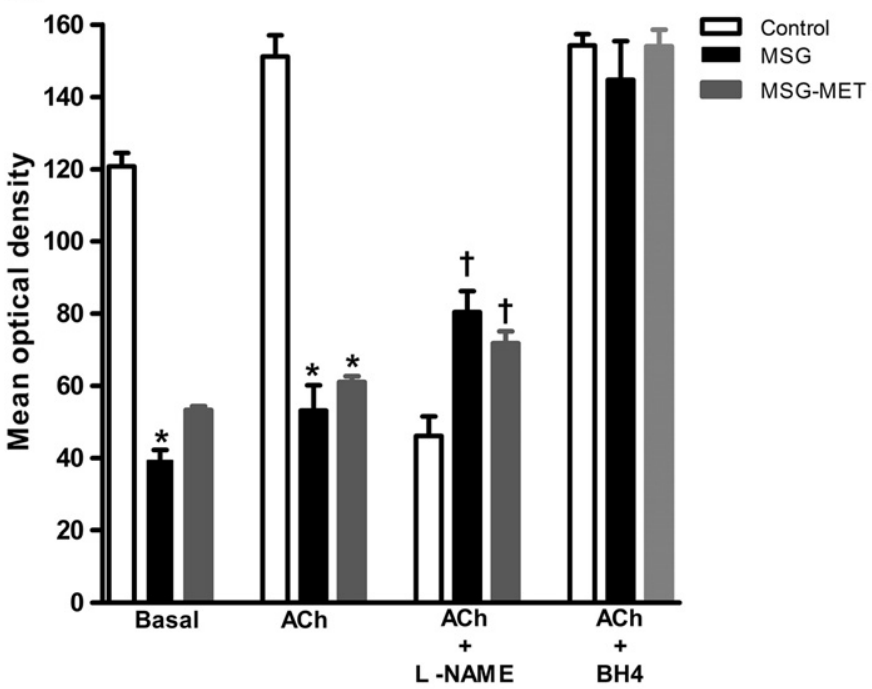

B

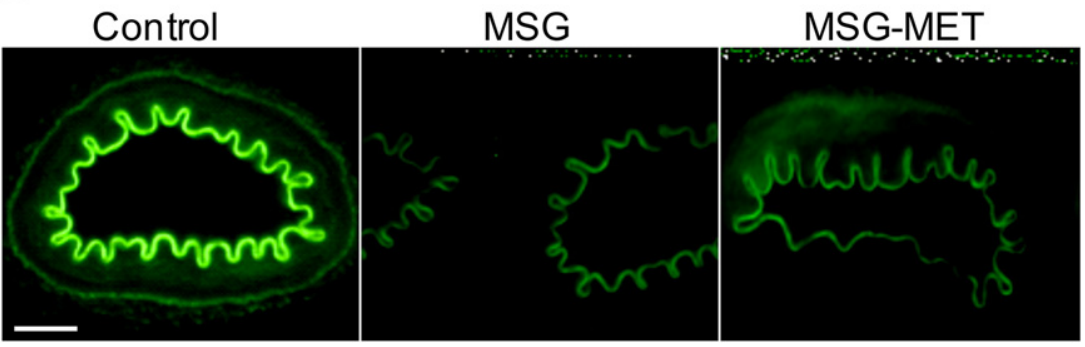

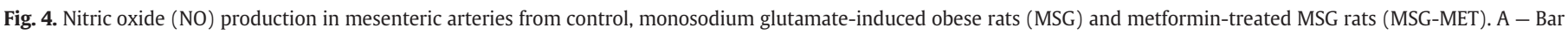

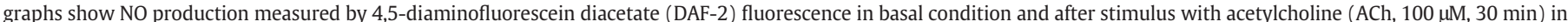

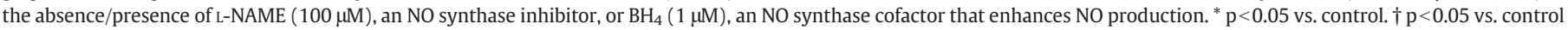

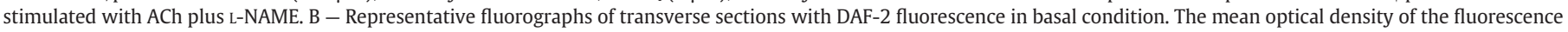
is presented as the mean \pm S.E.M of six independent experiments. Scale bar: $20 \mu \mathrm{m}$. 


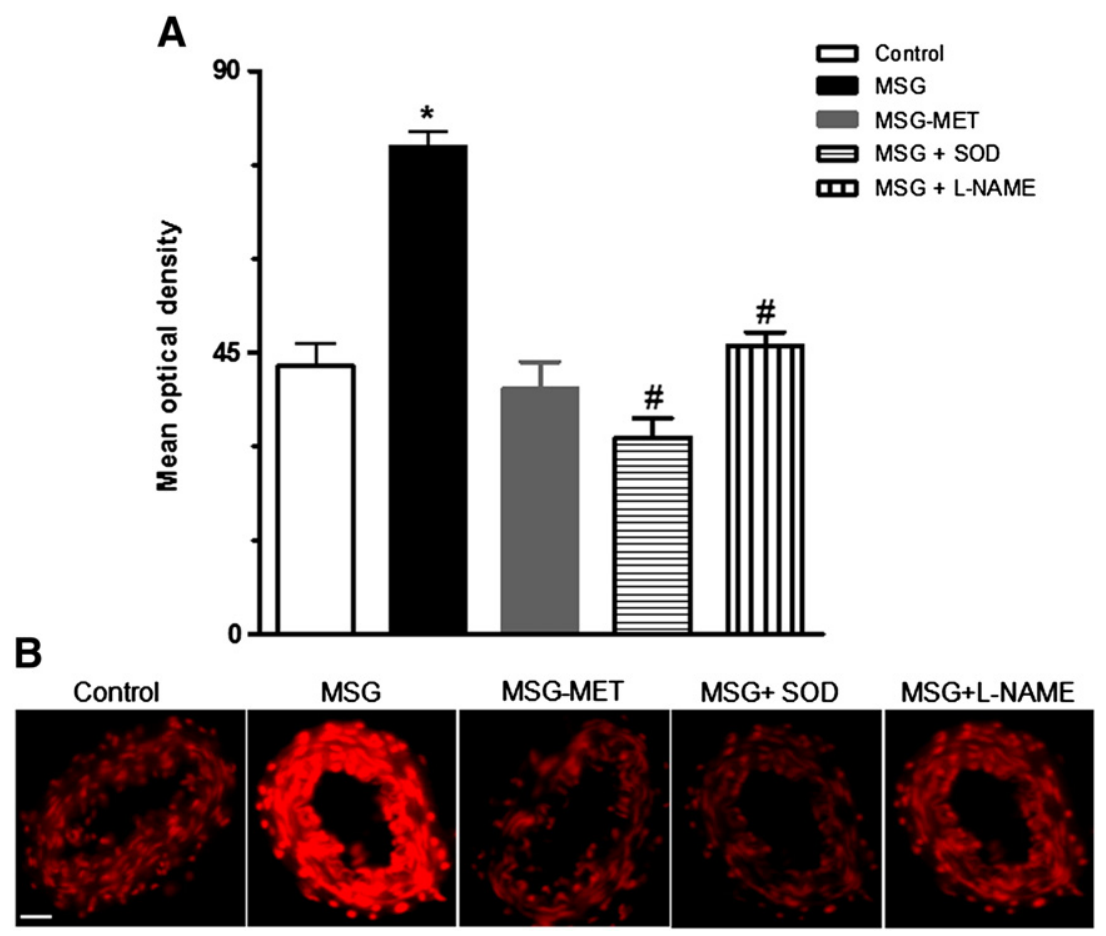

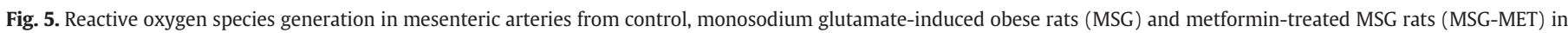

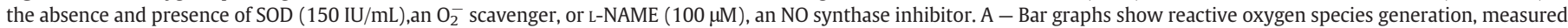

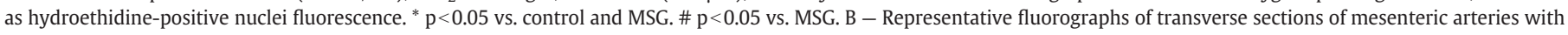
hydroethidine-positive nuclei. The mean optical density of the fluorescence is expressed as mean \pm SEM of six independent experiments. Scale bar: $20 \mu$ m.

smooth muscle cells, improving the responsiveness to NO, could contribute to the correction of the reduced vasodilatation in MSG rats. A vasodilating effect of metformin has been reported in ex vivo preparations of vascular smooth muscle cells, possibly due to altered calcium handling (Dominguez et al., 1996; Abbasi et al., 1998). Therefore, other mechanisms might be involved in the beneficial effects of metformin on vascular function, as demonstrated in the present study.

One limitation of the present study was the use of an animal model that may not necessarily reproduce the same pathophysiologic abnormalities of human obesity. The cause of obesity in MSG rats is not common among humans, although the phenotype parallels human obesity in many ways. Other limitations of this study include the short duration of metformin treatment, the use of only one vascular preparation (mesenteric arteriolar bed), that is not necessarily reflective of other circulatory beds and the absence of experiments to evaluate the direct action of this drug in the vessel. Thus, additional studies are required to investigate metformin effects in other models of obesity with additional time of treatment as well as in different vascular beds, both in vivo and in vitro.

\section{Conclusion}

In summary, the present study demonstrated that the metformin treatment improved the vascular function in MSG rats through reduction in ROS generation, modulation of membrane hyperpolarization, correction of the unbalanced prostanoids release and increase in the sensitivity of the smooth muscle to NO. Our findings support the beneficial effects of metformin previously demonstrated in large intervention studies in type 2 diabetic patients and also offer a credible evidence for the beneficial effects of this drug in obesity.

\section{Conflict of interest}

The authors declare that there are no conflicts of interest.

\section{Acknowledgments}

The authors are grateful to Sonia Leite and Marta Rodrigues for excellent technical assistance.

This work was supported by Fundacao de Amparo a Pesquisa doEstado de Sao Paulo (FAPESP), Conselho Nacional de Desenvolvimento Cientifico e Tecnologico (CNPq) and INCT Obesity and Diabetes/CNPq, Brazil.

\section{References}

Abbasi F, Carantoni M, Chen YI, Reaven GM. Further evidence for a central role of adipose tissue in the antihyperglycemic effect of metformin. Diabetes Care 1998;21: 1301-5.

Abbasi F, McLaughlin T, Lamendola C, Yeni-Komshian H, Tanaka A, Wang T, et al. Fasting remnant lipoprotein cholesterol and triglyceride concentrations are elevated in nondiabetic, insulin-resistant, female volunteers. J Clin Endocrinol Metab 1999;84: 3903-6.

Akamine EH, Kawamoto EM, Scavone C, Nigro D, Carvalho MH, Tostes RC, et al. Correction of endothelial dysfunction in diabetic female rats by tetrahydrobiopterin and chronic insulin. J Vasc Res 2006;43(4):309-20.

Bailey CJ. Metformin: effects on micro and macrovascular complications in type 2 diabetes. Cardiovasc Drugs Ther 2008;22(3):215-24.

Diabetes Prevention Program Research Group. Reduction in the incidence of type 2 diabetes with lifestyle intervention or metformin. N Engl J Med 2002;346:393-403.

Dominguez LJ, Davidoff AJ, Srinivas PR, Standley PR, Walsh MF, Sowers JR. Effects of metformin on tyrosine kinase activity, glucose transport, and intracellular calcium in rat vascular smooth muscle. Endocrinology 1996;137(1):113-21.

Du X, Edelstein D, Obici S, Higham N, Zou MH, Brownlee M. Insulin resistance reduces arterial prostacyclin synthase and eNOS activities by increasing endothelial fatty acid oxidation. J Clin Invest 2006;116(4):1071-80.

Effect of intensive blood-glucose control with metformin on complications in overweight patients with type 2 diabetes (UKPDS 34). UK prospective diabetes study (UKPDS) group. Lancet 1998;352:854-65.

Feletou M, Vanhoutte PM. Endothelial dysfunction: a multifaceted disorder (the Wiggers Award lecture). Am J Physiol Heart Circ Physiol 2006;291:H985-H1002.

Förstermann U, Münzel T. MD Endothelial nitric oxide synthase in vascular disease. Circulation 2006;113:1708-14.

Gallo A, Ceolotto G, Pinton P, Iori E, Murphy E, Rutter GA, et al. Metformin prevents glucose-induced protein kinase C-beta2 activation in human umbilical vein endothelial cells through an antioxidant mechanism. Diabetes 2005;54:1123-31. 
Glueck CJ, Fontaine RN, Wang P, Subbiah MT, Weber K, Illig E, et al. Metformin reduces weight, centripetal obesity, insulin, leptin, and low-density lipoprotein cholesterol in nondiabetic, morbidly obese subjects with body mass index greater than 30 . Metabolism 2001;50:856-61.

Goran MI, Ball GD, Cruz ML. Obesity and risk of type 2 diabetes and cardiovascular disease in children and adolescents. J Clin Endocrinol Metab 2003;88(4):1417-27.

Grant PJ. Beneficial effects of metformin on haemostasis and vascular function in man. Diabetes Metab 2003;29:6S44-6S52.

Hill JO. Understanding and addressing the epidemic of obesity: an energy balance perspective. Endocr Rev 2006;27:750-61.

Hopps E, Noto D, Caimi G, Averna MR. A novel component of the metabolic syndrome: the oxidative stress. Nutr Metab Cardiovasc Dis 2010;20(1):72-7.

Hundal RS, Krssak M, Dufour S, Laurent D, Lebon V, Chandramouli V, et al. Mechanism by which metformin reduces glucose production in type 2 diabetes. Diabetes 2000;49:2063-9.

Iñiguez MA, Cacheiro-Llaguno C, Cuesta N, Díaz-Muñoz MD, Fresno M. Prostanoid function and cardiovascular disease. Arch Physiol Biochem 2008;114(3):201-9.

Kuboki K, Jiang ZY, Takahara N, Ha SW, Igarashi M, Yamauchi T, et al. Regulation of endothelial constitutive nitric oxide synthase gene expression in endothelial cells and in vivo: a specific vascular action of insulin. Circulation 2000;101(6): 676-81.

Kurukulasuriya R, Banerji MA, Chaiken R, Lebovitz H. Selective decrease in visceral fat is associated with weight loss during metformin treatment in African Americans with type 2 diabetes. Diabetes 1999;48(suppl.):A315.

Lawrence JM, Reid J, Taylor GJ, Stirling C, Reckless JP. Favorable effects of pioglitazone and metformin compared with gliclazide on lipoprotein subfractions in overweight patients with early type 2 diabetes. Diabetes Care 2004;27(1):41-6.

Lerman A, Zeiher AM. Endothelial function: cardiac events. Circulation 2005;111: 363-8.

Lionetti L, Mollica MP, Lombardia A, Cavalierea G, Gifunia G, Barletta A. From chronic overnutrition to insulin resistance: the role of fat-storing capacity and inflammation. Nutr Metab Cardiovasc Dis 2009;19(2):146-52.

Lobato NS, Filgueira FP, Akamine EH, Davel AP, Rossoni LV, Tostes RC, et al. Obesity induced by neonatal treatment with monosodium glutamate impairs microvascular reactivity in adult rats: Role of NO and prostanoids. Nutr Metab Cardiovasc Dis 2011;21(10):808-16

Mahrouf M, Ouslimani N, Peynet J, Djelidi R, Couturier M, Therond P, et al. Metformin reduces angiotensin-mediated intracellular production of reactive oxygen species in endothelial cells through the inhibition of protein kinase C. Biochem Pharmacol 2006;72:176-83.

Matsuda M. Measuring and estimating insulin resistance in clinical and research settings. Nutr Metab Cardiovasc Dis 2010;20(2):79-86.

Matsumoto T, Noguchi E, Ishida K, Kobayashi T, Yamada N, Kamata K. Metformin normalizes endothelial function by suppressing vasoconstrictor prostanoids in mesenteric arteries from OLETF rats, a model of type 2 diabetes. Am J Physiol Heart Circ Physiol 2008;295(3):H1165-76.

Nathan DM, Buse JB, Davidson MB, Heine RJ, Holman RR, Sherwin R, et al. Management of hyperglycemia in type 2 diabetes: a consensus algorithm for the initiation and adjustment of therapy. Diabetes Care 2006;29:1963-72.

Nichols GA, Gomez-Caminero A. Weight changes following the initiation of new antihyperglycaemic therapies. Diabetes Obes Metab 2007;9:96-102.

Ouslimani N, Peynet J, Bonnefont-Rousselot D, Therond P, Legrand A, Beaudeux JL. Metformin decreases intracellular production of reactive oxygen species in aortic endothelial cells. Metabolism 2005;54:829-34.

Stapleton PA, James ME, Goodwill AG, Frisbee JC. Obesity and vascular dysfunction. Pathophysiology 2008;15(2):79-89.

Tziomalos K, Athyros VG, Karagiannis A, Mikhailidis DP. Endothelial dysfunction in metabolic syndrome: prevalence, pathogenesis and management. Nutr Metab Cardiovasc Dis 2010;20(2):140-6.

Wiernsperger NF, Bailey CJ. The antihyperglycaemic effect of metformin: therapeutic and cellular mechanisms. Drugs 1999;58(1):31-9.

Yuhki K, Kashiwagi H, Kojima F, Kawabe J, Ushikubi F. Roles of prostanoids in the pathogenesis of cardiovascular diseases. Int Angiol 2010;29(2 Suppl.):19-27.

Zalesin KC, Franklin BA, Miller WM, Peterson ED, McCullough PA. Impact of obesity on cardiovascular disease. Endocrinol Metab Clin North Am 2008;37(3):663-84. 
ANEXO B: Publicações em anais de congressos nacional e internacional 


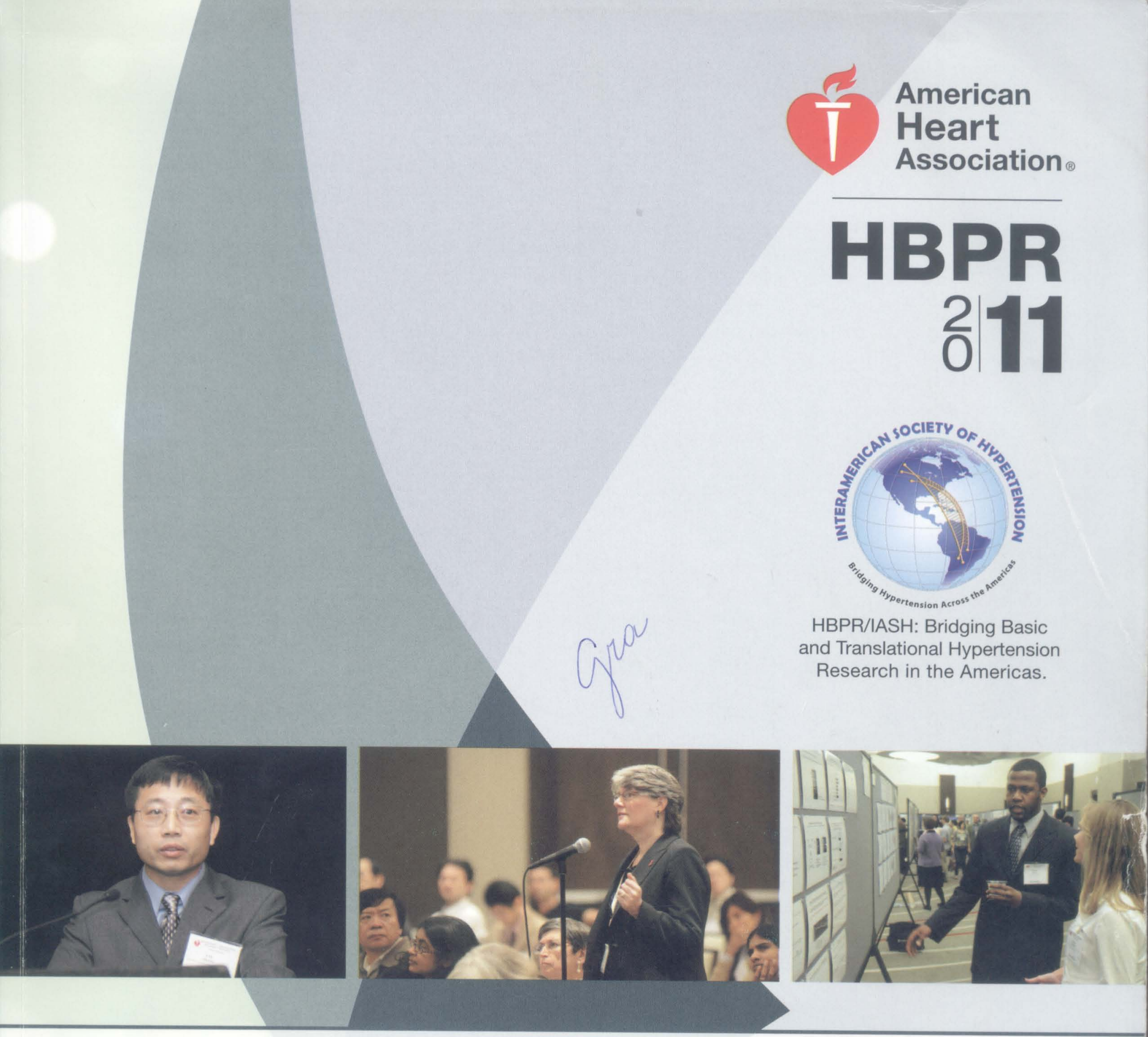

\section{High Blood Pressure Research 2011 Scientific Sessions \\ Final Program}

September 20-24, 2011 I Walt Disney World Dolphin Resort I Orlando, FL 
José Firmino Nogueira Neto, Rio de Janeiro State Univ, Rio de Janeiro, Brazil; Marcella Guedes, Carolina Lima, Antonio F Sanjulian MD, PhD, Discipline of Clinical and Experimental Pathophysiology Rio de Janeiro State Univ, Rio de Janeiro, Brazil

Background: Obesity is characterized by low-grade systemic inflammation, which has been linked to increased risk of endothelial dysfunction. Recent evidence suggests that, in obese individuals, calcium-rich diets help reduce adiposity and inflammation, but it is no known if it also helps reduce endothelial dysfunction. Objective: To evaluate, during energy restriction, the effects of dietary calcium on inflammation, fibrinolysis and endothelial function in obese subjects. Methods: Randomized clinical trial. Fifty subjects with grade 1 obesity, both gender, aged 22-55 years, with stable body weight and a low habitual calcium intake $(<500 \mathrm{mg} /$ day) were randomized into a low calcium diet (LCD; $<500 \mathrm{mg} /$ day; $n=25$ ) or a high calcium diet $(\mathrm{HCD} ; \pm 1200 \mathrm{mg} /$ day; $\mathrm{n}=25)$, supplemented with nonfat powdered milk $(60 \mathrm{~g} /$ day $)$. Both groups were instructed to follow an energy restricted diet $(-800 \mathrm{Kcal} / \mathrm{day})$ with similar levels of macronutrients, throughout the study (16 weeks). Results: After 16 weeks of intervention subjects in HCD compared with those in LCD exhibited a greater reduction in body weight $(-5.1 \pm 0.8 \mathrm{vs}-3.8 \pm 0.6 \mathrm{~kg})$, however the observed difference between the 2 diets was not statistically significant. Participants of HCD and LCD presented similar reductions in serum levels of plasminogen activator inhibitor -1 ( $-5 \pm 3 v s .-12 \pm 1$, respectively, $p=0.95)$; biomarkers of inflammation [C-reactive protein $0.05 \pm 0.2 \mathrm{vs} 0.06 \pm 0.4 \mathrm{mg} / \mathrm{l}$, respectively, $\mathrm{p}=0.76$ ) and tumor necrosis factor- $\alpha \quad(-0.1 \pm 0.3 \mathrm{vs},-0.7 \pm 0.4 \mathrm{pg} / \mathrm{ml}$, respectively $\quad \mathrm{p}=0.64)]$; $\quad$ and biomarkers of endothelial dysfunction [vascular cell adhesion molecule-1 (-15 $\pm 6 \mathrm{vs} .-24 \pm 10 \mathrm{pg} / \mathrm{dl}$, respectively, $\mathrm{p}=0.87)$, intracellular adhesion molecule-1(-115 $\pm 57 \mathrm{vs} .-52 \pm 41 \mathrm{pg} / \mathrm{dl}$, respectively $\mathrm{p}=0.53)$ and E-selectin ( $-3.2 \pm 1 \mathrm{vs} .-2.4 \pm 1 \mathrm{pg} / \mathrm{dl}$, respectively $\mathrm{p}=0.55)]$. Conclusion: The present study suggests that a high calcium diet does not enhance the beneficial effects of energy restriction on inflammatory state, fibrinolysis and endothelial function in obese individuals.

M. Torres: None. M. Rodrigues: None. D. Valença: None. L. Nogueira: None. J. Nogueira Neto: None. M. Guedes: None. C. Lima: None. A.F. Sanjuliani: None.

P509

Differential Participation Of Mapks In Angiotesin II-induced Contraction In Obesity

Graziela N Hagihara, Núbia S Lobato, Eliana H Akamine, Maria Helena C Carvalho, Zuleica B Fortes, São Paulo Univ, São Paulo, Brazil

Obesity is clearly associated with the development of vascular dysfunction, compromising the response to angiotensin II (Angll), a vasoactive peptide that can activate intracellular signaling pathways like mitogen-activated protein kinases (MAPKs). Recent studies have demonstrated an increased activation of MAPKs in obese tissues that control the energy homeostasis. The role of MAPKs in obese vascular tissues is unknown. Therefore, we investigated the role of MAPKs in the response to Angll in resistance mesenteric arteries of monosodium glutamate (MSG)-induced obese rats (Ob). Wistar rats received MSG $\left(4.0 \mathrm{~g} / \mathrm{kg}\right.$, s.c.) from $2^{\text {nd }}$ to $6^{\text {th }}$ day after birth. At the age of 16 weeks, mesenteric arteries were dissected and mounted in a wire myography. Concentration-effect curves to Angll $(0.1-100 \mathrm{nM})$ and to norepinephrine (NE, $1 \mathrm{nM}-30 \mu \mathrm{M})$ were performed in artery segments with $(E+)$ or without $(E-)$ endothelium. The Angll- and NE-induced responses were also evaluated in the presence of ERK1/2, JNK, or p38 MAPKs inhibitors $(1 \mu \mathrm{M})$ (Pd98059, Sb203580 and Sp600125, respectively). The results were calculated as $\%$ of $\mathrm{KCl}(120 \mathrm{mM})$ induced responses. In $(E+)$ mesenteric arteries, a lower response to Angll $(100 \mathrm{nM})$ was found in $\mathrm{Ob}$ rats $\left(\mathrm{Ob}: 42.1 \pm 5.1^{\star}, \mathrm{C}: 56.3 \pm 1.6, n=6\right)$. Because we did not observe difference between $\mathrm{C}$ and $\mathrm{Ob}$ rats in the response of arteries (E-) to Ang II, the studies were carried out in intact arteries only. The MAPKs inhibitors did not change the Angll-induced responses in $\mathrm{C}$ rats. However, in Ob rats, the inhibition of ERK1/2 corrected the reduced response to Angll $(\mathrm{Ob}+\mathrm{Pd}$ : $52.0 \pm 7.2, \mathrm{n}=6)$.
Inhibition of JNK and p38 MAPKs reduced even more Angll (10nM) response in $\mathrm{Ob}$ rats $\left(\mathrm{Ob}+\mathrm{Sb}: 15.7 \pm 4.4^{*}, \mathrm{n}=8 ; \mathrm{Ob}+\mathrm{Sp}^{*}: 9.3 \pm 2.6, \mathrm{n}=5\right)$. $\mathrm{NE}$-induced responses in both $\mathrm{E}+$ and $\mathrm{E}$ - arteries were not modified by either obesity or inhibition of MAPKs. ${ }^{*} \mathrm{p}<0.05$ vs $\mathrm{C}$. Obesity induced endothelium-dependent alterations of vascular reactivity that impaired the response to Angll in rats. The alteration was specific for this agent since the response to NE was not altered. Based on the effect of the inhibitors we concluded that ERK1/2 contributes to lower response to Angll while JNK and p38 MAPKs contribute to maintain the response to Angll in obesity. Financial Support: FAPESP, CNPq

G.N. Hagihara: None. N.S. Lobato: None. E.H. Akamine: None. M.C. Carvalho: None. Z.B. Fortes: None.

P510

Effects of Metformin on Cardiovascular Remodeling and Renal Morphology in Obese Rats with Insulin Resistance

Adriana K Burlá, State Univ of Rio de Janeiro, Rio de Janeiro, Brazil; Nubia Lobato, Zuleica B Fortes, Univ of São Paulo, São Paulo, Brazil; Wille Oigman, Mario F Neves, State Univ of Rio de Janeiro, Rio de Janeiro, Brazil

Many evidences show that obesity is associated to structural and functional changes in the heart of human and animal models. The objective of this study was to determinate morphological changes related to cardiac, vascular and renal remodeling in an experimental model of monosodium glutamate (MSG)-induced obesity and the effects of metformin on this finding. Twenty five rats were studied and divided into five groups: control with 16 e 22 weeks (CON-16 and CON-22); obese with 16 and 22 weeks (MSG-16 e MSG-22), and obese + metformin (MET-22) $300 \mathrm{mg} / \mathrm{Kg} /$ day per oral. The characterization of insulin resistance was done through measurement of plasma insulin and calculation of HOMA-IR index. The morphological analysis and the quantification of myocardial collagen were carried out by Image Pro Plus analysis system. The systolic blood pressure was slightly higher in MSG-22 group, reaching statistical significance when compared to MSG-16 group $(122 \pm 2 \mathrm{vs}$ $108 \pm 2 \mathrm{mmHg}, \mathrm{p}<0.05)$. On the other hand, the MET-22 group demonstrated lower blood pressure levels $(118 \pm 1 \mathrm{mmHg})$, without reaching statistical difference. The obese animals presented increase in media-to-lumen ratio with 16 weeks $(39.9 \pm 3.7$ vs $30.2 \pm 2.0 \%$, $p<0.05)$ and with 22 weeks $(39.8 \pm 1.3$ vs $29.5 \pm 1.2 \%, p<0.05)$, which was reduced with use of metformin $(31.5 \pm 0.9 \%)$. The collagen deposition in perivascular area of left ventricle was significantly greater in MSG-22 group ( $1.39 \pm 0.06$ vs $0.83 \pm 0.06 \%$ in $C O N-22, p<0.01)$, and attenuated by metformin $(1.02 \pm 0.04 \%)$. In the kidney, the media crosssectional area of intrarenal arterioles was similar among the groups $(18.5 \pm 2.2$ in CON-16; $19.9 \pm 3.7$ in MSG-16; $18.9 \pm 3.1$ in CON-22; $21.8 \pm 1.5$ in MSG-22; $20.2 \pm 1.4$ in MET-22). An increase of glomerular area was observed in MSG-22 group (141.3 \pm 4.5 vs $129.5 \pm 0.5 \mu \mathrm{m} 2$ ), but without statistical significance. In conclusion, rats with MSGinduced obesity and insulin resistance presented more pronounced cardiac changes than renal alterations. There were evidences of hypertrophic vascular remodeling of intramyocardial small arteries and cardiac perivascular fibrosis. These findings were, at least partially, attenuated by metformin, suggesting a beneficial effect for prevention of cardiovascular complications associated with obesity.

A.K. Burlá: None. N. Lobato: None. Z.B. Fortes: None. W. Oigman: None. M.F. Neves: None.

P511

Autonomic Contribution to Blood Pressure and Resting Energy Expenditure in Obese Hispanics

Luis E Okamoto, Cyndya Shibao, Alfredo Gamboa, Andre Diedrich Ginnie Farley, Sachin Paranjape, David Robertson, Italo Biaggioni, Vanderbilt Univ, Nashville, TN 


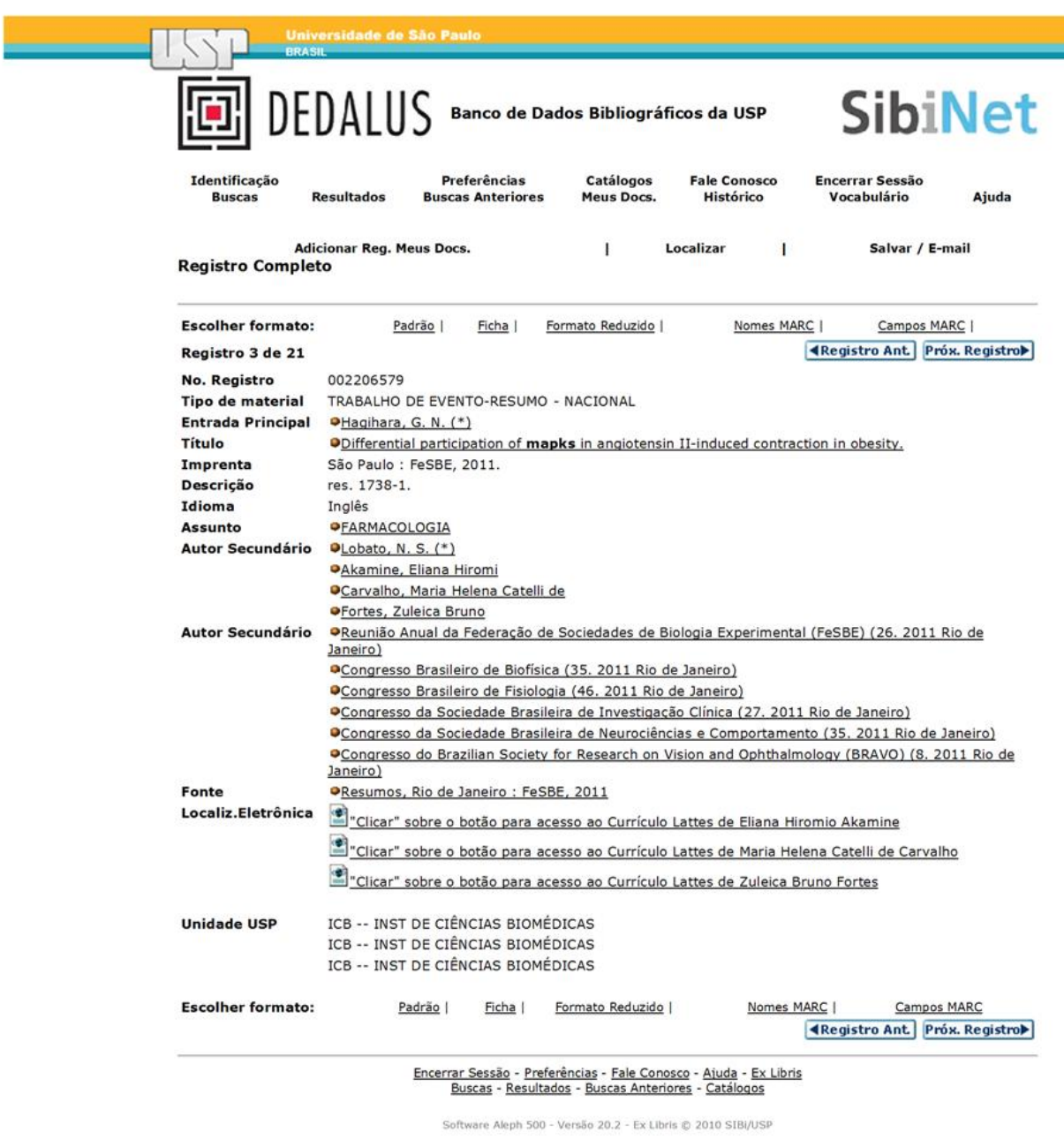


ANEXO C: Curriculum vitae 
Graziela Neves Hagihara

Curriculum Vitae

\section{Dados Pessoais}

Nome Graziela Neves Hagihara

\section{Formação Acadêmica/Titulação}

2005 - 2009 Graduação em Nutrição.

Universidade de São Paulo - Faculdade de Saúde Pública, USP - FSP, Sao Paulo, Brasil

2000 - $2001 \quad$ Ensino Profissional de nível técnico.

ETE Carlos de Campos, ETECC, Brasil

\section{Formação complementar}

2010 - $2010 \quad$ Extensão universitária em francês instrumental - 1.

Faculdade de Filosofia, Letras e Ciências Humanas - USP, FFLCH/USP, Brasil

2006 - 2006 Extensão universitária em inglês instrumental - 1.

Faculdade de Filosofia, Letras e Ciências Humanas - USP, FFLCH/USP, Brasil

2005 - $2005 \quad$ Extensão universitária em inglês instrumental - 1.

Faculdade de Filosofia, Letras e Ciências Humanas - USP, FFLCH/USP, Brasil

\section{Atuação profissional}

\section{Universidade de São Paulo - USP}

\section{Vínculo institucional}

2010 - Atual Vínculo: Bolsista , Enquadramento funcional: Bolsista, Regime:

2009 -2010 Vínculo: Bolsista, Enquadramento funcional: Bolsista , Carga horária: 30, Regime: Dedicação Exclusiva

2008 - 2009 Vínculo: Bolsista, Enquadramento funcional: Bolsista , Carga horária: 30, Regime: Dedicação Exclusiva

\section{Atividades}

2010 - Atual

Projetos de pesquisa, Instituto de Ciências Biomédicas

Participação em projetos:

Resposta à angiotensina // em artérias mesentéricas de resistência na obesidade: participação das MAPKs. 
2010 - Atual

$2009-2010$

$2008-2009$
Projetos de pesquisa, Instituto de Ciências Biomédicas

Projetos de pesquisa, Instituto de Ciências Biomédicas

Participação em projetos:

Estudo do tratamento com metformina nas alterações da reatividade vascular em modelo de resistência à insulina (obesidade): possíveis mecanismos

Projetos de pesquisa, Instituto de Ciências Biomédicas

Participação em projetos:

Estudo do tratamento com metformina nas alterações da reatividade vascular em modelo de resistência à insulina (obesidade): possíveis mecanismos

\section{Projetos}

2010 - Atual Resposta à angiotensina II em artérias mesentéricas de resistência na obesidade: participação das MAPKs.

Descrição: A obesidade é considerada um dos principais fatores de risco para o desenvolvimento de condições como o diabetes tipo 2 e a hipertensão arterial. Um fator que pode levar à resistência à insulina e hipertensão na obesidade é a ativação do sistema renina-angiotensina (SRA). Alterações na resposta mediada pela angiotensina II (Ang II) no sistema vascular têm sido descritas em modelos animais de obesidade, assim como em humanos. Considerando que a Ang II ativa a via das MAPKs e que na obesidade há ativação dessa via em tecidos que regulam a homeostase energética, o objetivo do presente projeto será investigar o papel da via de sinalização das MAPKs no aumento da resposta à Ang II em ratos obesos.

Situação: Em Andamento Natureza: Pesquisa

Integrantes: Graziela Neves Hagihara (Responsável); ;

Financiador(es): Fundação de Amparo à Pesquisa do Estado de São Paulo-FAPESP

$2009-2010$

Estudo do tratamento com metformina nas alterações da reatividade vascular em modelo de resistência à insulina (obesidade): possíveis mecanismos

Descrição: Resistência à insulina: diabetes, obesidade e alterações vasculares. Reversão farmacológica das alterações e seu mecanismo

Situação: Concluído Natureza: Pesquisa

Alunos envolvidos: Graduação (1); Doutorado (1);

Integrantes: Graziela Neves Hagihara; Núbia de Souza Lobato; Zuleica Bruno Fortes (Responsável)

Financiador(es): Pró Reitoria de Pesquisa da Universidade de São Paulo-USP

$2008-2009$

Estudo do tratamento com metformina nas alterações da reatividade vascular em modelo de resistência à insulina (obesidade): possíveis mecanismos

Descrição: Resistência à insulina: diabetes, obesidade e alterações vasculares. Reversão farmacológica das alterações e seu mecanismo

Situação: Concluído Natureza: Pesquisa

Alunos envolvidos: Graduação (1); Doutorado (1);

Integrantes: Graziela Neves Hagihara; Núbia de Souza Lobato; Zuleica Bruno Fortes (Responsável) Financiador(es): Pró Reitoria de Pesquisa da Universidade de São Paulo-USP

\section{Áreas de atuação}

1.

Nutrição 


\section{Idiomas}

Inglês

Compreende Bem , Fala Razoavelmente, Escreve Razoavelmente, Lê Bem

Francês

Compreende Razoavelmente, Fala Pouco, Escreve Pouco, Lê Razoavelmente

Japonês

Compreende Razoavelmente, Fala Razoavelmente, Escreve Pouco, Lê Pouco

\section{Produção em C, T\& A}

\section{Produção bibliográfica \\ Artigos completos publicados em periódicos}

1. Lobato, N.S., Filgueira, F.P., HAGIHARA, G. N., AKAMINE, E.H., Pariz, J.R., Tostes, R.C., Carvalho, M.H.C., Fortes, Z.B.

Improvement of metabolic parameters and vascular function by metformin in obese non-diabetic rats. Life Sciences (1973). , v.90, p.228 - 235, 2012.

Trabalhos publicados em anais de eventos (resumo)

1. HAGIHARA, G. N., LOBATO, N. S., AKAMINE, E. H., FORTES, ZB

Differencial participation of MAPKs in angiotensin II-induced contraction in obesety In: Reunião anual da Federação de Sociedades de Biologia Experimental (FeSBE), 2011, Rio de Janeiro.

FeSBE SBFTE. , 2011.

2. HAGIHARA, G. N., LOBATO, N. S., AKAMINE, E. H., FORTES, Z. B.

Differential participation of MAPKs in angiotensin II-induced contraction in obesity. In: High Blood

PrEssure Research, 2011, Orlando.

High Blood Prassure Research - Scientific Sessions. , 2011.

\section{Produção Técnica}

Demais produções técnicas

1. HAGIHARA, G. N., FORTES, ZB

Resposta à angiotensina II em artérias mesentéricas de resistência na obesidade: participação das MAPKs., 2012. (Relatório de pesquisa)

2. HAGIHARA, G. N., LOBATO, N. S., FORTES, ZB

Resposta à Angiotensina II em Artérias Mesentéricas de Resistência na Obesidade: Participação das MAPKs, 2011. (Relatório de pesquisa)

3. HAGIHARA, G. N., FORTES, ZB

Resposta à angiotensina II em artérias mesentéricas de resistência na obesidade: participação das MAPKs, 2011. (Relatório de pesquisa)

4. HAGIHARA, G. N., LOBATO, N. S., FORTES, ZB

Estudo do tratamento com metformina nas alterações da reatividade vascular em modelo de resistência à insulina (obesidade): possíveis mecanismos, 2009. (Relatório de pesquisa)

5. HAGIHARA, G. N., LOBATO, N. S., FORTES, ZB

Estudo do tratamento com metformina nas alterações da reatividade vascular em modelo de resistência à insulina (obesidade): possíveis mecanismos, 2008. (Relatório de pesquisa) 